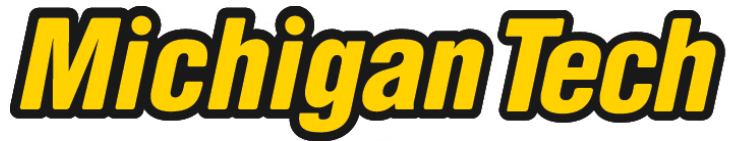 \\ Michigan Technological University Create the Future Digital Commons @ Michigan Tech
}

Dissertations, Master's Theses and Master's Reports - Open

Dissertations, Master's Theses and Master's

Reports

2013

\section{The Processing of Aluminum Gasarites via Thermal Decomposition of Interstitial Hydrides}

Joseph James Licavoli

Michigan Technological University

Follow this and additional works at: https://digitalcommons.mtu.edu/etds

Part of the Materials Science and Engineering Commons

Copyright 2013 Joseph James Licavoli

\section{Recommended Citation}

Licavoli, Joseph James, "The Processing of Aluminum Gasarites via Thermal Decomposition of Interstitial Hydrides", Dissertation, Michigan Technological University, 2013.

https://doi.org/10.37099/mtu.dc.etds/677

Follow this and additional works at: https://digitalcommons.mtu.edu/etds

Part of the Materials Science and Engineering Commons 


\title{
THE PROCESSING OF ALUMINUM GASARITES VIA THERMAL DECOMPOSITION OF INTERSTITIAL HYDRIDES
}

\author{
By:
}

Joseph J. Licavoli

\section{A DISSERTATION}

Submitted in partial fulfillment of the requirements for the degree of DOCTOR OF PHILOSOPHY

In Materials Science and Engineering

MICHIGAN TECHNOLOGICAL UNIVERSITY

2013

(C) Joseph J. Licavoli 
This dissertation has been approved in partial fulfillment of the requirements for the Degree of DOCTOR OF PHILOSOPHY in Materials Science and Engineering.

Department of Materials Science and Engineering

Dissertation Advisor: $\quad$ Dr. Paul G. Sanders

Committee Member: $\quad$ Dr. Timothy C. Eisele

Committee Member: $\quad$ Dr. Stephen A. Hackney

Committee Member: $\quad$ Dr. Douglas J. Swenson

Department Chair: $\quad$ Dr. Stephen L. Kampe 


\section{$1.0 \quad$ Table of Contents}

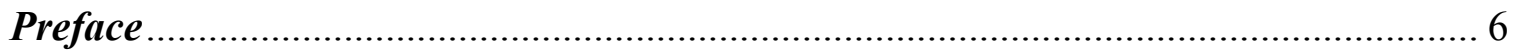

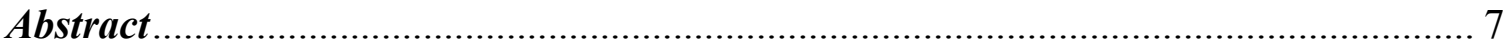

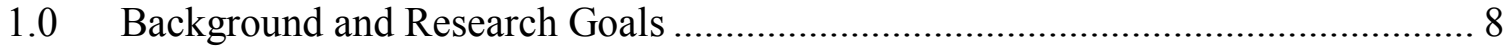



1.2 Metallic Foam Processing ........................................................................... 10

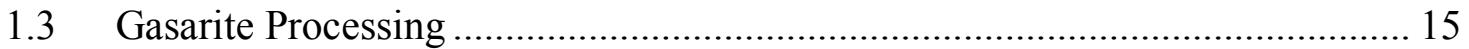

1.4 Thermal Decomposition Processing of Gasars ................................................... 19

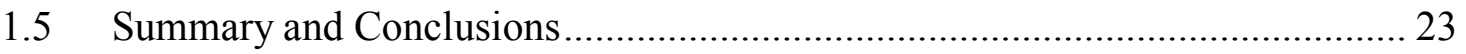

2.0 Conceptual Model of Gasarite Development During Thermal Decomposition .... 24

2.1 Model Construction and Gas Metal Eutectic Growth .......................................... 24

2.2 Bubble Capture Pore Formation and Growth.................................................... 28

2.3 Direct Gas Expansion Pore Formation and Growth .......................................... 32

2.4 Summary and Conclusions ............................................................................. 35

3.0 Replication of Literature Results ..................................................................... 37

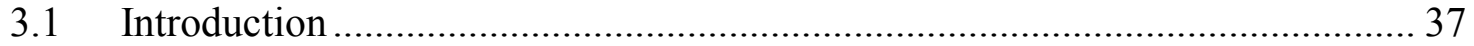

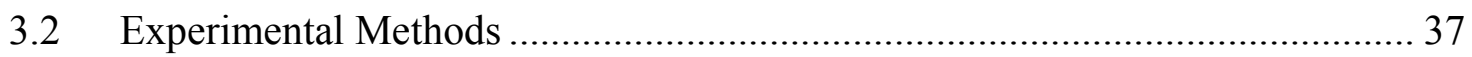

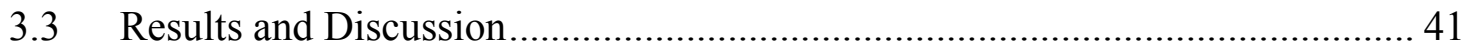

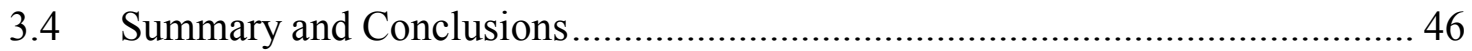

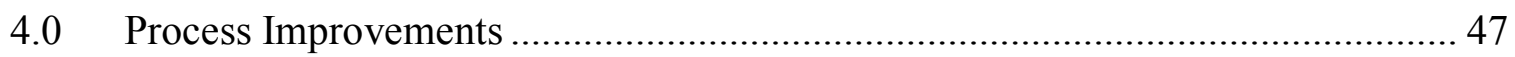

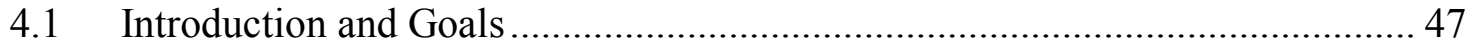

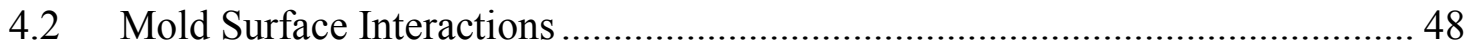

4.3 Multi-Packet Gas Source Introduction.......................................................... 49

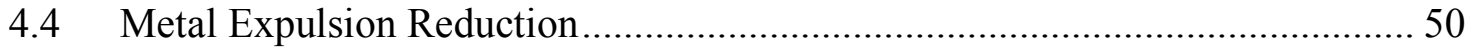

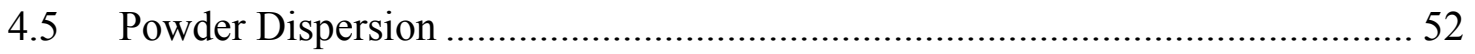

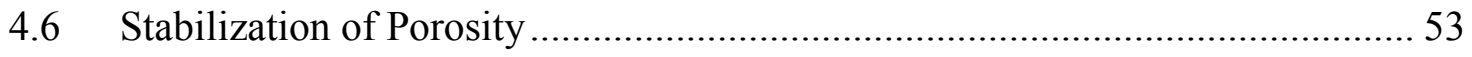

4.7 Thermal Decomposition Process For Creating Aluminum Gasarites ................ 59

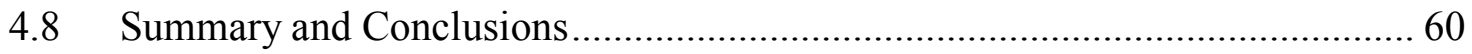


5.0 Baseline Process Capability and Pore Formation Mechanisms ........................... 62

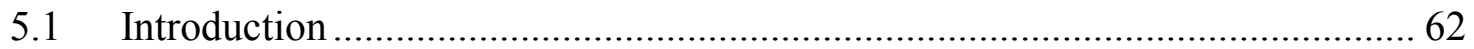

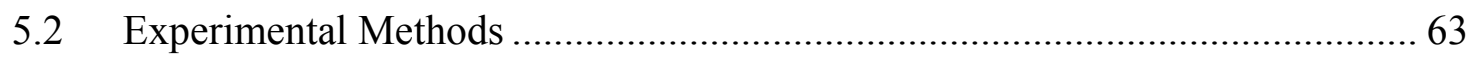

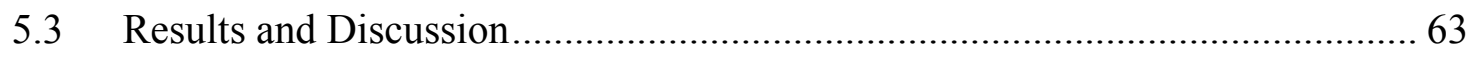

5.4 Summary and Conclusions ........................................................................ 71

6.0 High Ramp Rate Thermal Decomposition Kinetics of Titanium Hydride and

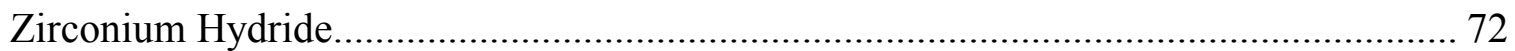

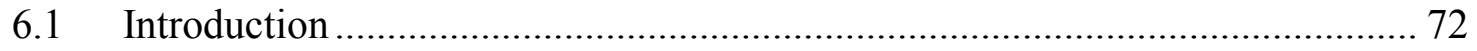

6.2 Experimental Methods ............................................................................... 73

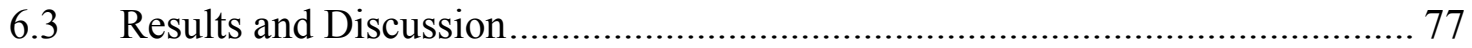

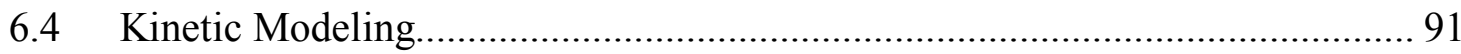

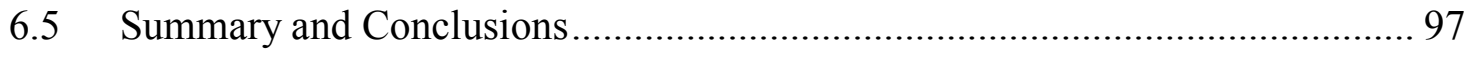

7.0 General Model of Gasarite Growth via Thermal Decomposition......................... 99

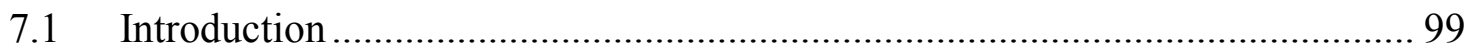

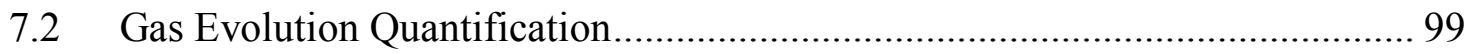

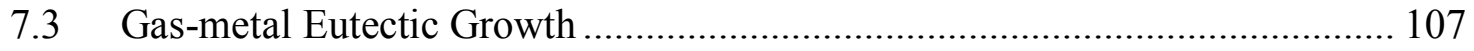

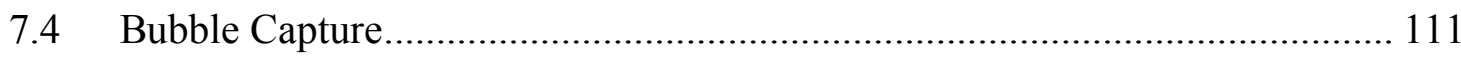

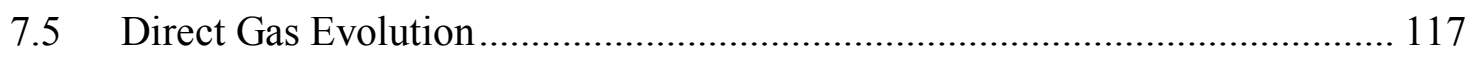

7.6 Summary and Conclusions ..................................................................... 128

8.0 Summary, Process Viability and Future Work ............................................ 130

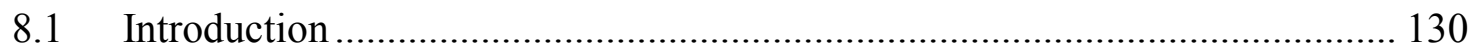

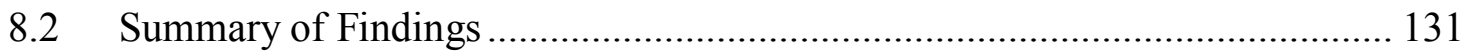

8.3 Comparisons to Gas Metal Eutectic Processing.......................................... 134

8.4 Assessment of Thermal Decomposition Processing .................................... 136

8.5 Conclusions and Future Work..................................................................... 138

9.0 Appendix: Thermal Decomposition-Experimental Data ................................. 140

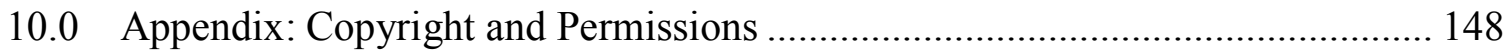

11.0 Appendix: Truncated Experimental Pore Size and Porosity Data ...................... 150

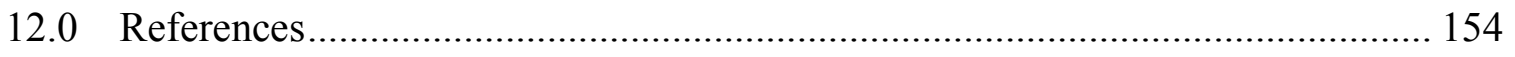


For my family, for all of their love and support. 


\section{Preface}

The following work is composed of a mixture of work that is not intended for publication, work that has been published, and works that are planned for publication. Sections 4.2-4.7 and all of Chapter 5 come from a published collaboration with the thesis

advisor Dr. Paul G. Sanders. ${ }^{[1]}$ The current author conducted all experiments analyzed all data and wrote the main body of that work. The thesis advisor provided general input throughout the work. Chapter 6 is a reproduction of an article to be submitted to the journal Thermomechanica Acta. This work was also a collaboration between the thesis advisor and the current author. The current author conducted all experiments, analyzed all data, performed all model fits and wrote a majority of the work to be submitted. The thesis advisor provided general input on content throughout the work. Some modifications have been made to the content either published or to be published. These modifications were minor and included referencing preceding data from non-publication material in order to more completely link together the current work. Chapter 7 is based on a work to be submitted to the journal Metallurgical and Materials Transactions A. The current author conducted all theoretical calculations and wrote a majority of the work to be submitted. The thesis advisor provided general input on content throughout the work. Some modifications have been made to the content either published or to be published. These modifications were minor and included referencing preceding data from nonpublication material in order to more completely link together the current work. Each chapter that included previously published data or data planned to be published contains a footnote with the included work and sections in which published data is utilized. 


\section{Abstract}

Gasarite structures are a unique type of metallic foam containing tubular pores. The original methods for their production limited them to laboratory study despite appealing foam properties. Thermal decomposition processing of gasarites holds the potential to increase the application of gasarite foams in engineering design by removing several barriers to their industrial scale production. The following study characterized thermal decomposition gasarite processing both experimentally and theoretically. It was found that significant variation was inherent to this process therefore several modifications were necessary to produce gasarites using this method. Conventional means to increase porosity and enhance pore morphology were studied. Pore morphology was determined to be more easily replicated if pores were stabilized by alumina additions and powders were dispersed evenly. In order to better characterize processing, high temperature and high ramp rate thermal decomposition data were gathered. It was found that the high ramp rate thermal decomposition behavior of several hydrides was more rapid than hydride kinetics at low ramp rates. This data was then used to estimate the contribution of several pore formation mechanisms to the development of pore structure. It was found that gas-metal eutectic growth can only be a viable pore formation mode if nonequilibrium conditions persist. Bubble capture cannot be a dominant pore growth mode due to high bubble terminal velocities. Direct gas evolution appears to be the most likely pore formation mode due to high gas evolution rate from the decomposing particulate and microstructural pore growth trends. The overall process was evaluated for its economic viability. It was found that thermal decomposition has potential for industrialization, but further refinements are necessary in order for the process to be viable. 


\subsection{Background and Research Goals}

\subsection{Introduction}

Interest in metallic foams as engineering materials has grown significantly during the period from the 1950's to the present. These materials are of interest due to the myriad of material properties that they exhibit such as high strength to weight ratio and energy absorption. ${ }^{[2-9]}$ Foams may also be used in functional applications such as biomedical implants. ${ }^{[10-12]}$ There are a number of metal foam processing routes available, capable of producing foams with different ranges of porosity and pore size in different materials systems. ${ }^{[13-14]}$ Depending on the process chosen, design engineers may either make use of very expensive foams with low pore morphology variation or foams that have low cost and high variance in pore morphology. Variability in pore structure translates to variation in material properties and has caused reluctance on the part of design engineers to integrate foamed materials into different applications. Given this issue, there is an obvious goal to pursue: material cost reduction coupled with enhanced process control. This goal has been pursued by many researchers and industrial engineers over the past decade with many improvements and new technologies being developed. ${ }^{[13,}$ $15-16]$

Studying foaming processes also offers the opportunity to conduct fundamental scientific research into the key concepts which govern them. These concepts include fluid dynamics, solidification and high temperature colloidal interactions. ${ }^{[17-19]}$ The following set of studies examines such fundamental concepts in the framework of the thermal decomposition process for producing gasarite structures. Gasarite structures are 
a unique subclass of metal foams characterized by tube-like porosity. The goal of this work is to better characterize the thermal decomposition processing of gasarite foams in order to determine whether or not this process is viable for foaming aluminum. This goal was accomplished by conducting foaming experiments which determined effective pore morphology control modes, the nature of pore formation and growth, and the decomposition behavior of gas evolving compounds under foam processing conditions. Aluminum was chosen as the system of study due to its naturally high strength to weight ratio. Aluminum is also readily foamed via thermal decomposition of common blowing agents such as titanium hydride $\left(\mathrm{TiH}_{2}\right) .{ }^{[2,20-21]}$

The study begins with a brief review of foam processing techniques (Chapter 1) highlighting the unique properties of gasarite metal foams and the challenges in their production. Following the short review, preliminary modeling (Chapter 2) and experimental investigations into thermal decomposition processing of gasarites (Chapter 3-4) are presented. This includes initial attempts to replicate results from literature, process modification trials, a study examining the influence of stabilizer particles on pore formation in gasarites and several variations of powder introduction techniques. These sections will highlight the technical challenges in producing gasarites via thermal decomposition and the open questions that drove further research.

Following the process development phase, a baseline process capability study which highlights active pore formation mechanisms (Chapter 5) was carried out utilizing different hydride gas source materials. Based on the results of this study, it was necessary to better characterize the high temperature decomposition behavior of several metal hydrides of interest including titanium hydride $\left(\mathrm{TiH}_{2}\right)$ and zirconium hydride 
$\left(\mathrm{ZrH}_{2}\right)$. A thermogravimetric analysis technique was developed and used to more accurately simulate the thermal states that powders experience during foam processing (Chapter 6). Using the results of all other studies a preliminary model for gasarite growth via thermal decomposition was proposed and predictions of this model were compared against experimental trends (Chapter 7). Utilizing the information gathered from all trials, a feasibility study is presented for the production of gasarites via thermal decomposition (Chapter 8). This chapter also summarizes the findings from the current study, includes suggestions for future work and additional open questions that have been revealed.

\subsection{Metallic Foam Processing}

Metallic foams may be produced using a number of techniques and have been utilized in a number of applications as shown in Table 1.1. The bulk of initial research and development on metallic foams was conducted by private companies leading to many unique, proprietary processes. ${ }^{[2,13-14]}$ A summary of the pore morphology control ranges of these techniques is provided in Figure 1.1. Pore morphology refers to the combination of pore (cell) size, distribution, and shape within a foamed metal. These factors along with overall porosity and characteristics of the base material define the foam properties. Porosity levels are typically presented either in volume fraction, volume percent, or by relative density which is defined as the density of the foam divided by that of the parent material. 
Table 1.1: Manufacturers, processes and applications of metal foams created from various materials. ${ }^{[2,13-14]}$

\begin{tabular}{|c|c|c|c|}
\hline Company & Process & Applications & $\begin{array}{l}\text { Materials } \\
\text { Available }\end{array}$ \\
\hline Alantum & $\begin{array}{c}\text { Polymer } \\
\text { Precursor(Powder } \\
\text { Slurry Enclosed } \\
\text { Treatment) } \\
\end{array}$ & Structural & $\mathrm{Fe}, \mathrm{Ni}$ \\
\hline Alusion(Cymat) & Melt Gas Injection & Structural/Aesthetic & $\mathrm{Al}$ \\
\hline $\begin{array}{l}\text { American } \\
\text { Elements }\end{array}$ & $\begin{array}{l}\text { Chemical Vapor } \\
\text { Deposition (CVD) }\end{array}$ & General Supply & $\mathrm{Al}$ \\
\hline $\begin{array}{l}\text { Chand } \\
\text { Eisenmann }\end{array}$ & Solid State-Sintering & $\begin{array}{l}\text { Filtration, Media } \\
\text { Retention, Flow } \\
\text { Control }\end{array}$ & $\begin{array}{c}\text { Stainless } \\
\text { Steel, Nickel } \\
\text { Superalloy, } \\
\text { Ni, Ti, Al, } \\
\text { Cu }\end{array}$ \\
\hline $\begin{array}{c}\text { Corex } \\
\text { Honeycomb }\end{array}$ & Machined/formed & $\begin{array}{l}\text { Structural, Various } \\
\text { Industrial Sectors }\end{array}$ & $\mathrm{Al}$ \\
\hline ERG(Duocell) & Investment Casting & Structural, Filtration & $\mathrm{Al}, \mathrm{Cu}, \mathrm{SiC}$ \\
\hline $\begin{array}{l}\text { Fraunhoffer } \\
\text { IFAM }\end{array}$ & $\begin{array}{c}\text { Hydride } \\
\text { Decomposition, } \\
\text { Hollow Sphere } \\
\text { Compaction }\end{array}$ & $\begin{array}{l}\text { Structural, General } \\
\text { Research }\end{array}$ & $\begin{array}{l}\text { Al, Fe, } \\
\text { Stainless } \\
\text { Steel, etc }\end{array}$ \\
\hline Porvair & $\begin{array}{l}\text { Reticulated Sponge } \\
\text { Precursor }\end{array}$ & Filtration & $\begin{array}{l}\mathrm{Cu}, \mathrm{Ni}, \mathrm{Ti}, \\
\mathrm{Fe}, \mathrm{Pt}, \mathrm{Ag}\end{array}$ \\
\hline $\begin{array}{c}\text { Reade } \\
\text { Advanced } \\
\text { Materials }\end{array}$ & $\begin{array}{l}\text { Polymer Precursor, } \\
\text { CVD, Sintered } \\
\text { Precursor }\end{array}$ & General Supply & $\begin{array}{c}\mathrm{Al}, \mathrm{C}, \mathrm{Cu}, \\
\mathrm{Hf}, \mathrm{Pb}, \mathrm{Ni}, \\
\mathrm{Nb}, \mathrm{Rh}, \mathrm{Ta}, \\
\mathrm{Sn}, \mathrm{W}, \mathrm{Zr}\end{array}$ \\
\hline $\begin{array}{c}\text { Shinko } \\
\text { Wire(Alporas) }\end{array}$ & $\begin{array}{c}\text { Hydride } \\
\text { Decomposition }\end{array}$ & $\begin{array}{l}\text { Structural, Filtration, } \\
\text { Heat Exchanger }\end{array}$ & $\mathrm{Al}$ \\
\hline
\end{tabular}

As shown in Figure 1.1, there is a great deal of overlap between the control ranges of different techniques, but there are some pore morphology regimes only accessible by certain techniques (most notably the regions encompassed by the gas metal eutectic 
technique and thermal decomposition techniques which can be used to produce gasarite structures). Many foaming techniques were developed specifically for niche markets therefore it is feasible that these processes could also be adapted to encompass wider ranges of pore size and porosity.

Generally, foam processing techniques can be subdivided into those that utilize precursor structures to form well controlled foam pores and those in which stochastic interactions result in more geometric variability. ${ }^{[19]}$ There is some debate as to whether porous metals formed using precursors may be truly defined as foams since they do not always entail the formation of a froth from the parent material. For the current discussion this distinction is ignored in order to highlight issues of more practical significance when comparing precursor processes to stochastic processes.

Precursor based foaming techniques include semi-solid thermal decomposition and hollow sphere compaction (Fraunhoffer). ${ }^{[22]}$ Additionally, polymer foam precursors may be used as targets for metal based chemical vapor deposition (CVD) forming porous metal structures. Investment casting techniques have also been employed in the ERG Duocell process with wax patterns acting as highly replicable precursors. Recently, syntactic foaming techniques have also been developed in which beds of hollow ceramic spheres are infiltrated with molten metal under pressure to create highly regular pore structures. ${ }^{[23]}$ The benefit of precursor techniques is that the pore structure variation is dependent on precursor processing. Many methods used to produce precursors are well controlled and thus lend a similar degree of control to metal foams that are produced from them. The primary drawback of these processes is they are usually more expensive 
since they have a higher number of unit operations and higher overall material costs. ${ }^{[24]}$ There are also processing limitations on precursor geometry making certain regimes of pore morphology unattainable. In order to produce lower cost foam structures and different pore morphologies stochastic processes may be utilized.

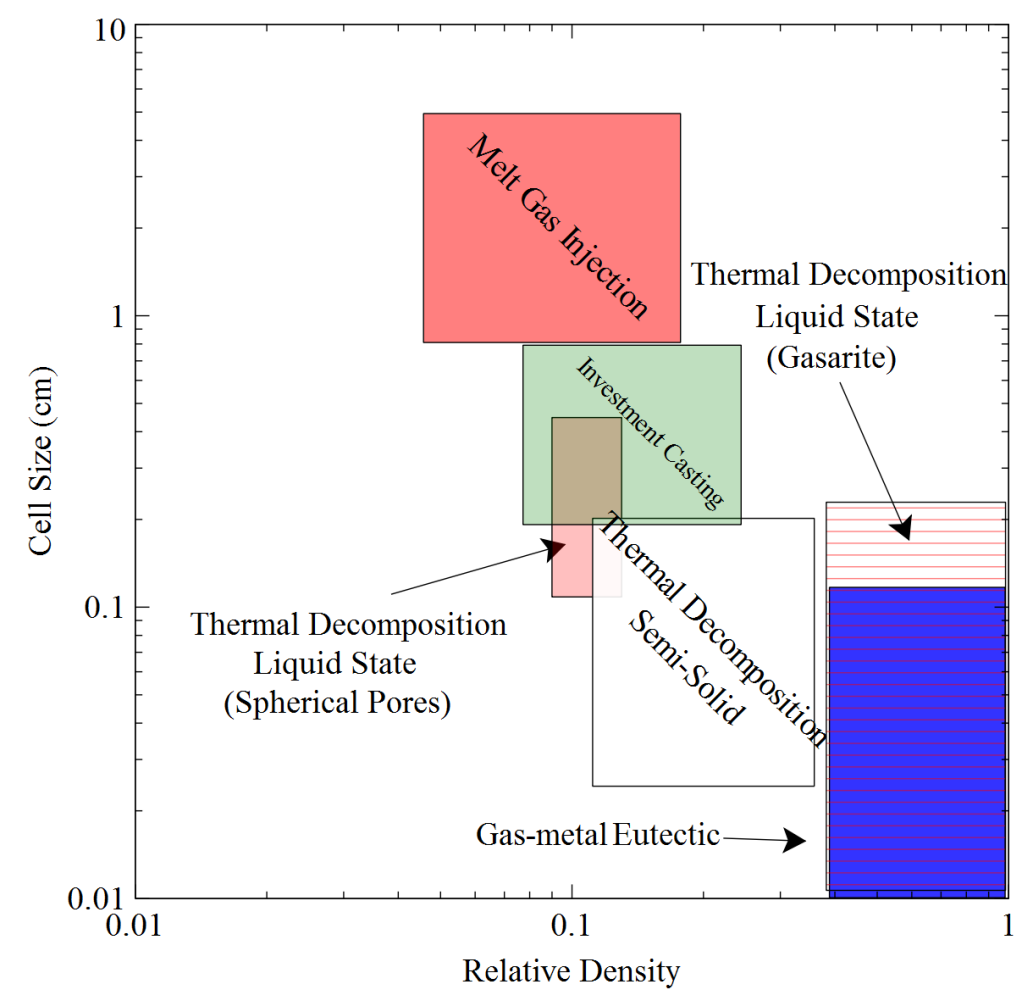

Figure 1.1: Pore morphology control ranges of common metal foam processes. Chart adapted from Ashby (2000) $)^{[2]}$ to include more current pore morphology control data for gas metal eutectic process and thermal decomposition process.

Stochastic metal foam processing techniques are typically carried out with the base material in the liquid state. Examples of these processes include thermal decomposition (Shinko Wire-Alporas), melt gas injection (Alusion-Cymat) and gas metal eutectic processing. Semi-solid stochastic foaming techniques have also been developed 
by Fraunhoffer in which steel sandwich structures are compressed around a mixture of metal hydride and aluminum powder. The major challenge in pore morphology control for stochastic techniques arises from the statistical processes that govern pore development. Most liquid phase foaming processes entail the introduction of gas bubbles to liquid metal shortly before solidification. Energetically, the pores formed by the gas bubbles are unstable leading to pore collapse and gas bubble coalescence. As these processes occur, pore morphology can become inhomogeneous. Stabilizing elements such as metal oxides (e.g. $\mathrm{CaO}, \mathrm{Al}_{2} \mathrm{O}_{3}$ ) are often added to the liquid metal (typically aluminum) allowing solidification to occur before significant pore rupture and coalescence. The exact mechanism of the stabilization effect is currently a topic of debate among researchers, however most agree it is related to the semi-wetting character (contact angles of $70-90^{\circ}$ ) of these oxides with liquid aluminum. ${ }^{[25-26]}$

Additional critical factors that influence foam pore morphology are the initial bubble distribution and size of gas bubbles. These two characteristics help determine the likelihood of coalescence as well as buoyancy driven bubble velocity which may cause gas to escape the system. The number of gas bubbles that form the cells of metallic foam is often large and they may be deformed by even the slightest external force. Large numbers combined with the sensitivity of gases to undetectable and uncontrollable forces leads to porous structure whose properties can only be defined by wide distributions. This is an undesirable quality and pore morphology control has been the primary topic of research over the past several decades. Current research on this topic has focused on 


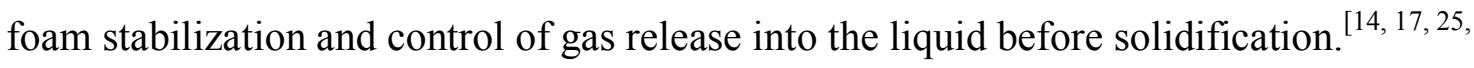
27-28]

The thermal decomposition method of producing gasarite structures studied in the current work is a stochastic foaming technique and suffers from many of the same difficulties outlined above. Due to its relative infancy compared to other foaming techniques, there was a lack of fundamental studies investigating the key factors which influence pore morphology. It was found that many of methods employed to attain control over pore morphology in similar foaming processes had not been evaluated in thermal decomposition gasarite processing. Several of these techniques were evaluated in the current study and the results are presented in Chapter 3. Before covering those studies it is first necessary to examine what defines a gasarite pore morphology and their means of production.

\subsection{Gasarite Processing}

Most foamed materials include pores with nearly spherical geometries. A gasarite structure is a unique subclass of metal foam in which pores are tubular. The original process to create these structures (gas-metal eutectic or GASAR process) was invented and extensively studied by V.I. Shapovalov from the late 1970's until the present with two recent reviews published. ${ }^{[29-30]}$ This foaming process was discovered during studies of gas solubility in molten metal. It was found that many gas-metal systems exhibit a feature similar to a liquid to solid phase eutectic point referred to as a gas-metal eutectic point. Solidification of metals that exhibit this feature leads to a single phase liquid 
turning into a gas and a solid. If directional solidification techniques are employed, this leads to phase growth similar to a rod eutectic and tube shaped pores.

The root of the term, GASAR, comes from a Russian acronym meaning gas reinforced or gas-containing. An example of such a structure is included in Figure 1.2. Due to less stress intensification around tubular pores gasarites exhibit higher mechanical strength than foams of the same material and relative density when loaded along the axis of pore elongation. ${ }^{[30]}$ For example in steel gasarites, tensile strength is $300-1100 \mathrm{MPa}$ (varied with relative density) which is 5-20 times greater than sintered steel foams of the same relative density range. ${ }^{[31]}$ This makes such structures appealing for light weight mechanical design. Gasarites may also be used for heat exchangers or in biomedical implants in which deep pores allow for more cohesive implant integration. ${ }^{[10]}$

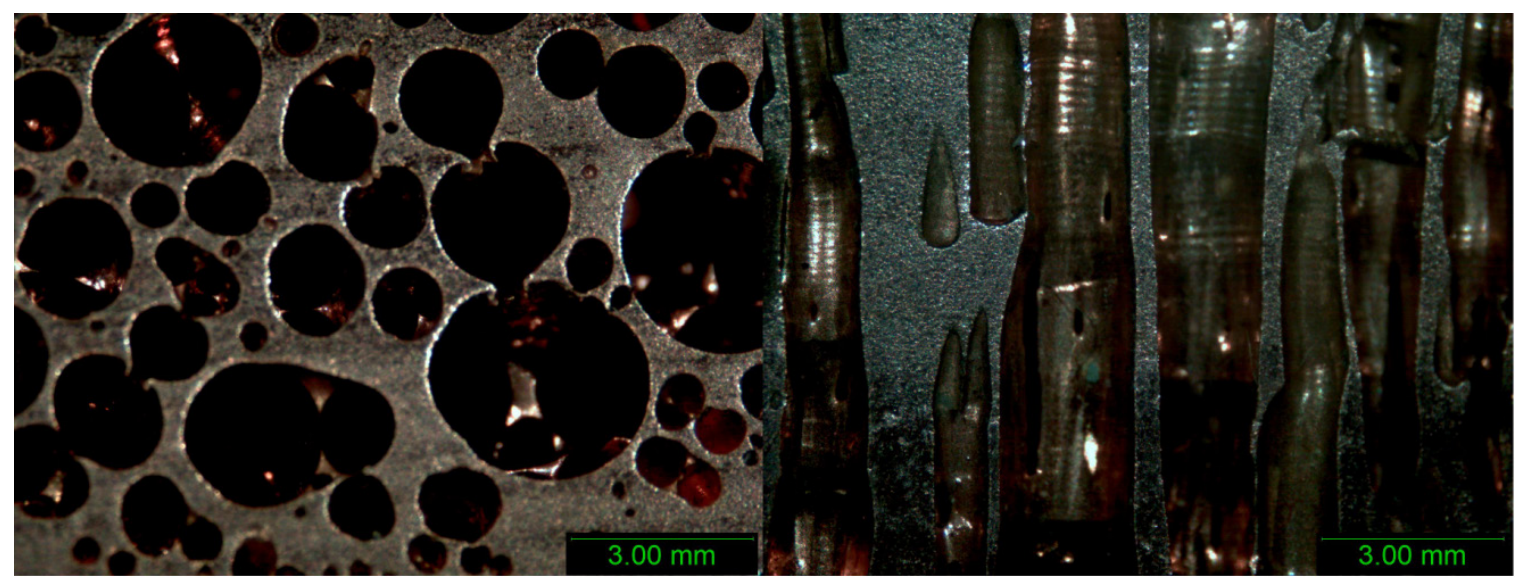

Figure 1.2: Transverse (L) and longitudinal (R) sections of a copper gasarite produced using dissolved hydrogen gas. Gas pressure during solidification was $0.9 \mathrm{~atm}$.

According to the process outlined by Shapovalov, there are two pressures used in gas-metal eutectic gasarite processing, a saturation pressure and a solidification 
pressure. ${ }^{[29]}$ The saturation pressure is applied during melting of the metal alloy and the solidification pressure is applied during foam solidification. Each type of processing pressure can be composed of soluble gas (typically hydrogen), or a mixture of soluble gas and inert gas (typically argon). Solidification pressures may be varied broadly to modify pore morphology making Gasar processing very versatile. ${ }^{[30]}$

Investigations into gasarite processing have focused on controlling porosity levels, foaming new materials, and pore morphology control. Table 1.2 summarizes the base materials, soluble process gases, porosity levels and pores sizes reported by Shapovalov in recent reviews. ${ }^{[29]}$ It should be noted that most conventional foaming techniques mentioned in Section 1.2 are severely limited in their ability to create metal foam from a variety of materials. Gas metal eutectic processing allows the formation of foams from many metals and some ceramics as long as the material has a significant decrease in gas solubility during solidification. The limitation of porosity for different materials is directly related to this solubility drop between the liquid and solid state. For example, under 1 atm of hydrogen copper rejects approximately five times more gas when it solidifies than aluminum. ${ }^{[32]}$ As a result, porosity levels for hydrogen formed aluminum gasarites are only $5-25 \%$ while those for copper may approach $70 \%$.

While general trends in porosity levels may be estimated from solubility data, solubility is not the sole factor that contributes to pore growth and formation. Had solubility been the sole factor in the example above, significantly more porosity would have resulted for copper versus aluminum. Another key factor that determines pore morphology and porosity levels is the solidification rate. Pore growth in gasarite 
structures is always aligned with the solidification. If sluggish solidification occurs or if equiaxed solidification becomes dominant then pore morphology will be influenced leading to different structures. In chill casting processes, the solidification rate is controlled by the conductivity of the base metal. Slow or non-unidirectional solidification alters pore formation and pore morphology leading to several different morphologies apart from ordered tubular structures. These pore morphologies include gas dendrites, ellipsoids and in some cases spheres. ${ }^{[2]}$

When directional solidification occurs at different rates, the pore spacing and size will also be influenced. The trend of this effect is as predicted by the Jackson and Hunt model for eutectic growth. This well known eutectic growth model has been applied by researchers to gas-metal eutectic growth with some success. ${ }^{[33-34]}$ The basic prediction of this model is that pore spacing and size are inversely proportional to solidification rate, while overall porosity remains constant. This is because kinetically, solidification rate limits the extent of lateral diffusion which governs the phase spacing and size. The key difference between gas-metal eutectic growth and rod eutectic growth is that gases are highly buoyant in liquid metal and have a considerable volume change upon formation versus the solid. These two factors need to be taken into account when using the Jackson and Hunt model to predict porosity levels, pore size, and spacing. Buoyancy driven gas escape effect has not been taken into account in many Jackson/Hunt modeling efforts possibly explaining some degree of disagreement with experimental results. 
Table 1.2: High pressure gasarite process control summary. ${ }^{[30]}$ Pore size and control ranges are very large compared to other foaming processes. Gasarite processing is uniquely able to produce foam from a number of material classes.

\begin{tabular}{|c|c|c|c|}
\hline Materials & Processing Gases & $\begin{array}{c}\text { Porosity } \\
\text { Range }(\%)\end{array}$ & $\begin{array}{c}\text { Pore Size } \\
(\mu \mathrm{m})\end{array}$ \\
\hline $\begin{array}{c}\mathrm{Al}, \mathrm{Fe}, \mathrm{Ni}, \mathrm{Cu}, \mathrm{Ti}, \mathrm{Co}, \mathrm{Mg} \\
\frac{\mathrm{Alloys}}{\mathrm{Cast} \text { Iron, Steel, Bronze, }} \\
\begin{array}{c}\text { Ni-Superalloy } \\
\text { Ceramics } \\
\mathrm{Al}_{2} \mathrm{O}_{3}, \mathrm{MgO}, \mathrm{ZrO}_{2}\end{array}\end{array}$ & $\mathrm{H}_{2}, \mathrm{~N}_{2}, \mathrm{O}_{2}$ & $10-65$ & $10-1000$ \\
\hline
\end{tabular}

The primary drawback of Shapovalov's gas metal eutectic technique is that it requires casting equipment capable of holding pressures ranging from vacuum to 50 atm. ${ }^{[29]}$ Additionally, special safety protocols are needed to handle hydrogen, which for many metals is the most soluble gas. Finally, the original processing methods were batch production techniques making it difficult to achieve industrial scale production. These issues have been partially addressed by both Shapovalov and Nakajima through the invention of new production techniques including the thermal decomposition method.

\subsection{Thermal Decomposition Processing of Gasars}

Nakajima and his coworkers have examined both the original gasar method as well as alternative gasarite processing techniques in order to promote application of gasarite foams on an industrial scale. ${ }^{[20-21,32,35-44]}$ Due to their extensive experimental work, Nakajima's group has renamed gasarites "lotus structured" metals after the lotus 
root. This term will not be used throughout this study to avoid confusion and retain consistency with the original literature.

One original process developed by Nakajima is a continuous casting technique which is capable of producing copper gasarite structures up to $700 \mathrm{~mm}$ long. ${ }^{[38]} \mathrm{In}$ addition to continuous casting, a zone refining method was developed capable of producing $300 \mathrm{~mm}$ long porous structures from various material systems. ${ }^{[32]}$ Additional techniques developed by Shapovalov include a plasma-printing technique in which additive manufacturing techniques utilize highly soluble gas-plasmas in order to construct porous structures a layer at a time. ${ }^{[29]}$ While these methods helped increased the limits of sample length and overall process efficiency they remained reliant on the application of hydrogen gas. In order to reduce the amount of hydrogen gas utilized in processing, more direct methods of introducing gas to the molten metal were employed.

Several investigations were carried out by Nakajima and others focusing on applying thermal decomposition foaming techniques to the production of gasarites. ${ }^{[20-21,}$ 39-40, 42, 44-45] Thermal decomposition processing is an industrial foaming technique employed by Fraunhofer and Shinko Wire Co. and has been studied by others in the context of non-gasarite foams. ${ }^{[28,46-47]}$ As shown below (Figure 1.3), thermal decomposition processing of gasarites involves pouring molten metal upon a compound which rests on top of a water cooled chill plate. After the metal comes into contact with the compound, it is raised above its decomposition temperature and gas is liberated. Porosity is formed by interactions with the unidirectional solidification front. Various compounds and base metals were demonstrated as suitable gasarite forming materials 
including aluminum foamed with metal hydrides, moisture, and other compounds. A summary of the materials, pore morphology ranges and foaming agents is included in Table 1.3.

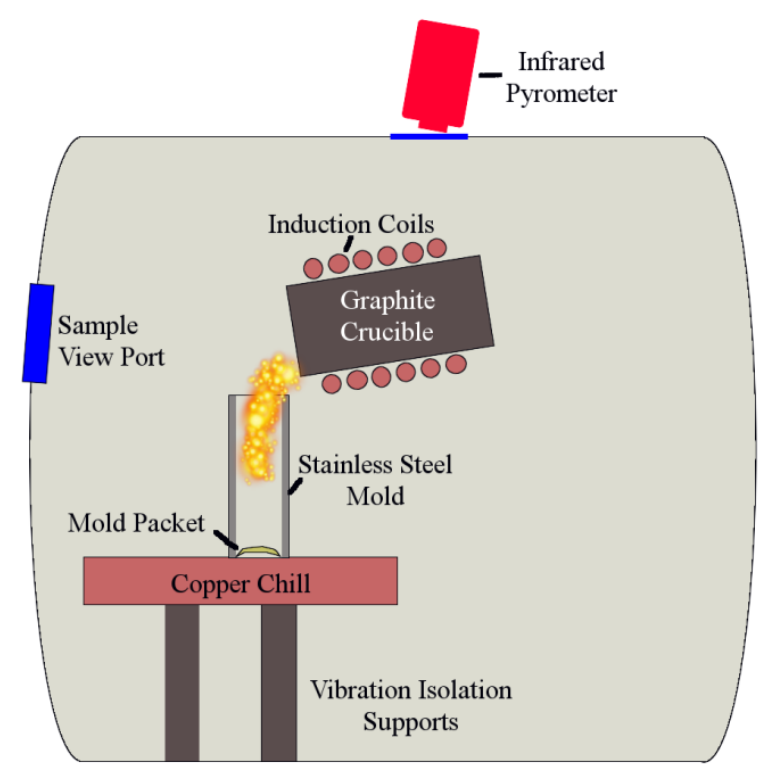

Figure 1.3: Schematic of the thermal decomposition process showing the experimental configuration for creating gasarite structures. The key difference between thermal decomposition and the original gasar process is the use of a mold packet instead of pressurized gas.

Table 1.3: Materials and compounds used to form gasarite structures via thermal decomposition. ${ }^{\text {[20-21, 39-40, 42, 44] }}$

\begin{tabular}{|c|c|c|c|}
\hline Material & Decomposition Compound(s) & $\begin{array}{c}\text { Maximum } \\
\text { Porosity }\end{array}$ & $\begin{array}{c}\text { Inert Gas } \\
\text { Pressure }\end{array}$ \\
\hline Aluminum & $\mathrm{H}{ }_{2} \mathrm{O}$, & $25 \%$ & Vacuum \\
\hline Copper & $\mathrm{TiH}_{2}$ & $60 \%$ & $1 \mathrm{~atm}$ \\
\hline Magnesium & $\mathrm{MgH}_{2}$ & $40 \%$ & $1 \mathrm{~atm}$ \\
\hline Iron & $\mathrm{CrN}_{2}$ & $30 \%$ & $5 \mathrm{Titm}$ \\
\hline
\end{tabular}


Aluminum and its alloys are often chosen for metallic foam applications due to their naturally high strength to weight ratio and ease of foaming. ${ }^{[2]}$ Aluminum gasarite structures can be produced using the pressurized gas-metal eutectic method, but porosity values are typically low due to limited gas solubility in molten aluminum compared with other materials. ${ }^{[20]}$ Thermal decomposition foaming of aluminum gasarites has the potential to increase the usage of gasarite foams since it is unlikely to rely on the establishment of global equilibrium gas concentrations for pore formation. ${ }^{[39]}$ For these reasons aluminum has served as the primary system of study for all foamed samples in the current study.

In foaming trials carried out by Nakajima's group, external pressure was found to significantly influence the porosity produced in gasars formed via thermal decomposition in multiple materials systems. ${ }^{[45]}$ As predicted by the ideal gas law, the volume of the gaseous phase decreased with increasing inert gas pressure. Increasing the amount of hydride, increased porosity until reaching a plateau level. The reasoning for this plateau behavior was assumed to be related to attainment of solubility limits within the molten metal. This implied that pore formation is due to gas-metal eutectic growth, but no evidence was provided in support of this hypothesis aside from the plateau of porosity.

Gasarites formed via thermal decomposition have only been studied to a limited extent for their mechanical properties as well as their functional properties. No studies have been presented in which the mechanical properties of gasarites processed via pressurized gas and those processed by thermal decomposition have been compared. Copper gasarites formed by decomposition of $\mathrm{TiH}_{2}$ were utilized in high surface area heat 
exchangers and exhibited four times greater performance than conventional heat sinks. ${ }^{[39]}$ While the nature of processing is different, it should be expected that gasarite structures produced using thermal decomposition should exhibit identical properties of gasarites produced using high pressure techniques as long as the pore morphology is comparable. The current set of studies focuses entirely on characterizing key elements of the thermal decomposition process and making comparisons between the resulting pore morphologies and those found for foams using the pressurized gas process. Mechanical and functional characterization of the foams produced in the current work is suggested as future work.

\subsection{Summary and Conclusions}

Many foaming techniques exist, each with their own advantages and disadvantages. The primary advantage to the original gasar process was its ability to create a wide variety of uniquely structured metal foams. The main disadvantage to the original gasar process was reliance on high pressure of hydrogen gas making it difficult to scale on an industrial level. Several researchers including the original inventor are pursuing alternative gasarite production techniques in order to increase the usage of gasarites in engineering design. The thermal decomposition method has only been studied on a proof of concept level more therefore more in depth investigations were necessary in order determine how pores form and how pore morphology may be controlled. Before pursuing such investigations, it is necessary to develop a theoretical framework for use in explaining experimental results. This framework has been developed below and will be used to link together experimental results. 


\subsection{Conceptual Model of Gasarite Development During Thermal Decomposition}

\subsection{Model Construction and Gas Metal Eutectic Growth}

The following model is a hypothesized sequence of events that occurs during thermal decomposition framed within the fundamentals of fluid dynamics and solidification. For the following model system, it is assumed that hydrogen is the sole gas released and the only interacting species considered are hydrogen gas, liquid aluminum, solid aluminum and gas source particles. For simplicity it is also assumed that decomposing particles are stationary in the melt as they decompose.

When metal is poured upon the powdered gas source, the powder will become dispersed due to turbulence. In the absence of external mixing, the dispersion will be incomplete leading to a higher proportion of the hydride residing close to the chill plate. As the powder rapidly heats beyond its decomposition point, it will begin to evolve gas resulting in more turbulence and additional powder dispersion, making the system more uniform. As the system becomes less turbulent, gas evolution will continue, leading to formation of gas bubbles around the dispersed particles. As gas bubbles grow several moving interfaces will be formed around the particles: a gas-liquid interface, a gas-solid interface, and an interface between decomposed and pristine gas source (Figure 2.1). It is assumed that the gas source decomposes via a shrinking core mechanism similar to many

metal hydrides. ${ }^{[47]}$ Under these assumptions, the motion of each interface is governed by a combination of diffusion, gas source decomposition kinetics, and fluid dynamics. 


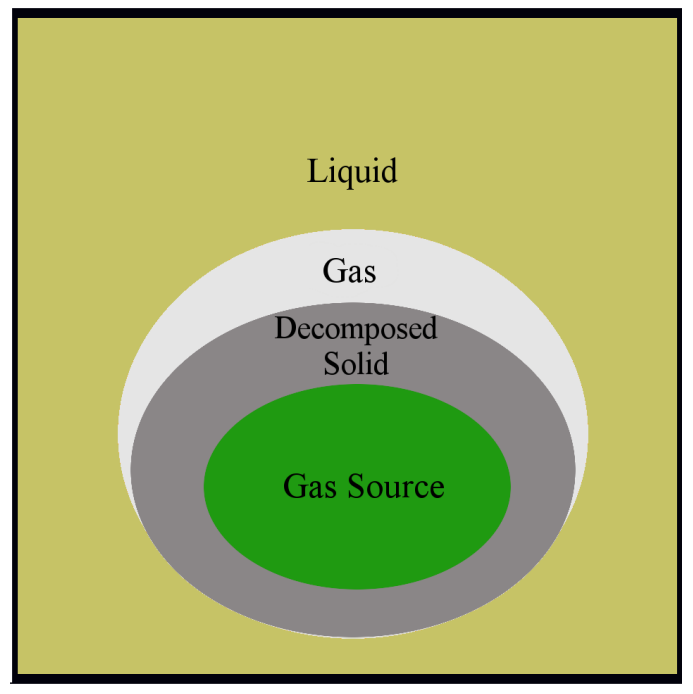

Figure 2.1: Schematic interface development during steady state decomposition of a gas source particle in a molten liquid. This schematic assumes a shrinking core model for the gas source and allows buoyancy force to act on evolved gas.

The concentration gradient driving diffusion through the liquid aluminum will initially be very high, causing a flux of gas into solution and away from the gas source. If the rate of gas diffusion into the liquid exceeds the rate of gas evolution from the particle, the gas-liquid interface will draw closer to the decomposing particulate. In the case where more gas is produced than can diffuse into the liquid, a gas bubble will grow. If the saturation limit of the liquid surrounding bubble has been met, then the bubble will also grow. This saturation limit $\left(\mathrm{C}_{\mathrm{H}-\text { local }}\right)$ may be defined with respect to the hydrogen partial pressure within the bubble, $\mathrm{P}_{\mathrm{H}}$, by Sieverts' law (Equation 2.1). ${ }^{[48]}$

$$
C_{H-l o c a l}=K_{H-A l} \sqrt{P_{H}}
$$


where $\mathrm{K}_{\mathrm{H}-\mathrm{Al}}$ is the Sieverts' coefficient for hydrogen in aluminum. The hydrogen partial pressure within the bubble, $\mathrm{P}_{\mathrm{H}}$, may be estimated by assuming bubble growth must overcome the hydrostatic head $\left(\mathrm{P}_{\text {Head }}\right)$ and externally applied inert gas pressure $\left(\mathrm{P}_{\text {Ext }}\right)$. For the sake of the current discussion it is assumed that Laplace surface tension effects are not significant so capillary pressure is neglected. Under these assumptions, $\mathrm{P}_{\mathrm{H}}$ is simply equivalent to the sum of head pressure and externally applied pressure (Equation 2.2). Hydrostatic head $\left(\mathrm{P}_{\text {Head }}\right)$ varies with $\mathrm{z}$, the distance of the particle from the chill plate, as shown in Equation 2.3. Here $\rho_{\mathrm{f}}$ is the density of the liquid metal and $\mathrm{g}$ gravitational acceleration.

$$
\begin{aligned}
& P_{H}=P_{\text {Head }}+P_{\text {Ext }} \\
& P_{\text {Head }}=\rho_{f} g z
\end{aligned}
$$

The Sieverts' constant for aluminum used for the current calculation is $\mathrm{K}_{\mathrm{H}-\mathrm{Al}}=0.275$ $\mathrm{cm}^{3} / 100 \mathrm{~g}-\mathrm{atm}^{0.5} .{ }^{[49]}$ The volumetric solubility included in Sieverts' constant are reported at standard temperature and pressure, therefore the ideal gas law must be used to estimated the solubility at thermal decomposition processing conditions (Equation 2.4).

$$
C_{H-\text { Operating }}=C_{H}\left(\frac{T_{m}}{298 K}\right)\left(\frac{1 \mathrm{~atm}}{P_{\text {Ext }}+P_{\text {Head }}}\right)
$$

If it is assumed that all dissolved gas comes out of solution during solidification, and does not escape to the atmosphere, porosity values may be estimated using Equation 2.5 . 


$$
f_{p}=\frac{V_{p}}{V_{p}+V_{m}}=\frac{C_{H-\text { Operating }}}{C_{H-\text { Operating }}+\frac{1}{\rho_{l}}}
$$

Here the solid metal density must be converted to agree with the concentration units (in this case $100 \mathrm{~g} / \mathrm{cm}^{3}$ so $\rho_{\mathrm{f}}=2.7 \times 10^{-2} 100 \mathrm{~g} / \mathrm{cm}^{3}$ ). Assuming that the entire liquid cast into the mold takes on the maximum calculated solubility at the base $\left(7.1 \mathrm{~cm}^{3} / 100 \mathrm{~g}\right)$ the largest amount of porosity that could be formed is $15 \%$. Preliminary data ${ }^{[20]}$ for gasarites produced using thermal decomposition show that maximum porosity levels are $25 \%$ for a sample weighing $100 \mathrm{~g}$ resulting in some discrepancy between the predictions above and experiments.

Nakajima and Kim have asserted that all gasarite porosity formed via thermal decomposition of metal hydrides is due to a gas-metal eutectic reaction, but little basis for this assertion was given. ${ }^{[20,45]}$ Since pore formation via gas metal eutectic reactions is strongly influenced by gas solubility, this mechanism is not likely the sole pore formation mode given the low estimated porosity levels calculated above relative to experiments. Based on these observations it is necessary to examine alternate pore formation and growth modes in order to determine all of the means by which pore morphology may be influenced in thermal decomposition processing of aluminum foams. The most likely pore growth modes include bubble capture and direct gas evolution. 


\subsection{Bubble Capture Pore Formation and Growth}

The bubble capture pore formation and growth mode entails the encapsulation of bubbles by the advancing solidification front over time. This pore formation mode is likely only if the solidification front moves quickly enough to compete with bubble motion. Several simple relations may be used in order to estimate whether this condition may occur. Assuming the construction in Figure 2.1, the interface between a gas bubble and the liquid aluminum will be deformed easily since gases are highly compressible. Buoyancy forces will have the tendency to elongate the gas-liquid interface anti-parallel to the gravitational vector. If bubble volumes grow either by heating or introduction of more gas, buoyancy forces will increase according to Equation 2.6:

$$
F_{B}=V_{b} g \rho_{f}
$$

where $V_{b}$ is the bubble volume, $g$ is gravitational acceleration, and $\rho_{\mathrm{f}}$ is the density of the liquid aluminum $\left(2300 \mathrm{~kg} / \mathrm{m}^{3}\right)$. If buoyancy force exceeds the forces acting to prevent bubble motion (inertial forces, drag forces etc) the bubble will detach and begin to move upward through the open liquid. This process will repeat several times releasing many bubbles until the gas source can no longer produce bubbles of the needed detachment volume or the solidification front overtakes and seals the particle. The terminal velocity of the released bubbles may be estimated by Stokes' Law for spherical volumes moving through a fluid (Equation 2.7).

$$
v_{t}=\frac{2}{9} \frac{\left(\rho_{g}-\rho_{f}\right)}{\mu} g r^{2}
$$


Here $\rho_{\mathrm{g}}$ is the gas density, $\mu$ is the dynamic viscosity and $\mathrm{r}$ is the radius of the gas bubble assuming a spherical geometry. This equation may be simplified by assuming the density of the gas is much less than the density of the liquid metal resulting in Equation 2.8. The negative sign indicates bubble motion opposite the direction of the gravitational vector.

$$
v_{t}=-\frac{2}{9} \frac{\rho_{f}}{\mu} g r^{2}
$$

The ideal gas law (Equation 2.9) may be used to estimate the bubble volume if the temperature profile, $\mathrm{T}(\mathrm{t})$, number of moles of gas released through decomposition as a function of temperature $\mathrm{n}[\mathrm{T}(\mathrm{t})]$, and pressure $\mathrm{P}$ are known. Taking the derivative of volume with respect to time gives a general expression (Equation 2.10) for the volumetric expansion rate of gas bubbles forming in the thermal decomposition foaming process.

$$
\begin{array}{r}
V_{b}(t)=\frac{n[T(t)] R T(t)}{P} \\
\frac{\delta V_{b}}{\delta t}=\frac{R}{\rho_{f} g z+P_{\text {ext }}} \frac{\delta}{\delta t}[n[T(t)] T(t)]
\end{array}
$$

$\mathrm{T}(\mathrm{t})$ may be estimated either by solidification modeling or via thermocouple data from experiments. The number of moles of gas evolved, $\mathrm{n}[\mathrm{T}(\mathrm{t})]$, may be estimated by the decomposition kinetics of the gas source while integrating the thermal profile $\mathrm{T}(\mathrm{t})$ into the governing equations. It is assumed that the internal bubble pressure, $\mathrm{P}$, is the same as above (Equation 2.2). Equation 2.10 may be used to estimate variation of buoyancy forces acting on bubbles as they grow from decomposing particulate. At a given volume, the buoyancy force will cause the gas bubble to detach. After the bubble is detached 
from the decomposing hydride, its radius may be used to estimate its terminal velocity using Equation 2.8 and gauge whether or not the solidification front will have an opportunity to interact with it in order to form porosity.

While gas evolution from the gas source occurs, solidification will begin at the interface between the molten metal and chill plate. Ansys Fluent's heat transfer finite difference algorithm was used to estimate the solidification velocity profile that a copper chill imparts to a cylindrical $(25.4 \mathrm{~mm} \phi \times 127 \mathrm{~mm}$ tall) pure aluminum sample. The model assumed three dimensional Fourier heat transfer via conduction, neglecting any thermal losses due to radiation or convection. This model also assumes perfect interfacial heat transfer which is likely not the case in this process due to varying dispersions of titanium hydride and other particulate near the chill plate. Some disagreement between the results presented and actual experimental data is expected.

Using Equations 2.3 and 2.8, theoretical terminal velocity profiles as a function of distance from the chill plate were calculated for bubbles rising in molten aluminum. These profiles were then compared to the profile modeled in Ansys Fluent (Figure 5). In order to gauge buoyancy effects, two different initial bubble radii, $\mathrm{r}_{\mathrm{o}}$, were used $(5 \mu \mathrm{m}$ and $50 \mu \mathrm{m})$. The temperature was assumed to be constant at $933 \mathrm{~K}\left(660^{\circ} \mathrm{C}\right)$, and the dynamic viscosity of molten aluminum was assumed to be $1.3 \mathrm{mPa} \mathrm{s} .{ }^{[50]}$ As is observed from these examples, bubble terminal velocities are quite high, even for very small gas bubbles with low buoyancy forces acting on them. According to Kim, ${ }^{[20]}$ the range of observed pore radii was $250-800 \mu \mathrm{m}$ in gasarite foams produced using thermal decomposition of titanium hydride. Bubbles of this size would move very fast unless 
they are slowed considerably by forces not taken into consideration in the calculations above. Such forces may include decreased buoyancy forces resulting from attraction of insoluble solid phases to bubble surfaces (via Gibbs-Marangoni effect). ${ }^{[27]}$ The hypothesis that bubbles must be slowed in order to increase porosity will be tested in Chapter 4 through studies on addition of stabilizer particles. Based on the above calculations, bubble capture would only be likely in very small bubbles making it unlikely to produce significant porosity.

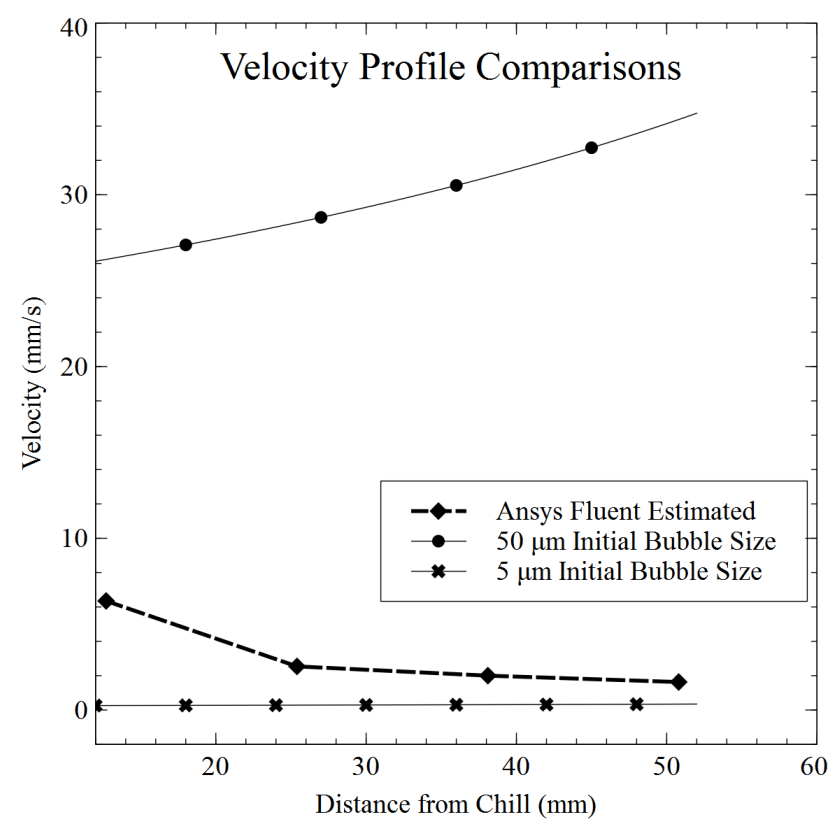

Figure 2.2: Theoretical solidification velocity profile found using Ansys Fluent's finite difference heat transfer and solidification software compared to calculated velocities of bubbles rising through an open liquid at $660^{\circ} \mathrm{C}$. Only bubbles with very low radius are likely to be captured by the solidification front. 


\subsection{Direct Gas Expansion Pore Formation and Growth}

The final pore growth mode considered entails capture of gas source by the solidification front and pore growth via continued gas evolution. This process is shown in Figure 2.1 and will be referred to as direct gas expansion. Many gas sources used in foaming processes have decomposition temperatures well below the melting point of the foamed metal. For example, $\mathrm{TiH}_{2}$ has a decomposition temperature of $450-460^{\circ} \mathrm{C}$ and the melting point of aluminum is $660^{\circ} \mathrm{C}$. This makes it possible for additional gas to evolve after the solidification front envelops the decomposing particulate. If the internal pressure of the bubble exceeds the high temperature creep resistance of the newly formed solid or if the gas evolution rate from the hydride produces larger volumes of gas than can be accommodated by the solidification front, further pore growth is possible. For gas evolving particulate entrapped by the advancing solidification front (Figure 2.3), as before, the internal pressure is assumed to be equivalent to that predicted by Equation 2.9 (the sum of head and inert gas pressure). As the gas source continues to decompose, the change of internal pressure at constant temperature may be estimated by rearranging the ideal gas law for pressure (Equation 2.11).

$$
\Delta P=\frac{\Delta n(T) R T}{V_{b}}
$$

As stated earlier, if the internal pressure of the encapsulated volume exceeds the high temperature creep resistance of the solidified metal, deformation of the thin metal film at the pore tip is likely to occur. Near the melting point, stresses as low as $1 \mathrm{~atm}$ can activate creep in aluminum alloys. ${ }^{[51]}$ If the pore has not been encapsulated the 
volumetric increase due to gas evolution must simply remain above the change in pore volume due to formation of solid around the gas.

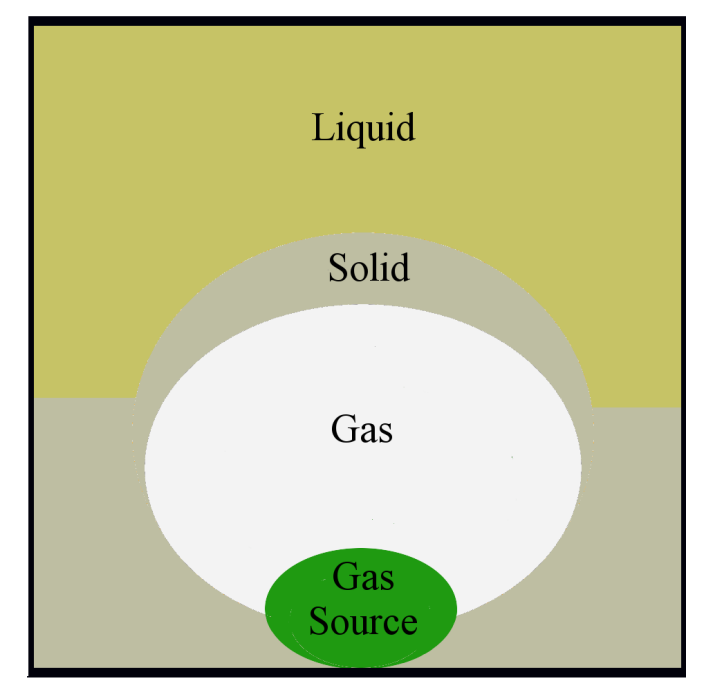

Figure 2.3: Schematic of a gas source particulate entrapped by the solidification front. This schematic assumes an initial bubble radius, and that the gas source has not completely decomposed.

For $\mathrm{TiH}_{2}$, the amount of gas trapped in a single $43 \mu \mathrm{m}$ particle is approximately $5 \times 10^{-8}$ mol. Assuming all gas is released; Equation 2.11 may be used to determine the pressure increase for pores of varying initial sizes (Figure 2.4). This plot reveals that under thermal decomposition processing conditions, a single particle may increase the bubble pressure by up to $0.2 \mathrm{~atm}$ for small pores $(0.5 \mathrm{~mm})$. In a real system there are hundreds to thousands of such particles that may become connected to the pore surface making it highly likely that creep will be activated causing the pore to grow. If the pore has not been encapsulated this large number of particles will ensure that continued 
growth can occur as long as a majority of particles remain above their decomposition temperature.

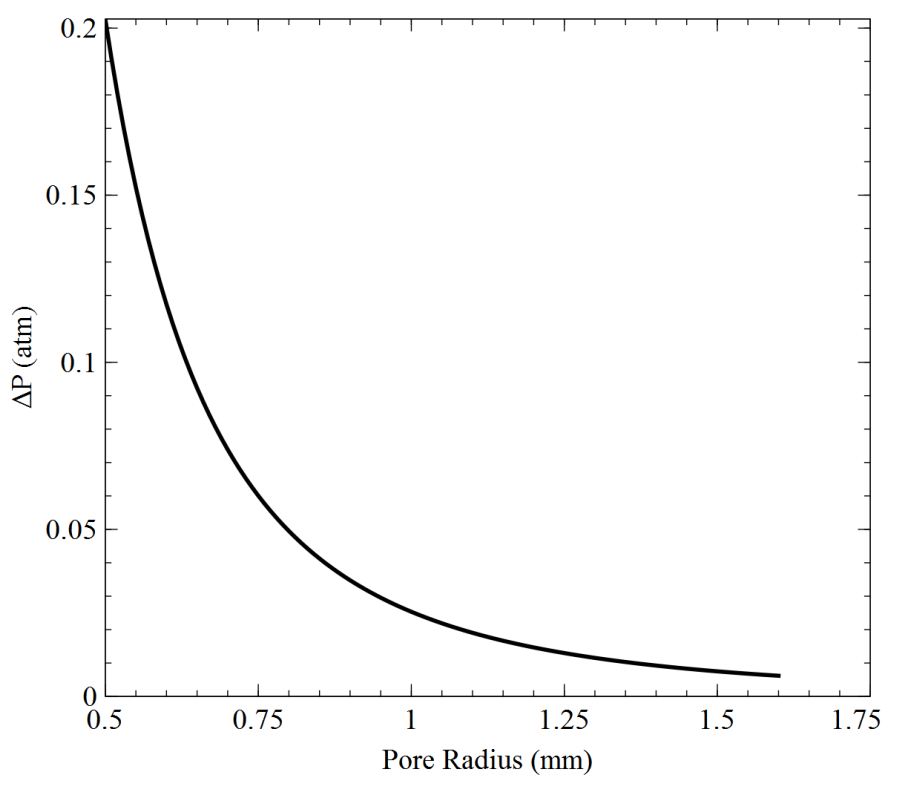

Figure 2.4: Pressure increase resulting from the gas release from a single $43 \mu \mathrm{m}$ particle inside a pore of varying radius encapsulated by the solidification front in an aluminum gasarite at $933 \mathrm{~K}\left(660^{\circ} \mathrm{C}\right)$. Many particles are likely to be trapped on a single pore surface leading to high potential gas expansion after solidification.

The resulting expansion of the pore wall into the open liquid may have several effects depending on the rate of expansion versus rate of solidification. If the solidification rate is greater than the rate of pore expansion, the wall of the pore tip will grow thicker leading to higher pressures necessary for continued upward expansion. Due to limited gas production and cooling of the particulate, this rate balance will eventually cause the pore to stop growing. If the expansion rate is greater than the solidification rate, the tip of the pore may thin significantly leading to rupture. This rupture may be accompanied by a sudden release of the entrapped gas and backfill the pore with liquid 
metal. This is one type of growth defect that may be apparent in foams that grow in this fashion. Again a balance between solidification and pore expansion (driven by gas release from the particulate) is necessary for stable foam growth. If pore expansion rate and solidification rate are equal to one another, it is possible that very long pores may be formed, consistent with what defines a gasarite.

Due to the fact that all particulate will eventually become entrapped by the growing solidification front, it is expected that this pore formation mode will be more prevalent as opposed to bubble capture and may compete with gas-metal eutectic growth as a dominant pore formation mechanism. In order to test this hypothesis samples must be examined for evidence of gas source entrapment on pore surfaces. This is accomplished in Chapter 5. In order to determine the rates of pore growth and potential magnitude of pore expansion due to this mechanism, more accurate estimates of high temperature decomposition kinetics are required. High temperature kinetics of several types of hydride are investigated in Chapter 6 and used in the final theoretical treatment for pore formation and growth in Chapter 7.

\subsection{Summary and Conclusions}

During thermal decomposition processing three different pore formation mechanisms are possible. Gas metal eutectic growth is driven by saturation of the liquid. Under vacuum or inert gas processing conditions, this mechanism will only result in significant porosity if global equilibrium conditions are not achieved. Bubbles that have detached from the hydride may be captured and grow along with the solidification front if their velocities are not too high. A gas source that is continuously evolving hydrogen 
may also be captured by the advancing solidification front and expand pores if enough gas evolves. Only gas metal eutectic growth has been considered as a pore formation mechanism by those who have researched thermal decomposition processing of gasarites. An open question that will be answered in subsequent chapters is whether or not bubble capture and direct gas evolution from the hydride results in significant pore growth. 


\subsection{Replication of Literature Results}

\subsection{Introduction}

An experimental knowledge base is needed validate the theoretical framework above. At the beginning of the current study, there were only two active university research groups that were capable of producing gasarites. One group was Nakajima's in Japan and the other was Li and Liu in China. Only Nakajima's group had successfully

produced gasarites via thermal decomposition ${ }^{[20]}$ therefore it was necessary to first replicate their experiments to conduct additional investigative foaming studies. The following set of studies replicates a subset of experiments conducted by Kim in 2009 . Only a single factor was varied, the inert gas pressure over the melt during foam solidification. The results were then compared to those published in order to assess replicability.

\subsection{Experimental Methods}

As shown previously (Figure 1.3), all one needs to create an aluminum gasarite structure is charge material, a thin walled stainless steel mold, a gas source contained in an aluminum foil packet, and a vacuum melting system equipped with a chill plate. During experimental planning it became apparent that several key factors were not reported in Kim and Nakajima's work. The copper chill design and resulting solidification rates were never reported therefore a plate with the spiral flow pattern (Figure 3.1) was created. Additionally, the particle size range of the materials used as gas 
sources was not reported. In the replication study, powders were used in their as-received size ranges.

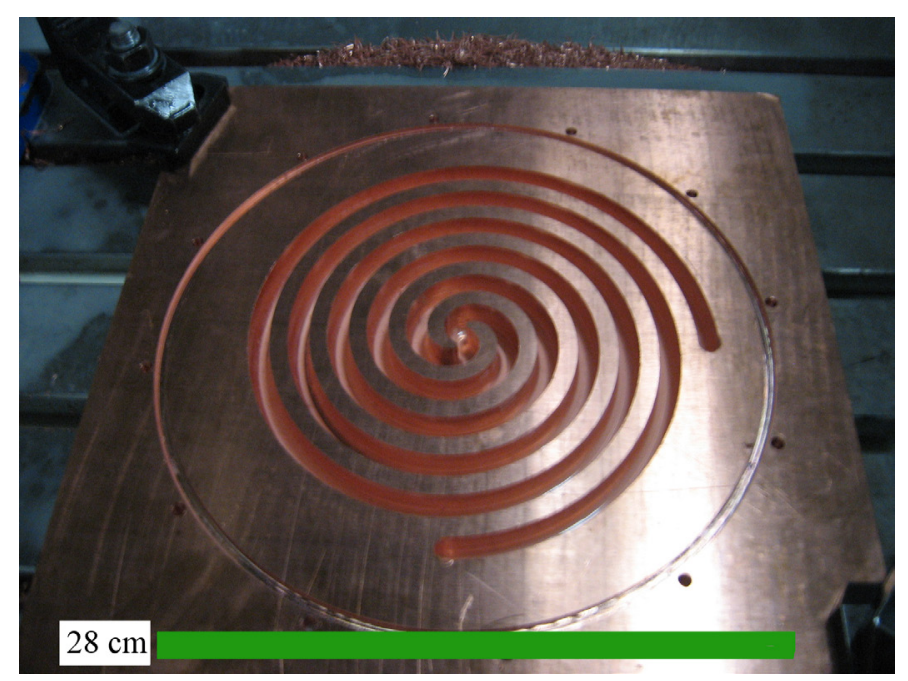

Figure 3.1: Spiral flow pattern machined in copper chill plate. Flow channels were 0.635 $\mathrm{cm}$ wide and $1.27 \mathrm{~cm}$ deep. The chill surface was $28 \mathrm{~cm}$ in diameter with a $2.54 \mathrm{~cm}$ diameter circular groove placed on the top surface to secure molds.

Stainless steel cylindrical molds with $0.01 \mathrm{~mm}$ wall thickness were not commercially available, so molds were fabricated by spot welding $0.01 \mathrm{~mm}$ thick sheets of type 301 stainless steel around a $25.4 \mathrm{~mm}$ diameter graphite rod. These molds were limited to a height of $127 \mathrm{~mm}$, but this is roughly five times taller than the size Nakajima and Kim investigated. The configuration of the mold, chill plate and interior of the vacuum chamber is shown in Figure 3.2. 


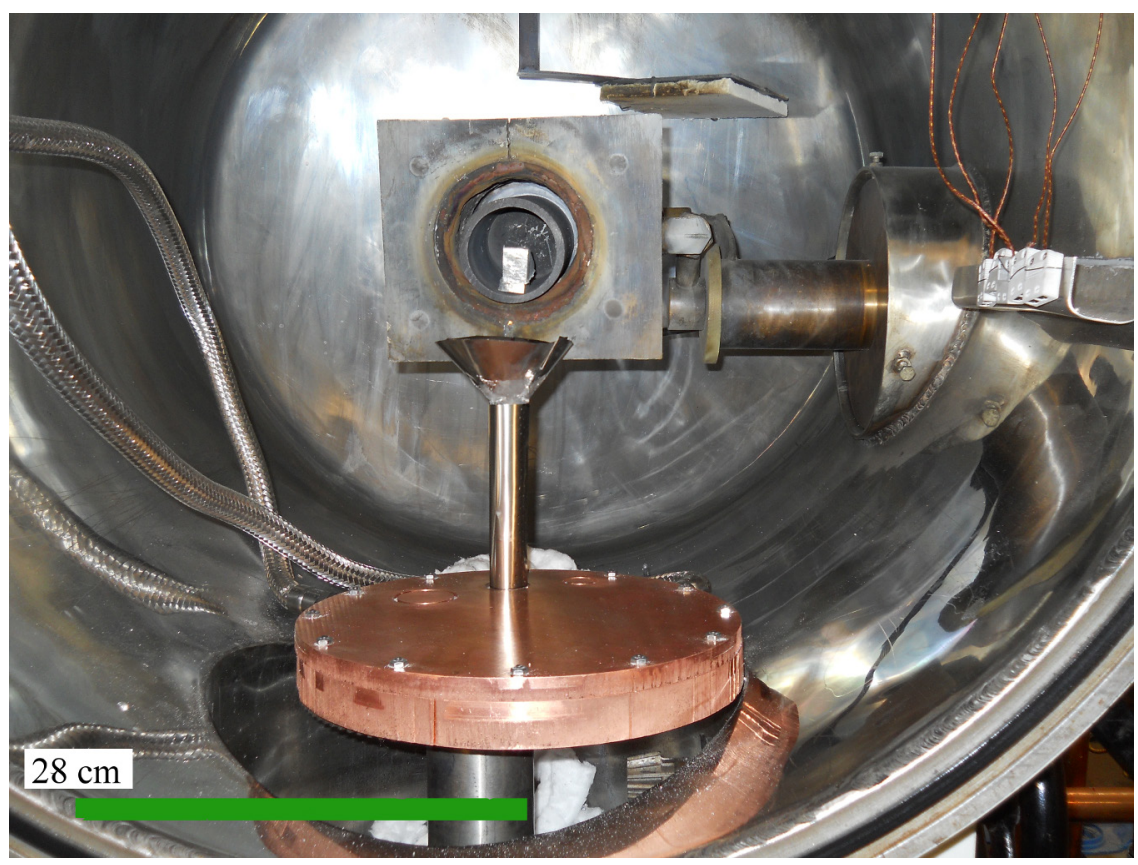

Figure 3.2: Interior of vacuum induction melter showing the copper chill, mold with funnel attachment, and a graphite crucible inside of the induction furnace (tilted to show contents). Thermcouple connections (right) were added to the chamber in order to estimate thermal profiles during solidification.

The replication study conducted was of limited scope and was intended to validate Nakajima and Kim's work on aluminum gasarite formation via decomposition of titanium hydride, calcium hydroxide and sodium bicarbonate. Porosity response to argon pressures was determined at five different levels between $10^{-7}$ to $1 \mathrm{~atm}$. This pressure range was greater than that tested by Nakajima, but encompassed their processing conditions. The $100 \mathrm{~g}$ aluminum charge material was $99.99 \%$ pure and gas source additions of $0.2 \mathrm{~g}$ were added to form porosity in all trials.

The $\mathrm{TiH}_{2}$ used in the replication trials was obtained from Alfa Aesar and was $98 \%$ pure on a metals basis. The nominal size designation on the powder was -325 mesh 
or less than $43 \mu \mathrm{m}$. The calcium hydroxide and sodium bicarbonate were fine powders and did not come in a designated particle size range, but were American Chemical Society (ACS) grade. As with Kim's trial all powders were folded inside of an aluminum foil envelope after weighing. The melting crucible was composed of graphite and the temperature of the melt was monitored via an infrared pyrometer. Thermocouples were added to select molds in order to estimate and compare the solidification front velocity during foam solidification to theoretical predictions.

Samples were sectioned using an abrasive cutoff saw transverse to solidification direction every $12.4 \mathrm{~mm}$ from the bottom of the sample. Every whole $12.4 \mathrm{~mm}$ thick section was measured for mass and dimensions. Porosity levels were estimated using Equation 3.1, in which $\mathrm{m}$ is the sample mass, $\mathrm{r}$ is the estimated radius, and $\mathrm{h}$ is the sample thickness. The density of aluminum, $\rho_{\mathrm{al}}$, was assumed to be $2.7 \mathrm{~g} / \mathrm{cm}^{3}$. After porosity levels were estimated, longitudinal slices were made to bisect any porosity present. Samples were polished using 400-1200 grit sand paper and taken to final polish using colloidal silica. Significant time was spent on the sanding steps in order to clear the pore profiles of any cutting burrs. Samples were etched for five minutes using a $10 \mathrm{wt} \%$ sodium hydroxide solution heated to $50^{\circ} \mathrm{C}$.

$$
\text { Porosity }=\left(1-\frac{\frac{\pi r^{2} h}{m}}{\rho_{A l}}\right) \times 100
$$




\subsection{Results and Discussion}

The solidification profile from the thermocouple data is compared to modeling results from Ansys Fluent (Figure 3.3). The two profiles do not match well close to the chill plate with the Ansys Fluent estimations being significantly lower than experimental values. This was unexpected given the optimistic modeling assumption of complete contact between the liquid aluminum and copper chill. As expected, both velocity profiles predict a decrease in solidification velocity as a function of distance from the chill plate with minimums of $1 \mathrm{~mm} / \mathrm{s}$ observed during experiments. With regard to the bubble capture mechanism outlined in Chapter 2, this trend is detrimental to pore formation since bubbles will accelerate as a function of distance from the chill by virtue of a reduction in head pressure.

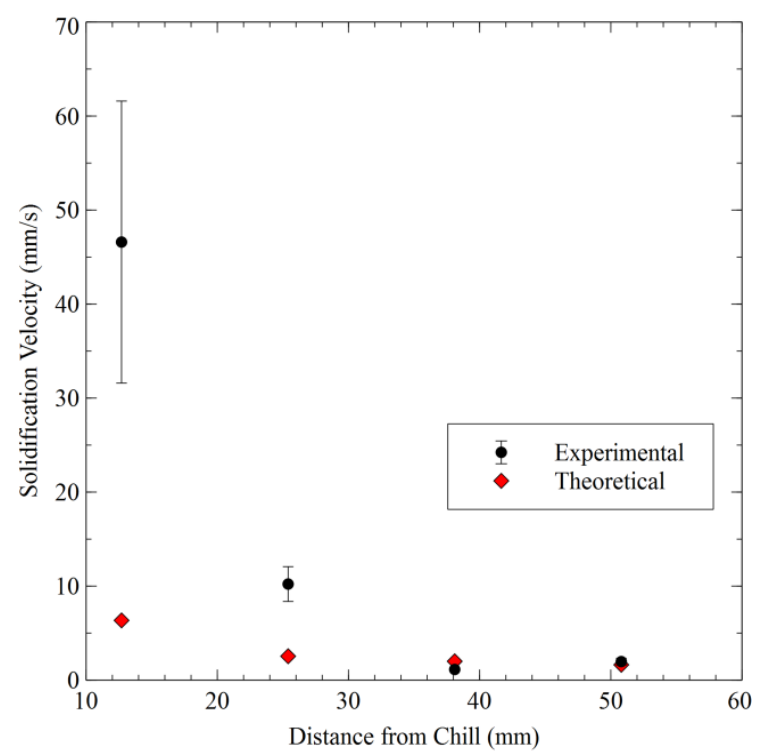

Figure 3.3: Comparison of experimentally determined solidification velocity profile versus that modeled in Ansys Fluent. Some initial disagreement between calculations and real values is evident. 
Images of aluminum gasarite structures produced by Nakajima are compared to those produced in the current study below (Figure 3.4). There were several differences between the quantitative and qualitative results of the replicated process and the reported results from Kim's study. First, there was significant variation in porosity levels from sample to sample. Some samples exhibited virtually no porosity while others were more porous. Second, the pore aspect ratio of 2.3 was quite low when compared to other gasarite structures. Ripples were also apparent on the pore surfaces and may have been cause by vibrations transmitted to the liquid metal as it was solidifying.
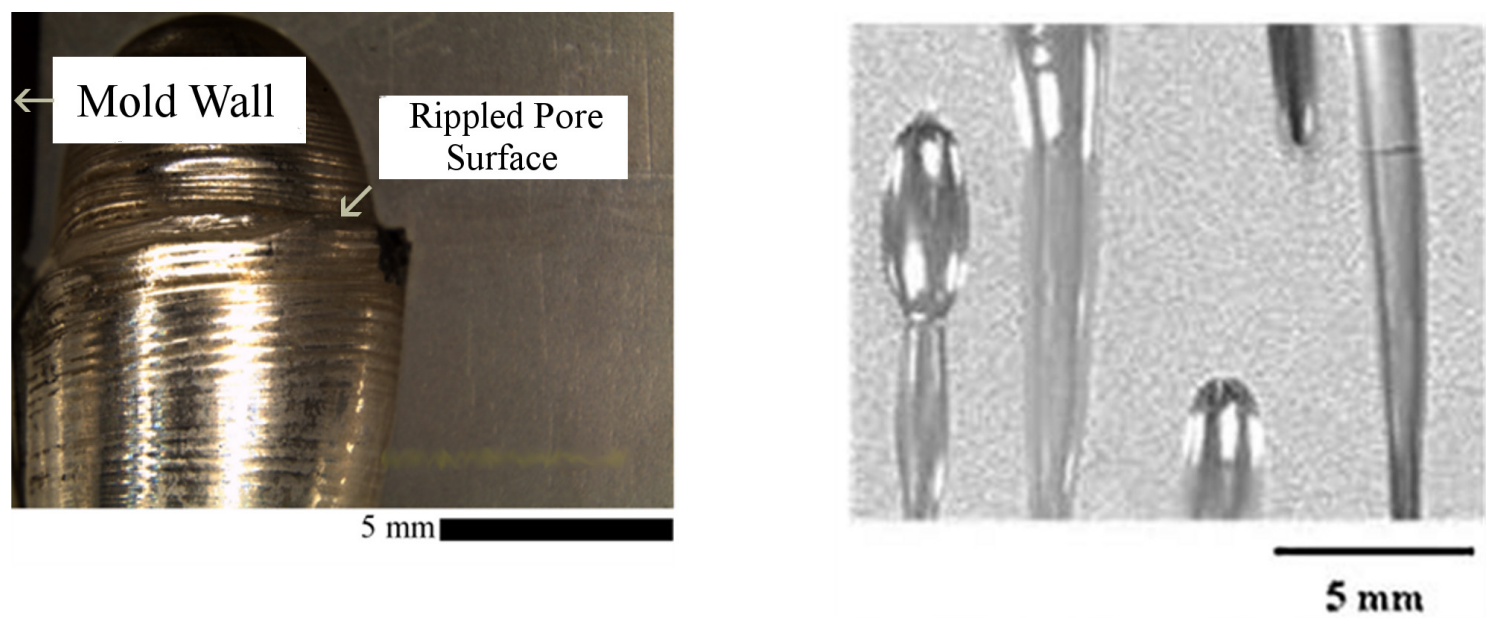

Figure 3.4: Side by side comparison of the longitudinal pore profiles of aluminum metal foams created by decomposing titanium hydride under vacuum conditions in the current study (left) and by Kim (right).

Metallographic analysis of the etched longitudinal samples revealed the expected columnar grain structure surrounding pores indicating directional solidification. However, most pore tips showed evidence of pore collapse possibly from either gas cooling or escape from the system (Figure 3.6). A crown of columnar grains was found at the pore tips surrounded by a more chaotic pore structure (Figure 3.5). This "crown" 
section could represent the thin metal film that encapsulated the pore and was

subsequently stretched by direct gas evolution from entrapped hydride particles as

outlined in Chapter 2. The chaotic zone above could have arisen due to either a partial rupture of the pore tip, or pore collapse due to contraction of the gas as it cooled.

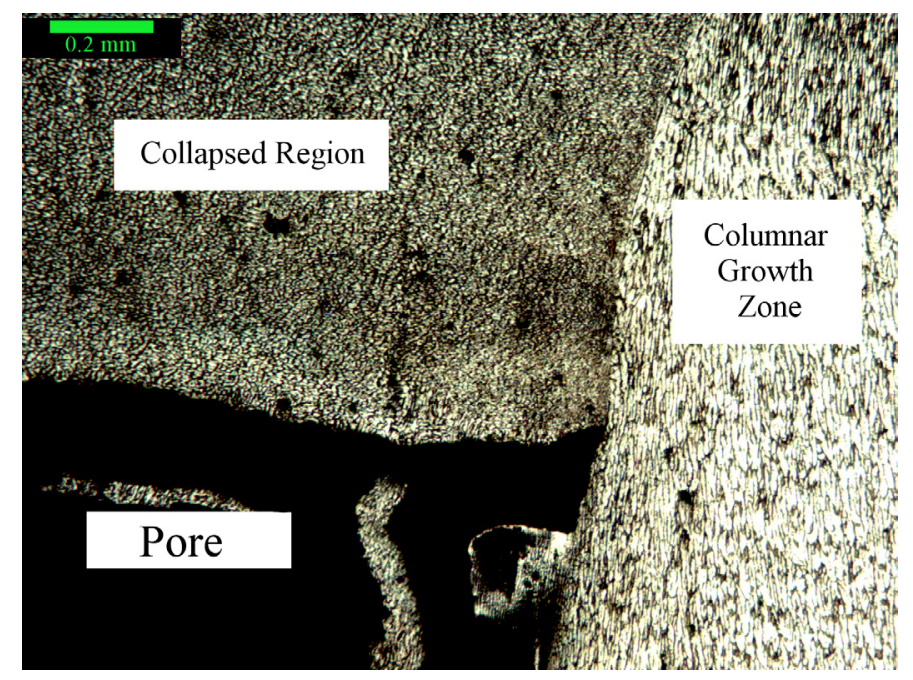

Figure 3.5: Collapsed chaotic grain structure above porosity in aluminum gasarite foam produced by decomposition of titanium hydride. This collapse region was most likely due to pore contraction upon cooling.

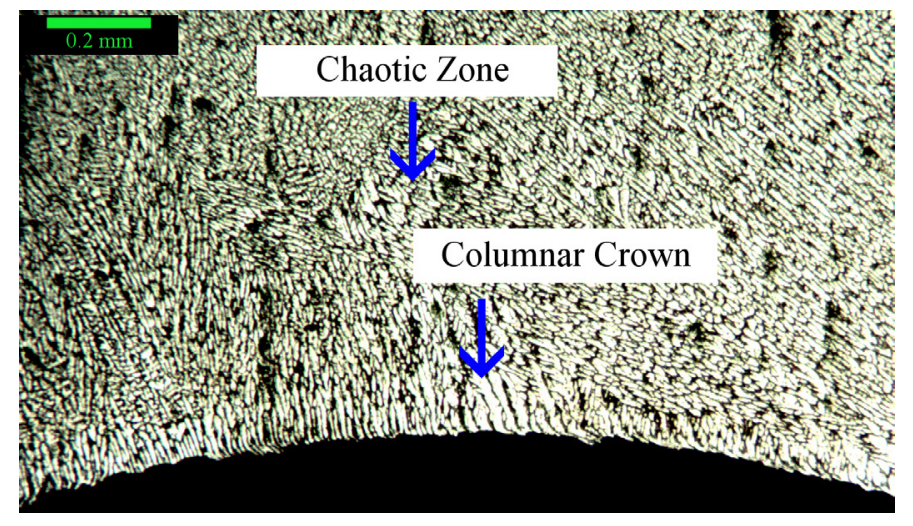

Figure 3.6: Columnar crown surrounding pore tips in aluminum gasarite foam produced by decomposition of titanium hydride. The columnar crown may have been solidified aluminum that was expanded by entrapped gas. 
In all porous samples, there appeared to be preferential segregation of pores toward the mold wall as shown in Figure 3.4 indicating attraction of the evolved gas to the mold surface. This interaction possibly explains why pores were isolated to the lowest sections of the mold. Another potential explanation is that the titanium hydride particles were not well dispersed leading to highly localized gas evolution. The head pressure on the lowest sections is also higher which may prevent bubble escape via buoyancy leading to higher porosity in these sections. Table 3.1 summarizes the pore morphology information obtained during these trials and compares it to the work of Kim. From these results it was determined that as published, Kim's process was not replicable.

Table 3.1: Comparison of initial results to those of Nakajima and Kim. Values reported are sample averages. ${ }^{[20]}$

\begin{tabular}{ccccccc}
\hline \multirow{2}{*}{ Study } & \multicolumn{2}{c}{ Porosity } & & \multicolumn{2}{c}{ Pore Diameter } & Aspect Ratio \\
\cline { 6 - 7 } & Min & Max & Min $(\mathrm{mm})$ & Max $(\mathrm{mm})$ & Major/Minor \\
\hline Kim $^{[20]}$ & $\mathrm{n} / \mathrm{a}$ & $25 \%$ & 0.5 & 1.6 & $\mathrm{n} / \mathrm{a}$ \\
Initial trials & $0 \%$ & $4 \%$ & 1 & 7 & 2.3 \\
\hline \hline
\end{tabular}

While overall porosity levels were low compared to Nakajima and Kim the influence of inert gas pressure on porosity seemed to be reproduced (Figure 3.7). Porosity levels were greatest when pressures of approximately 0.1 atm were utilized. Porosity decreased to $1 \%$ when pressure was increased to $0.33 \mathrm{~atm}$ and vanished when pressure was increased to $1 \mathrm{~atm}$. Porosity levels at lower vacuum levels of $10^{-5} \mathrm{~atm}$ were within the range of the $0.1 \mathrm{~atm}$ samples. When vacuum levels of $10^{-7} \mathrm{~atm}$ were used porosity seemed to decrease. Given that head pressure was already the dominant term in 
governing gas bubble volume at higher pressures, this is likely an artifact from the stochastic nature of pore formation as opposed to an indication of additional bubble escape. From the general trends that were observed and utilizing the treatment of bubble capture pore formation in Chapter 2, there appears to be a balance that must be achieved between gas bubble escape and shrinkage of pores when considering the amount of inert gas to apply during processing. The arrows in Figure 3.7 indicate that between $10^{-5} \mathrm{~atm}$ and $10^{-1}$ atm there appears to be an optimal operating pressure.

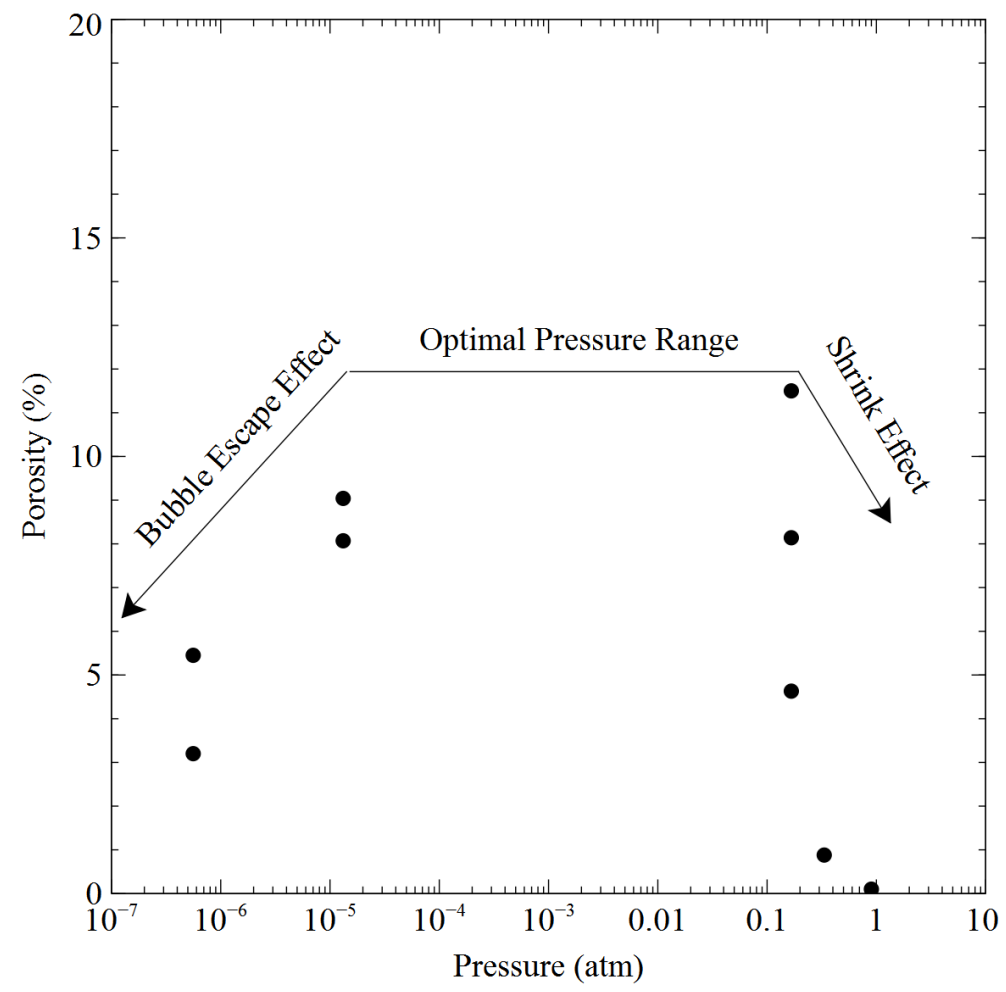

Figure 3.7: Influence of pressure on porosity levels in aluminum samples created using thermal decomposition of $\mathrm{TiH}_{2}$. Values reported are for the first $25.4 \mathrm{~mm}$ of the $60-80$ mm tall sample. 
Samples created using sodium bicarbonate and calcium hydroxide did not contain significant amounts of porosity. These results contradict those reported by Kim and Nakajima as they identified calcium hydroxide as the most potent gasarite forming compound in their study. ${ }^{[20]}$ The only positive gas forming characteristic that calcium hydroxide exhibited was that the few pores produced were approximately $50 \mathrm{~mm}$ long spanning most of the sample length. The reasons for this were not investigated, but since calcium hydroxide decomposition can lead to oxide formation it is possible that the metal oxide stabilized the pore over a greater length by preventing gas escape. Due to the fact that such low levels of porosity were observed these powders were not explored further.

\subsection{Summary and Conclusions}

Many discrepancies were observed when replicating the process used by Kim in producing aluminum gasarite structures. Pores did not take on the desired gasarite pore morphology nor were porosity levels comparable. Very general trends for the relationship between porosity and argon pressure were observed that were in agreement with literature for both aluminum and copper gasarites formed via thermal decomposition. Based on these results it was apparent that changes needed to be made in order to obtain a process that could be used to study thermal decomposition formation of gasarite structures. In order to increase process reliability and form porous gasarite structures throughout samples it was necessary investigate a series of process changes that would address the issues observed in the replication trials. 


\subsection{Process Improvements ${ }^{1}$}

The following contains selections from the work, ““"Processing and Pore Formation Mechanisms in Aluminum Gasarites Produce by Thermal Decomposition" Met. Trans. A Vol 44 No. 12. Specifically results published for the effects of different processing modifications and associated images.

\subsection{Introduction and Goals}

During preliminary trials several processing issues became apparent:

$>$ Pores tended to segregate to the mold surface indicating a possible mold wall interaction.

Significant a expulsion of molten metal from the mold due to rapid gas expansion resulted in sample height variation.

$>$ Overall porosity levels were low.

$>$ Pore morphology was not tubular in form.

The process development phase was aimed at addressing these issues so that further studies could be carried out. While some of these process changes were carried out independently, sometimes several processing changes were made simultaneously. Where possible the direct influence of each of the processing changes is reported. Unless otherwise noted, the analytical techniques and experimental methods for evaluating each of the changes is consistent with the methods outlined in Section 3.2.

\footnotetext{
${ }^{1}$ Sections 4.2-4.7 were adapted from "Processing and Pore Formation Mechanisms in Aluminum Gasarites Produce by Thermal Decomposition" Met. Trans. A Vol 44 No. 12
} 


\subsection{Mold Surface Interactions}

Gas bubble segregation observed in the preliminary trials was addressed by introduction of an alumina mold coating. Mold coating is a simple and effective way to prevent interactions between the solidifying metal, the gas bubbles, and the mold. The choice of alumina as a mold coating was driven by several factors. First, alumina is the native oxide to aluminum and is almost always present to some extent when processing aluminum at high temperatures. This means that no additional chemical species would be present to further complicate the system. Second, alumina has a contact angle of 80 degrees with aluminum giving it a partial wetting character. ${ }^{[27]}$ If mold coating is continuous, the alumina should remain at the mold wall since it will not completely wet the liquid aluminum.

An alumina slurry coating process was developed for application of alumina to the molds. Approximately $150 \mathrm{~mL}$ of isopropyl alcohol was mixed with $27 \mathrm{~g}$ of $0.3 \mu \mathrm{m}$ polishing grade alumina powder. The mixture was agitated on a magnetic stirring plate for 30 minutes. The slurry was then cascaded inside of the mold while rotating the mold by hand. Two revolutions per mold were used. After several molds were coated, the slurry was agitated for an additional minute before being poured onto additional molds in order to ensure a consistent application. After drying for an hour, remaining organic materials were removed by baking the molds in a box furnace at $390^{\circ} \mathrm{C}$ for 1 hour. Molds were weighed both before and after coating in order to evaluate the mass of alumina added. On average this process resulted in the addition of approximately 0.085 $+/-0.02 \mathrm{~g}$ of powder. This corresponds to a coating thickness of approximately $200 \mu \mathrm{m}$. 
Figure 4.1 shows the surfaces of samples processed using no mold coating and mold coating. The mold coating had the effect of making the sample surface much duller and completely prevented open porosity at the sample surface. The dimple features on the coated sample should not be misidentified as pores and were formed by agglomerations of alumina from the coating process. The gasarite porosity distribution was more uniform throughout the sample, and the average aspect ratio increased from 2.3 to 5.5. Overall porosity levels remained low with a maximum average porosity of only $5 \%$ in transverse sections $13-25 \mathrm{~mm}$ from the chill plate surface. These results were obtained on a limited number of samples (2-3) limiting statistical inference capabilities. Since additional modifications were required to increase the porosity levels, expanded trials were postponed until all processing issues had been addressed.

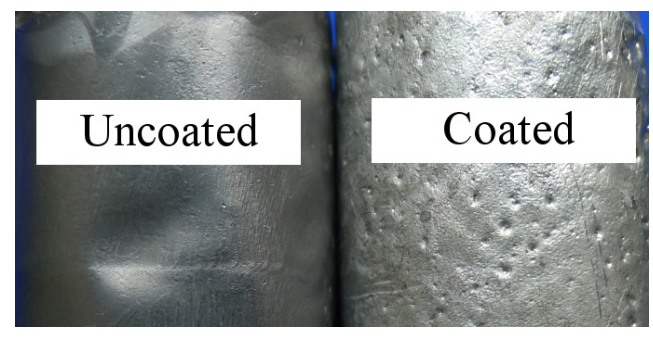

Figure 4.1: Comparison of aluminum samples foamed with titanium hydride without and with alumina coating of the stainless steel molds. Samples shown had diameters of 25.4 mm.

\subsection{Multi-Packet Gas Source Introduction}

It was observed during preliminary investigations that significant amounts of hydride was not dispersed throughout the molten metal as was apparent by powder agglomerations near the bottom of the mold. In order to form metal foams with 
continuous porosity an additional gas source packet was added to the crucible. This method was originally motivated by results of limited trials conducted using re-melted samples. The samples that were remelted had reserves of hydride within them. While much of the hydrogen was likely to be lost during the re-melting process, some authors have shown common decomposing gas sources like titanium hydride and zirconium hydride can evolve gas for more than 10 minutes after being raised above the melting

point of aluminum. ${ }^{[46]}$ Samples produced using the thermal decomposition method in the current study were poured within 10 minutes meaning that hydrogen was likely still being evolved from particles dispersed throughout the melt before it was poured into the mold. This means that in addition to pouring the molten aluminum into the mold, the hydride that becomes mixed into the liquid during melting is also poured leading to more widespread hydrogen release throughout the sample. Instead of relying on a double melting procedure to produce re-melt ingots, another hydride packet was simply added to the crucible. Based on a limited test set of three samples, adding the hydride packet to the melt produced more uniform porosity that ranged from $5 \%$ to $15 \%$ throughout the length of each sample. Better pore uniformity represented a large improvement in foam morphology and was adopted in further trials.

\subsection{Metal Expulsion Reduction}

During the initial stages of gas evolution significant amounts of the molten metal were expelled from the mold leading to variation in sample height as well as potential loss of gas source powder. In order to alleviate this, gas source tablets were created by pressing $0.5 \mathrm{~g}$ of $\mathrm{TiH}_{2}$ under pressures of approximately $680 \mathrm{MPa}$ in a $25.4 \mathrm{~mm}$ diameter 
die. Hydride tablets were used by Nakajima ${ }^{[39]}$ in copper foaming studies and were shown to completely dissolve during foam solidification. It was an unclear whether similar tablets would dissolve into molten aluminum therefore this strategy was assessed experimentally. Utilization of tablets reduced metal expulsion significantly, however porosity levels were nearly zero in all samples since no particle dispersion occurred. Figure 4.2 shows the bottom portion of several molds revealing that the tablets remained almost intact. This was most likely due to their contact with the copper chill plate and shape.

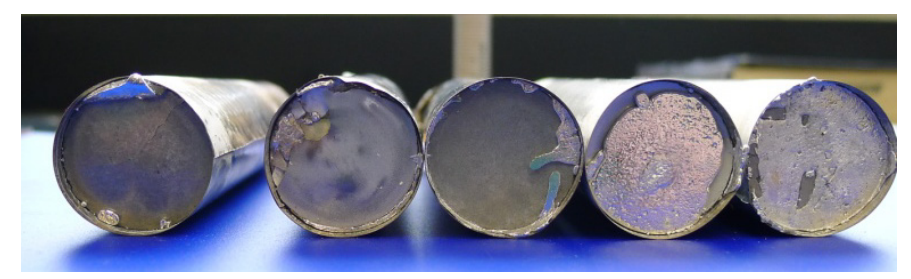

Figure 4.2: Images of the bottom of several molds cast using pressed powder tablets. The liquid metal slightly encapsulated the tablets in some cases (far left), while other tablets became more engulfed by the metal (far right). Sample diameters were $25.4 \mathrm{~mm}$.

In order to alleviate metal expulsion without diminishing gas evolution, alternative methods were explored. One method was to utilize inert gas pressure to decrease the magnitude of gas expansion during foam processing as opposed to operating under vacuum. A 0.05 atm pressure of argon gas was applied during processing of several foams leading to significantly less sample height variation and more consistent results. This pressure was selected since it fell within what appeared to be the optimal inert gas pressure range determined from preliminary trials (Figure 3.7). When compared to trials run with previous process improvements, the porosity standard deviation was 
reduced from $20 \%$ to $7 \%$, but average porosity was reduced by about $3-5 \%$ overall. This tradeoff was deemed acceptable in order to achieve more homogeneous pore distributions in future trials.

\subsection{Powder Dispersion}

The gas sources were used in their as-received powdered form. Based on the poor results from the preliminary trials using hydride tablets, it was clearly necessary to disperse the powder in order to promote a uniform pore structure. One issue that was apparent during preliminary trials was that flat aluminum foil envelopes were not effective since their thermal contact with the chill plate led to incomplete melting of the aluminum foil and limited dispersion of the hydride (Figure 4.3).

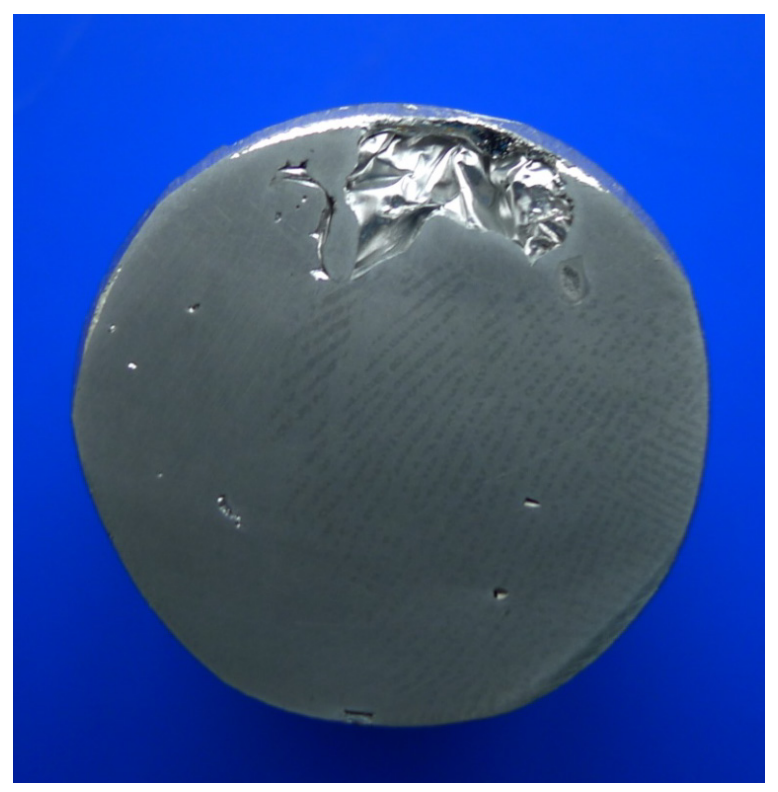

Figure 4.3: Example of sample in which powdered gas source was not dispersed during solidification. The aluminum foil packet was likely not melted due to its close proximity to the chill plate. Sample diameter was $25.4 \mathrm{~mm}$. 
An alternate gas source introduction scheme was to make a packet that was secured at top of the mold instead of near the chill plate. The molten metal was poured through the packet causing release of the gas source throughout the stream of liquid entering the mold. It was found that when this introduction technique was used, significant amounts of hydride remained within the packet and the stream of molten metal would not be enough to cause the packet to completely melt. This method of gas source introduction was not used in further trials.

Another attempt to improve particle dispersion was to use dome-shaped packets. The dome shape was used in order to suspend the powder above from the chill plate to enable more complete hydride dispersion. The process for making the domed packets entailed cutting two circular discs of aluminum foil $37 \mathrm{~mm}$ in diameter. The gas source powder was measured onto the lower disc and spread evenly over the center of the disc's area. The second disc was placed on top and the edges were crimped approximately 6$7 \mathrm{~mm}$ around the circumference in order to seal the powder. The packets were then pressed into a dome shape using a shaping tool so that their outer diameter was no greater than $25.4 \mathrm{~mm}$ and the top of the dome was approximately $12-13 \mathrm{~mm}$ away from the chill surface. This completely eliminated issues with particle dispersion leading to more consistent release of particulate to the molten aluminum and was used in all further studies.

\subsection{Stabilization of Porosity}

It is well known that pure liquid metals are very difficult to foam by virtue of

significant liquid drainage around gas bubbles during solidification. ${ }^{[14,52]}$ Many foaming 53 
processes utilize metal oxides having a contact angle with the liquid/gas system of approximately $70-90^{\circ} .{ }^{[27]}$ Some claim that the metal oxides have a tendency to segregate to an equilibrium position near the pore surface leading to higher resistance to liquid metal drainage and pore rupture during processing while others claim that the particles raise the bulk viscosity of the melt making gas bubble escape less likely. ${ }^{[14,25]}$ Regardless of the mechanism, the question is whether or not the same particle semiwetting characteristics may be used to help reduce bubble escape in thermal decomposition processed gasarites.

As shown in preliminary calculations (Figure 2.2), only small bubbles may form pores via the bubble capture mechanism because of the magnitude of buoyancy driven bubble velocities. The likelihood of large bubbles being captured by the solidification front is greatly increased if the effective bubble velocity is decreased. This can be accomplished by adding substances that would have a tendency to increase viscous drag effects on the bubble. This approach has been used in the Alporas process through the addition thickening agents such as calcium oxide $(\mathrm{CaO})$ to the melt prior to foaming. Additionally, bubbles may be slowed by particles that have a large adhesive force to their surfaces causing them to effectively gain weight. If these particles are non-buoyant within the metal being foamed, they will decrease the buoyancy driven bubble acceleration and velocity. Due to alumina's semi-wetting behavior and higher density than aluminum, ${ }^{[27]}$ it was expected that introducing a small volume fraction of alumina to the mold gas source packet would help increase porosity formed via the bubble capture mechanism. Additional literature indicated that grain refiners such as $\mathrm{TiB}_{2}$ may have the 
same effect on porosity, however the contact angle of $\mathrm{TiB}_{2}\left(0^{\circ}\right)$ was significantly lower than that of alumina $\left(80^{\circ}\right) \cdot{ }^{[53]}$ Experiments were needed to determine whether or not either of these particles would be effective in increasing porosity in gasarite structures.

A set of studies utilizing varying volume fractions and contact angles of stabilizers was carried out in order to determine the effects of stabilization in gasarite structures produced using thermal decomposition. The volume fractions chosen were $0.1 \%$ and $0.5 \%$ calculated by dividing the volume of stabilizer by the total charge mass. The two stabilizers chosen were $\mathrm{TiB}_{2}$ and $\mathrm{Al}_{2} \mathrm{O}_{3}$. These were chosen due to their widely different contact angles of $\sim 0^{\circ}$ and $80^{\circ}$ respectively. The stabilizers were layered on top of the hydrides to give them an advantage in segregating to the pore surfaces since the gas release would disperse them ahead of the bubbles. Five replicates were cast using the matrix below (Table 4.1) and evaluated for porosity responses in the three $25.4 \mathrm{~mm}$ thick sections starting from the bottom of the sample.

Table 4.1: Foam stabilization experimental design matrix. Levels were chosen to give maximum differences within the bounds of experimental techniques.

\begin{tabular}{|c|c|c|}
\hline Factors & Level 1 & Level 2 \\
\hline Stabilizer Contact Angle & $0^{\circ}\left(\mathrm{TiB}_{2}\right)$ & $80^{\circ}\left(\mathrm{Al}_{2} \mathrm{O}_{3}\right)^{2}$ \\
\hline Volume fraction by charge volume & $0.10 \%$ & $0.50 \%$ \\
\hline
\end{tabular}

The experimental results for these sections are provided in Figure 4.4. As can be seen from this plot there was significant variation in both pore size and porosity levels. This variation may have been related to pore coalescence and other stochastic bubble 
interactions that can occur during solidification. A main effects plot showing the general trends observed for the average values of porosity in all sections is shown in Figure 4.5. As can be seen from this plot there are some general trends which indicate stabilization by higher contact angle particulate is more effective than low contact angle particles. This trend is statistically weak and cannot be used to make strong assertions. Additionally, a decrease in porosity with increasing particle volume fraction is observed. It was expected that higher volume fractions would result in more porosity due to more pore stabilization, but one possible effect is that the particulate served to prevent gas release by insulating the hydride against the heat of the melt since it was layered on top of the gas source.

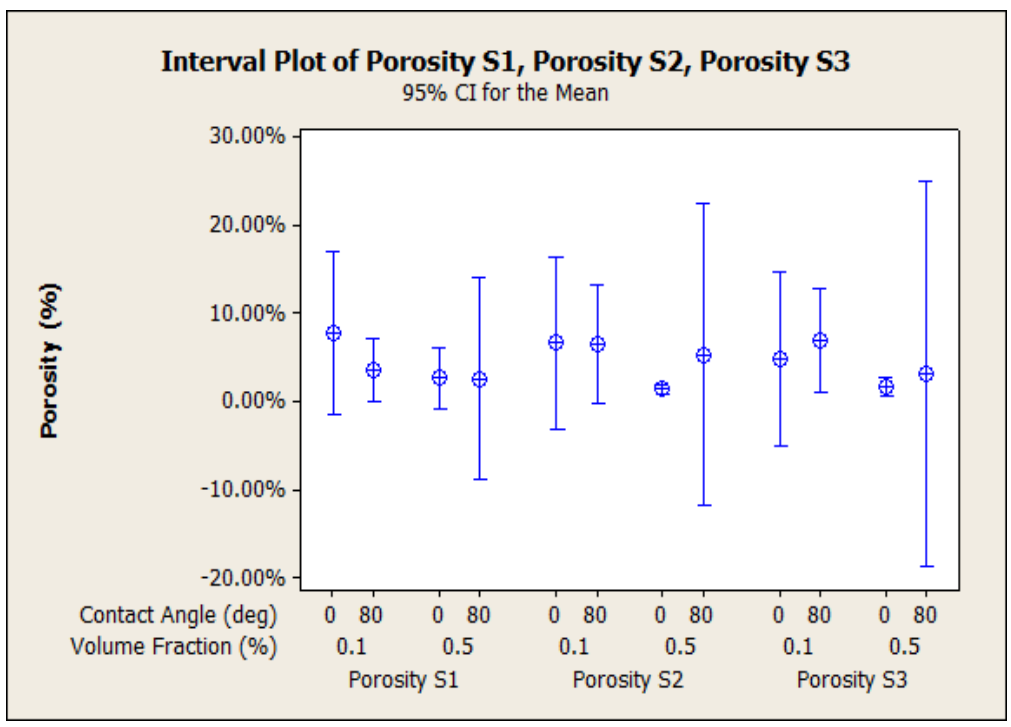

Figure 4.4: Effect of stabilizer contact angle and volume fraction on the porosity fraction (error bars represent $95 \%$ confidence interval for the mean). S1 is the first $25.4 \mathrm{~mm}$ thick section taken from the bottom of the sample, $\mathrm{S} 2$ the second section from the bottom, and $\mathrm{S} 3$ is the third section from the bottom. 
While the numerical results were ambiguous due to the scatter in the data, SEM analysis on pores processed in the presence of $\mathrm{Al}_{2} \mathrm{O}_{3}$ showed supported bubble stabilization by presence of $\mathrm{Al}_{2} \mathrm{O}_{3}$ near the pore tip (Figure 4.6). Qualitative energy dispersive spectroscopy revealed oxygen peaks when scans were taken on and off of the charging sections (Figure 4.7-Figure 4.8). This pore was over $2 \mathrm{~mm}$ in diameter which is much larger than the radii of bubbles that can be captured by the solidification front according to the treatment used in the preliminary model. Due to this fact further trials were carried out examining alumina as a stabilizer and the results were compared to samples created with no stabilizer. Alumina additions increased porosity based on a limited number of samples ( $\% 3-20 \%$ vs. $0-4 \%$ max porosity). Due to this fact alumina was added as a stabilizer in all other trials $(0.1 \%$ volume fraction of the total charge volume).

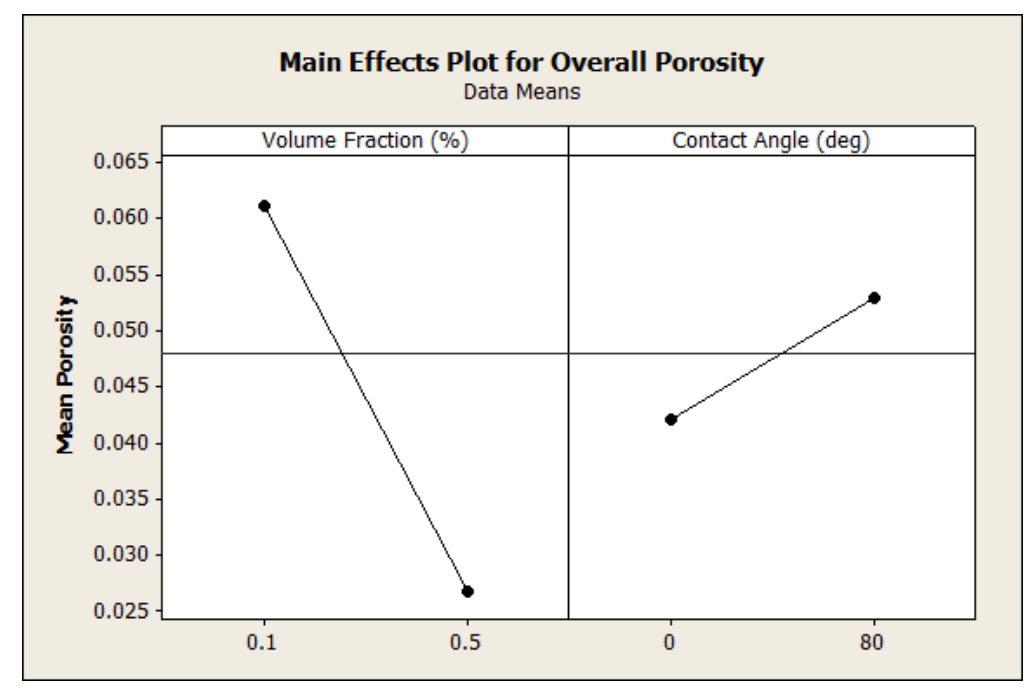

Figure 4.5: Main effects plot for overall porosity as a function of stabilizer volume fraction and contact angle. Values represent averages between all sections. Only slight dependence of porosity on either factor was observed, well below statistically significant values. 


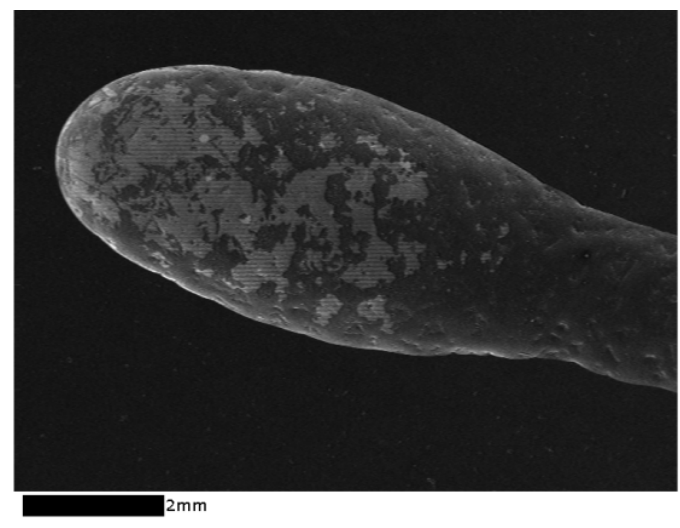

Figure 4.6: Segregation of alumina to a pore surface indicating segregation and potential pore speed reduction. This effect was not apparent in samples cast with $\mathrm{TiB}_{2}$.

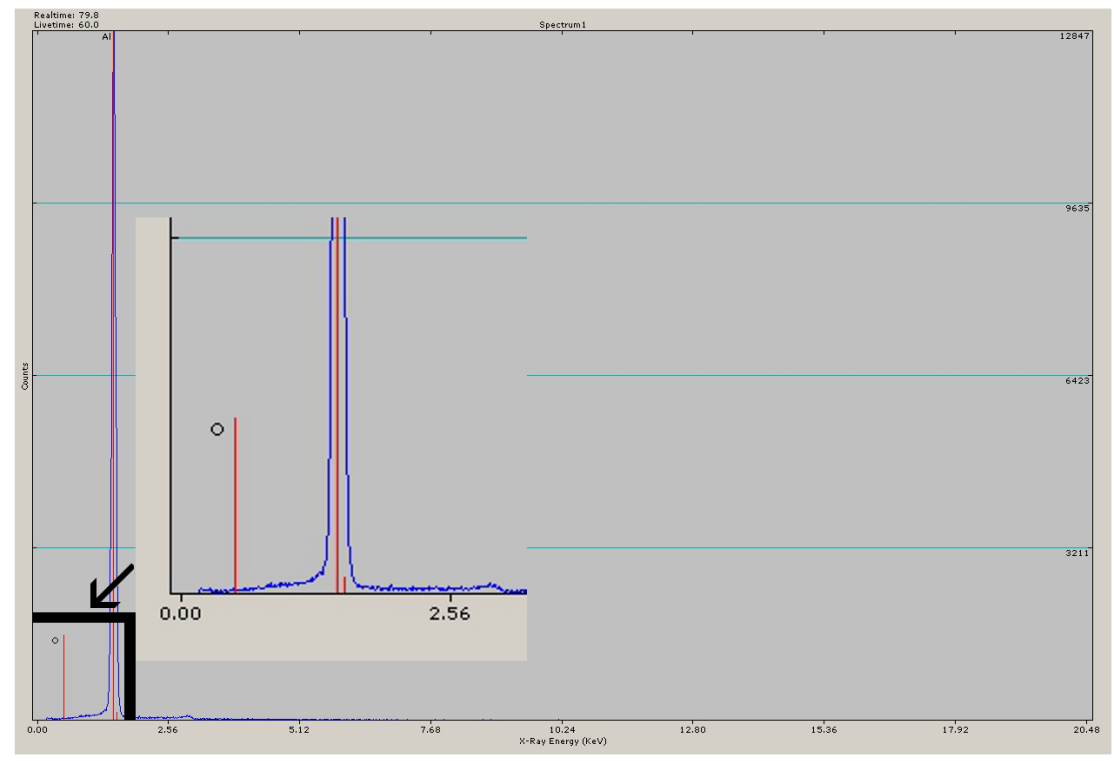

Figure 4.7: Qualitative EDS scan on non-charging pore surface of aluminum sample showing no oxygen peak. This indicated no stabilizer presence. 


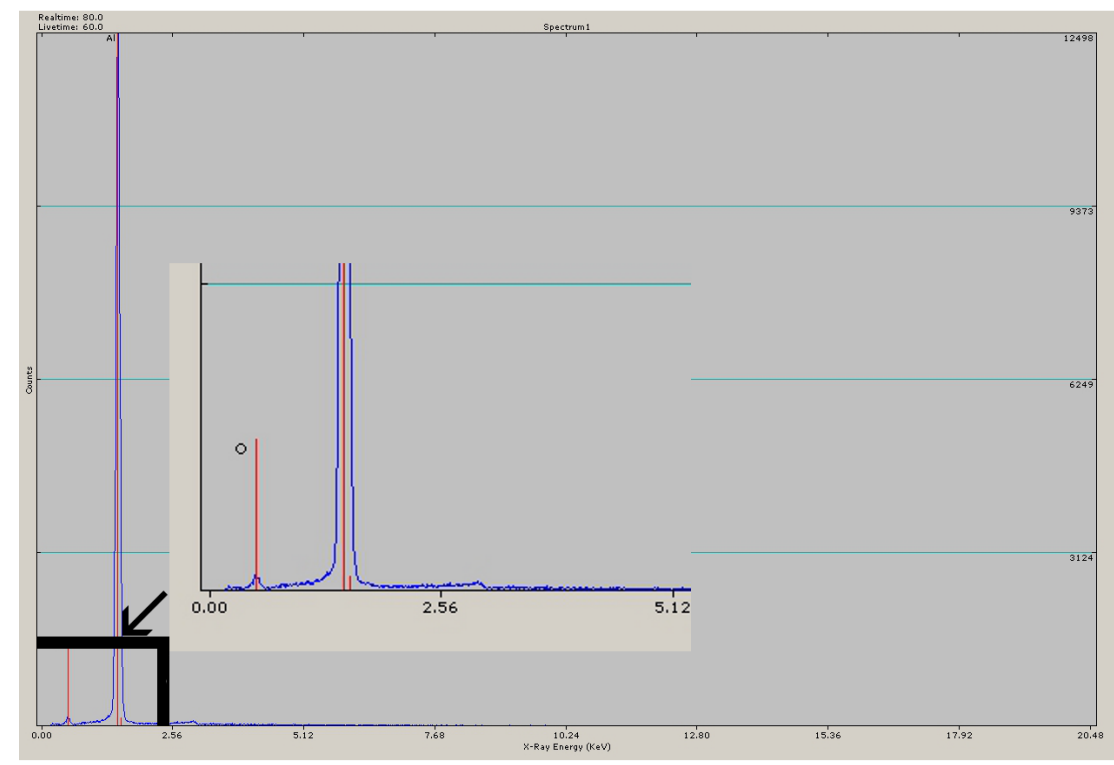

Figure 4.8: Qualitative EDS scan on charging region of aluminum pore surface showing oxygen peak. This indicated the presence of stabilizer at or below the surface.

\subsection{Thermal Decomposition Process For Creating Aluminum Gasarites}

Based on the preceding studies the following final processing conditions were used in all for all remaining trials foaming trials. A graphite crucible with an inner diameter of $75 \mathrm{~mm}$, a height of $127 \mathrm{~mm}$, and a wall thickness of $6.4 \mathrm{~mm}$ was charged with $200 \mathrm{~g}$ of high purity aluminum (99.99\%) and an aluminum foil packet containing $0.20 \mathrm{~g}$ of titanium hydride $\left(\mathrm{TiH}_{2}\right)$ or $0.37 \mathrm{~g}$ of zirconium hydride $\left(\mathrm{ZrH}_{2}\right)$ (equivalent hydrogen content). The nominal hydride particle size was -325 mesh $(<43 \mu \mathrm{m})$, with over half of the particle mass less than $20 \mu \mathrm{m}$ in size. The chamber was evacuated to $10^{-7}$ atm after charge outgassing, backfilled with 0.04 to 0.05 atm argon, and then the charge was heated for $500 \mathrm{~s}$ until melted. The pouring temperature measured with an infrared 
pyrometer was $1123-1173 \mathrm{~K}\left(850-900{ }^{\circ} \mathrm{C}\right)$, but due to thermal radiation from the graphite crucible the pyrometer overestimated the actual melt temperature.

The mold material was $0.1 \mathrm{~mm}$ thick 301 stainless steel spot-welded into a $25 \mathrm{~mm}$ diameter by $127 \mathrm{~mm}$ tall cylinder. A slurry of $0.3 \mu \mathrm{m}$ alumina powder in isopropyl alcohol was applied to the interior mold surface, yielding a mold coating mass of $0.085 \mathrm{~g}$ (200 $\mu \mathrm{m}$ thick) after baking at $663 \mathrm{~K}\left(390^{\circ} \mathrm{C}\right)$. The mold was placed on a $300 \mathrm{~mm}$ diameter by $37.5 \mathrm{~mm}$ thick copper chill plate cooled to $286-291 \mathrm{~K}\left(13-18^{\circ} \mathrm{C}\right)$ by a 7.5 $\mathrm{L} / \mathrm{min}$ flow of circulating water. The chill plate rested atop three vibration-isolation compression springs to mitigate oscillations from the pumping systems. This minor process change prevented the rippled pore surfaces encountered in preliminary trials (Figure 3.4). A second aluminum foil packet containing $0.20 \mathrm{~g}$ of titanium hydride or $0.37 \mathrm{~g}$ of zirconium hydride as well as $0.10 \mathrm{~g}$ of $0.3 \mu \mathrm{m}$ alumina powder was folded into a dome shape and placed at the bottom of the mold.

\subsection{Summary and Conclusions}

Each of the issues encountered during preliminary trials were addressed through processing changes that highlighted the delicate balance between many factors that influence pore formation and growth within gasarites produced via thermal decomposition. With a finalized process in place several key questions arose with regard to the assertions in literature related to pore formation and growth modes:

1. Is pore growth driven only by gas metal eutectic? 
2. If gas metal eutectic growth is dominant will the relationship between pore spacing and solidification rate predicted by the Jackson and Hunt model be observed?

3. If pore growth occurs by means other than gas metal eutectic, what are they and can evidence of them be obtained experimentally?

These questions were addressed by carrying out additional foaming studies using both titanium hydride and zirconium hydride as gas sources. 


\subsection{Baseline Process Capability and Pore Formation Mechanisms ${ }^{2}$}

The following was adapted from "Processing and Pore Formation Mechanisms in Aluminum Gasarites Produced by Thermal Decomposition" published in Metallurgical and Materials Transactions A Vol. 44 No. $12 .{ }^{[1]}$

\subsection{Introduction}

Metallic foams are produced using stochastic processes characterized by a wide distribution of pore morphologies. In order to characterize this distribution it was necessary to carry out an expanded survey of gasarite foams produced via thermal decomposition and characterize a larger number of porous structures cast using the final process outlined above. To achieve better control over the production of gasarites by thermal decomposition it was also necessary to understand how pores form and how their growth may be controlled. As stated previously, Nakajima and Kim support nonequilibrium gas-metal eutectic growth as the sole pore formation mechanism. As shown in preliminary calculations both bubble capture and direct gas evolution from hydride are viable alternative pore formation and growth modes.

Direct experimental evidence of different pore formation mechanisms was sought while analyzing the porous structures produced utilizing the final process developed in Chapter 4. Evidence of pore formation mechanisms was obtained by closely examining the pore morphologies of aluminum foams produced by decomposition of both titanium hydride and zirconium hydride. Zirconium hydride has not yet been evaluated as a gasarite forming decomposition material in aluminum. Due to zirconium hydride's

\footnotetext{
${ }^{2}$ Chapter 5 was adapted from "Processing and Pore Formation Mechanisms in Aluminum Gasarites Produce by Thermal Decomposition" Met. Trans. A Vol 44 No. 12
} 
higher activation energy for hydrogen desorption and slower decomposition kinetics ${ }^{[47,54]}$ it is expected that the overall porosity levels will be smaller compared to titanium hydride, but that pores should exhibit less variance due to less turbulent gas evolution.

\subsection{Experimental Methods}

Twelve titanium hydride and six zirconium hydride aluminum gasarites were produced by thermal decomposition under nominally equivalent processing conditions outlined in Section 4.7. Samples were sectioned using a wire electrical discharge machine. Transverse sections were made every $12.7 \mathrm{~mm}$ from the chill and longitudinal sections every $6.35 \mathrm{~mm}$ from the sample centerline. The spark-eroded surface was ground with 1200 grit sand paper to avoid damaging or masking small pores, and image analysis was used to quantify pore radii by manual measurement. The Archimedes density of transverse sections was measured after sealing exposed pores with $25.4 \mathrm{~mm}$ diameter adhesive disks (with corrections made for disk buoyancy). All longitudinal samples were polished and etched using a $30 \% \mathrm{NaOH}$ solution for $300 \mathrm{~s}$ to reveal the grain structure around porosity. Transverse and longitudinal sections were analyzed using optical and scanning electron microscopy (SEM) and energy dispersive spectroscopy (EDS).

\subsection{Results and Discussion}

During melting, the aluminum charge enveloped the hydride packet at the bottom of the crucible. The molten aluminum effervesced for a short time before the target superheat was achieved, confirming release of hydrogen gas through the melt. After pouring the hydride-charged melt into the mold, a more vigorous reaction occurred due to 
release of gas from the second hydride packet, resulting in expulsion of small quantities of aluminum from the top of the mold. A plume of particle-laden gas was also observed indicating dispersions of fine particulate throughout the melt and some degree of gas escape from the solidifying system. During the first few seconds of solidification a dome of molten aluminum would form, expand, and rupture repeatedly at the top of the sample. Depending on the solidification rate this solidification dome resulted in a conical "turban" structure ${ }^{[29]}$ in which the sample freezes along the mold wall circumference but continues to expand at the center. The formation of this structure is a positive indication that enough porosity has been formed to compensate for the contraction of the liquid upon solidification. Due to the formation of this structure total sample height varied between 60 to $80 \mathrm{~mm}$.

The solidification process could be observed as the red-hot stainless steel mold cooled from the chill plate to the top of the mold. Samples took approximately $120-150 \mathrm{~s}$ to completely solidify based on thermocouple data presented in section 3.3. Mold removal revealed a dull surface from the mold coating with no apparent interaction between porosity and the mold surface. A small amount of undispersed residual hydride was often present at the bottom of the sample.

The porosity level as a function of distance from the chill had some correlation with solidification velocity (Figure 3.3) for the zirconium hydride (both decrease). Porosity peaked at moderate solidification velocities $(38.1-50.8 \mathrm{~mm}$ from chill) for the titanium hydride. Average porosity levels were $2-4 \%$ for zirconium hydride and $4-10 \%$ for titanium hydride (Figure 5.1a). Pore sizes were relatively constant as a function of distance from the chill plate, with titanium hydride producing pore sizes around $300 \mu \mathrm{m}$ 
and zirconium hydride generating pores smaller than $50 \mu \mathrm{m}$ (Figure 5.1b). Significant variation between specimens (error bars in Figure 5.1 represent standard error in the 6 replicates of zirconium hydride or 12 replicates of titanium hydride) limit the inferences that can be drawn from experimental data.
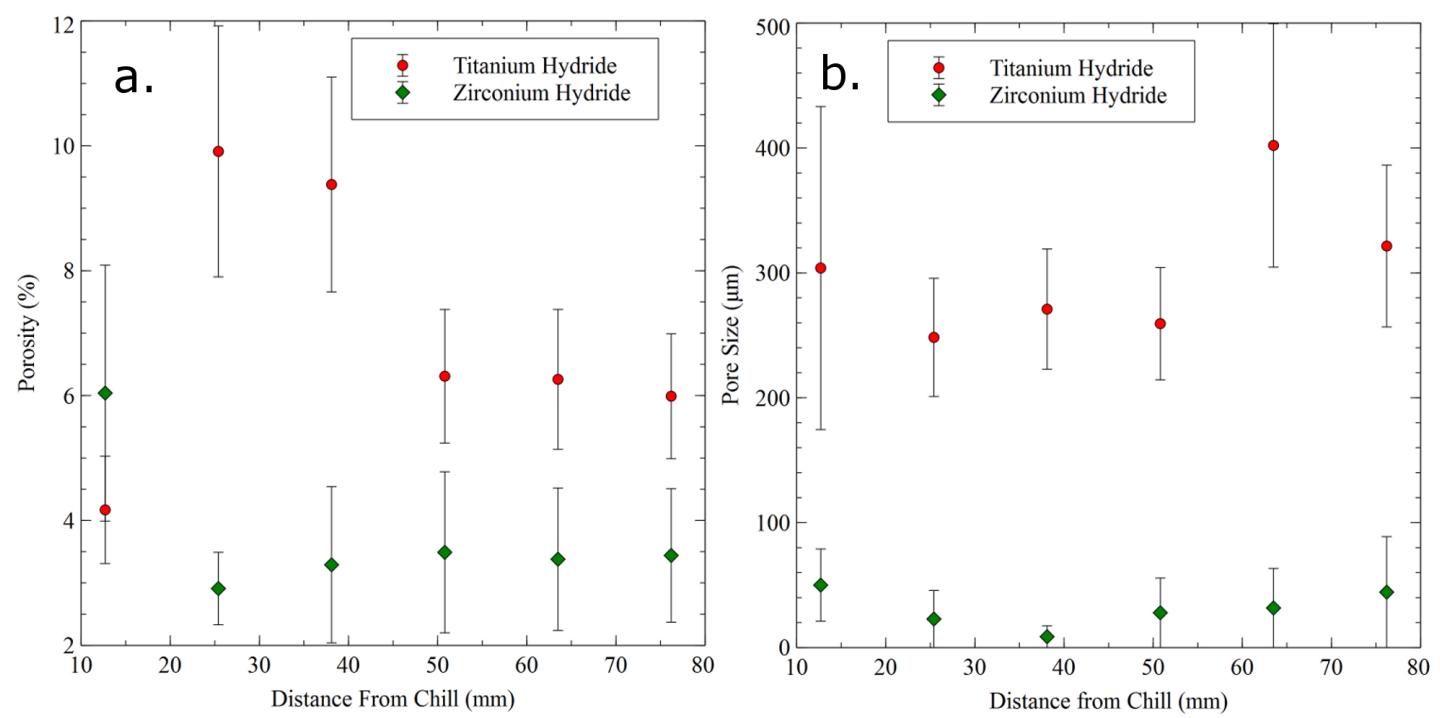

Figure 5.1: Average porosity (a.) and pore size values (b.) of titanium hydride and zirconium hydride samples. Error bars represent one standard error of the mean.

Typical transverse sections for foams created using each hydride type are provided in Figure 5.2. The size difference between pores created using each type of hydride is apparent. Longitudinal sections from the hydride specimens reveal a pore morphology resembling a tadpole, with a narrow tail on the bottom and an expanded bulb at the top (Figure 5.3). Blocky features connected to the pore surface (Figure 5.4) were observed both optically and with SEM throughout the longitudinal and transverse sections. The regions surrounding these features were analyzed with EDS and found to be rich in either titanium or zirconium depending on the type of hydride utilized. This 
indicated that residual gas sources were trapped at or near the pore surface in support of the direct gas evolution pore formation mode. Un-etched samples did not exhibit these features as prevalently when examined under an optical microscope, signifying that the residual titanium or zirconium particulate may have been preferentially attacked by the $\mathrm{NaOH}$ etchant due to its high reactivity with aqueous solutions and formation of $\mathrm{TiO}_{2}{ }^{[55]}$ The occurrence of residual hydride in close proximity to porosity may signal a relationship between pore formation and hydride gas evolution.

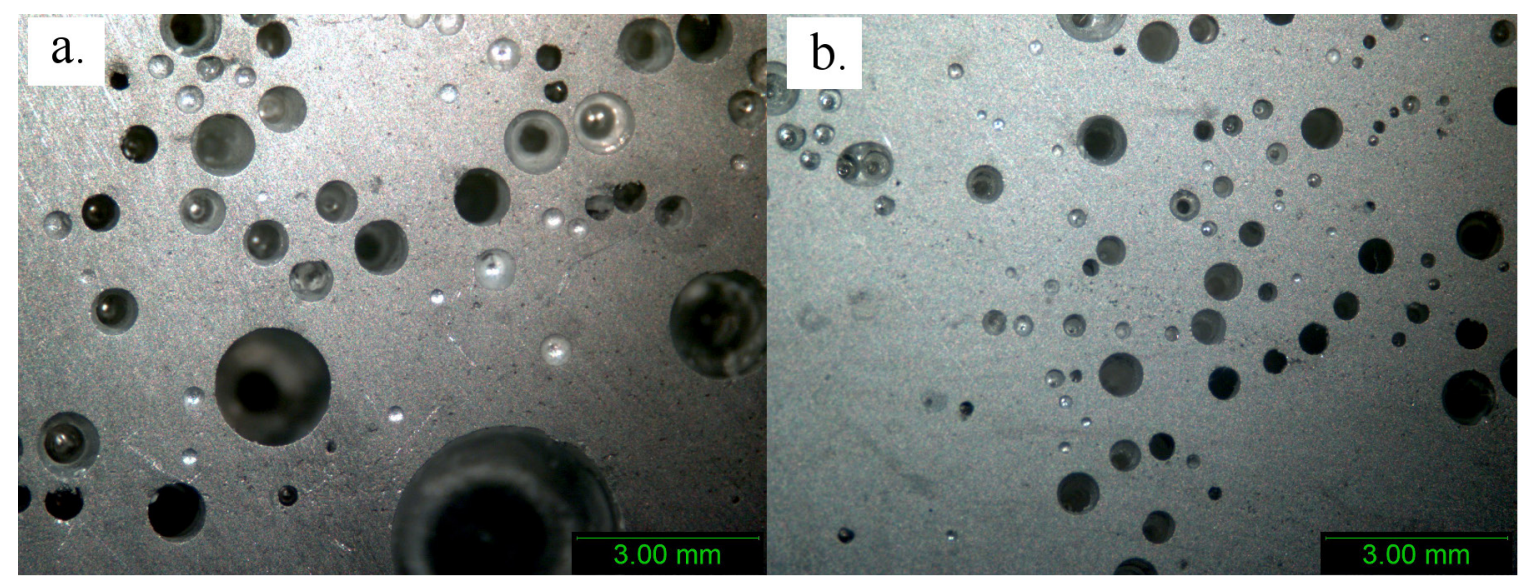

Figure 5.2: Transverse sections from foams created using $\mathrm{TiH}_{2}$ (a.) and $\mathrm{ZrH}_{2}$ (b.). Pore size was greater for foams created using $\mathrm{TiH}_{2}$, but variation in pore size was also greater. 


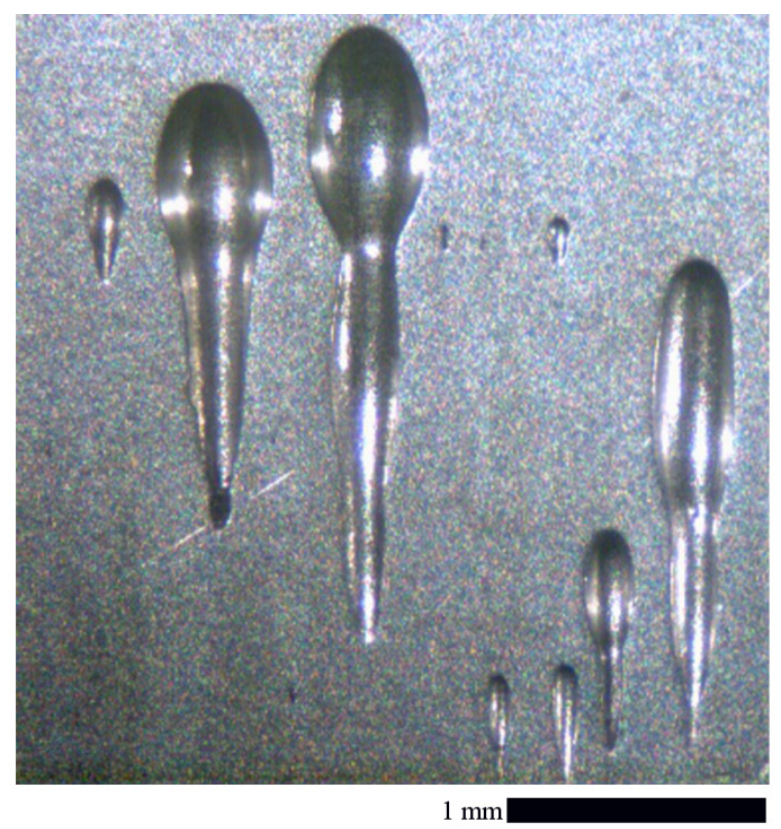

Figure 5.3: Group of tadpole-shaped pores in aluminum processed with $\mathrm{TiH}_{2}$ the unique pore morphology.

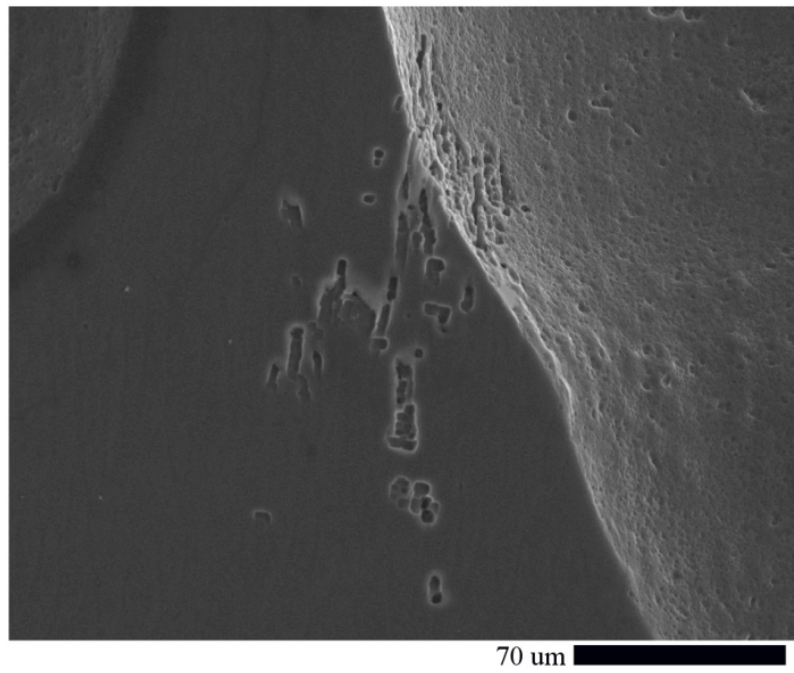

Figure 5.4: Pore surface blocky features after $\mathrm{NaOH}$ etching aluminum gasarite processed with tiatnium hydride. The polished surface is on the left; the pore is on the right.

If gas-metal eutectic growth was a dominant pore formation mechanism during thermal decomposition, the resulting structure should provide evidence to support this 
hypothesis. In the case of directional, diffusion-limited eutectic growth, as the solidification velocity is increased, the lateral diffusion length is reduced and the spacing of the pores will decrease at constant porosity. This general relationship is the predicted by the well known eutectic growth models such as that of Jackson and Hunt, which has been applied to the formation of gasarites via the pressurized gas method ${ }^{[56]}$. However, due to the potential for localized liquid saturation around hydrides, one may expect local pore colonies instead of a uniformly spaced pore structure. Although some pore colonies could be identified (Figure 5.3), pore spacing was often inconsistent when comparing regions with the same solidification rate. Although this would seem to discredit the gasmetal eutectic hypothesis, there are several simultaneous stochastic processes that may have a tendency to cause variation in pore spacing at the same solidification rate. For instance, during solidification, coalescence of bubbles may cause a sudden increase in bubble velocity causing an amount of hydrogen to escape the system.

For significant gas-metal eutectic growth to occur via thermal decomposition several conditions must be met. First, upon heating, the thermally-decomposing species must release gas and saturate the surrounding molten liquid to a concentration that approaches the eutectic point. Based on results presented below in Chapter 6, hydrides may take over 5 minutes to decompose at $933 \mathrm{~K}\left(660^{\circ} \mathrm{C}\right)$, (longer than the 2-3 minutes it takes for the solidification of the foamed aluminum samples). Continuous introduction of hydrogen to the system during both melting and solidification aids in saturating the melt with hydrogen leading to the potential for gas metal eutectic growth.

This hydrogen saturation must not dissipate via diffusion away from the decomposing particulate before the solidification front passes through this region. 
According to Carlson ${ }^{[57]}$, liquid cooling rates on the order of 3-4 K/s enable solidification to occur rapidly enough to compete with the diffusive mobility of hydrogen in liquid aluminum. Using the cooling rates estimated from thermocouple data to estimate solidification velocity, typical minimum cooling rates for regions $50 \mathrm{~mm}$ from the chill plate were $5 \mathrm{~K} / \mathrm{s}$. The solidification front is moving quickly enough to compete with the hydrogen diffusion as long as the hydride particles continuously saturate the local surroundings during solidification. Continuous gas evolution and high cooling rates near the chill make gas metal eutectic growth possible during thermal decomposition processing.

As shown in Chapter 2, bubble capture may only occur in gasarites if the solidification front velocity is moving quickly enough to compete with buoyancy driven bubble acceleration. Using the largest experimentally determined pore size of $500 \mu \mathrm{m}$ (produced using $\mathrm{TiH}_{2}$ ), the maximum velocity determined from Equation 2.8 (Stokes' Law) is approximately $2500 \mathrm{~mm} / \mathrm{s}$. This speed is several hundred times that of the solidification front velocity shown in Figure 3.3. The gas bubble that formed this pore must have formed via other means than bubble capture or was stabilized quite effectively by alumina additions. For gas bubbles of the minimum size of $10 \mu \mathrm{m}$ found in zirconium hydride produced foams, the bubble velocity would be on the order of $1 \mathrm{~mm} / \mathrm{s}$. This is well below the solidification front velocity indicating such pores may have been formed by bubble capture. Aside from rough estimations, it is difficult to experimentally verify which pores formed via bubble capture and which formed via gas metal eutectic. Due to this fact, bubble capture is a possible growth mode for $\mathrm{ZrH}_{2}$ foamed aluminum. 
Gasarite production via direct gas evolution occurs when the gas source (e.g. hydride particulate) is directly connected to a growing pore. The pore size and length will vary depending on the quantity of hydride connected to the pore surface as well as the amount of hydrogen released before cooling below the decomposition temperature. In contrast to the diffusion-limited pore spacing of gas metal eutectic growth, one would expect the nearly random pore distribution pattern that was observed in the current work. Pore size, shape, and distribution are determined by how the hydrides are dispersed in the molten liquid. Due to the melt practice and pouring in the current study, hydrides are dispersed by turbulent flow that results in random pore distributions.

Based on the fact that hydrides are connected to many pore surfaces (Figure 5.4) and evolve gas continuously throughout solidification of aluminum gasarites, it is likely that direct gas evolution from the hydride particles is not only responsible for pore formation but also continued pore growth. Since the hydride decomposition temperatures are below the melting point of aluminum, they may continue to evolve gas after being captured by the solidification front. If the internal pressure of the developing pore exceeds the yield strength of the hot solid metal, the pore may continue to expand. Since directional solidification techniques were employed, preferential weakening would occur at the hottest section of a pore (i.e. the tip) likely causing asymmetric pore expansion. This asymmetric expansion at the pore tip is likely the cause of the "tadpole" pore structure observed in both the current study as well as by Kim $^{[20]}$ (Figure 3.4 and Figure $5.3)$.

It is likely that eutectic growth, bubble capture, and direct gas evolution contributed to the growth of the porosity in this study. Addition of hydride to the charge 
and rapid initial solidification velocities promote eutectic growth and bubble capture respectively. Random pore distributions, hydrides on the pore surface, and tadpole pore shapes support the direct gas evolution mechanism. This distinction between growth mechanisms is important since it dictates the strategies employed to control pore morphology in gasarites created via thermal decomposition. For example, if pores are connected to residual hydride particles, it may be possible to anneal castings to further expand the porosity. Having a "pre-cast" gasarite structure in this case may allow for the retention of that structure and the tailoring of porosity levels to vary performance.

\subsection{Summary and Conclusions}

Aluminum gasarite structures formed using the optimized process and decomposition of two different hydrides have been investigated. For titanium hydride, the resulting pore morphologies were highly variable but overall exhibited both higher porosity levels and larger pore sizes than zirconium hydride. Zirconium hydride was for the first time used as an alternative gas source in gasarite processing, producing lower porosity levels than titanium hydride with similar structural variation. Although the gasarite microstructure did not provide evidence of gas-metal eutectic growth or bubble capture, these mechanisms cannot be completely ruled out. There was, however, significant evidence of pore formation via direct gas evolution from hydrides open to pore surfaces. Continued gas evolution after solidification may explain the "tadpole" pore structure evident throughout the foam. Interconnected hydride to pore surfaces also may enable pore expansion by high temperature annealing. This would enable the tailoring of porous structures to different applications. 


\subsection{High Ramp Rate Thermal Decomposition Kinetics of Titanium Hydride and Zirconium Hydride ${ }^{3}$}

The following Chapter is a reproduction of an article that will be submitted to the journal, ThermoMechanica Acta for review. According to the copyright transfer agreement (included in Chapter 10: Copyright and Permissions) the current author retains the right to reproduce the entirety of the work as has been done below. Projected submittal date is Dec. 202013.

\subsection{Introduction}

Titanium hydride and zirconium hydride are used in laboratory and industrial scale aluminum foaming processes due to the proximity of their decomposition temperatures to aluminum's melting point. ${ }^{[2,20,39]}$ The gas evolution rate from these hydrides affects the foam pore morphology ${ }^{[1]}$; therefore it is important to understand the kinetics of hydrogen evolution from these compounds. There are several routes for utilizing hydrides in foam production, the choice of which determines the thermotemporal profile governing hydride decomposition kinetics. For example, the thermal decomposition method, recently studied by $\mathrm{Kim}^{[20]}$, and Licavol ${ }^{[1]}$, involves casting molten aluminum upon titanium hydride placed upon a copper chill plate resulting in hydride heating rates on the order of $18,000 \mathrm{~K} / \mathrm{min}$, according to thermocouple data from foaming experiments.

Several studies have been conducted utilizing a spectrum of analytical techniques to characterize the decomposition hydrides subjected to various treatments. ${ }^{[28,47,58-59]}$

\footnotetext{
${ }^{3}$ Chapter 6 was adapted from an article with the working title "High Ramp Rate Thermal Decomposition of Titanium Hydride and Zirconium Hydride"
} 
These studies examine hydride decomposition kinetics using very slow heating rates (10$40 \mathrm{~K} / \mathrm{min}$ ) due to limitations of the analytical techniques. ${ }^{[28,47,60]}$ Unfortunately, these slow heating rates prevent the characterization of decomposition kinetics since the reaction has proceeded significantly during heating to the foam-processing temperature.

In the current study both titanium and zirconium hydrides were decomposed using a modified xenon arc image apparatus with thermo-gravimetric instrumentation. This allowed for high temperatures to be reached rapidly before the decomposition reaction was complete. In addition to analyzing commercially pure titanium and zirconium hydride, an oxidizing treatment was applied to the titanium hydride and these powders were tested in the same fashion as above to evaluate the influence of oxide barriers in high temperature decomposition. Oxidation of hydride powders has been used to better control pore morphology in metallic foams, but kinetic data for oxidized hydride are also only characterized at low heating rates. ${ }^{[28,58]}$ Since these powders have an additional oxide layer over most of their surface, and hydrogen transport through the oxides of zirconium and titanium is significantly slower than through pure metals ${ }^{[61-62]}$, the overall decomposition rate should be significantly lower than that for the untreated powders.

\subsection{Experimental Methods}

The as-received titanium hydride powders had nominal sizes of -325 mesh $(<43 \mu \mathrm{m})$ and 1-5 $\mu \mathrm{m}$ and were purchased from Alfa Aesar in purities of $98 \%$ on a metals basis. The zirconium hydride powder had a nominal particle size of -325 mesh $(<43 \mu \mathrm{m})$ and was from Alfa Aesar at a purity of $98 \%$ on a metals basis. The size distribution of the 325 mesh powders of titanium hydride and zirconium hydride was narrowed to $20-30 \mu \mathrm{m}$ 
using dry micro-sieves. A portion of the two size ranges of titanium hydride were heat treated in air at $663 \mathrm{~K}\left(390^{\circ} \mathrm{C}\right)$ for 30 minutes to form an oxide layer. All powders were stored in a desiccator until just before they were loaded into the TGA apparatus to reduce adsorption of moisture.

A high ramp-rate TGA apparatus was constructed utilizing a xenon arc-image projector as a heat source (Figure 6.1). A $10 \mu \mathrm{g}$ resolution balance was used to measure hydrogen mass loss of samples suspended from the bottom attachment hook. Mass readings were output using a HyperTerminal connection at a sampling frequency of 7.14 Hz. A battery-operated thermocouple logger was hung from the balance and sample holders were suspended by plugging into the thermocouple logger. High conductivity alloy 101 copper sample holders were fabricated from $25 \mathrm{~mm}$ tubing crimped at the bottom. A hole was drilled through the tubing diameter and thermocouple wire was threaded through the holes and welded so that the thermocouple junction was within the tube and in direct contact with the hydride powders.

Argon cover gas was flowed through a rubber stopper at the bottom of the fused quartz protective tube in order to avoid powder and sample holder oxidation. To calibrate for any weight change due to contaminant burn off from within the sample holder and cover gas convection, each empty sample holder was held at the test temperature for a period of 100 seconds prior to every test. The weight change was recorded and used as a correction factor when analyzing the hydride decomposition curves. After each calibration, the holder was cooled to a temperature of $298-323 \mathrm{~K}\left(25-50^{\circ} \mathrm{C}\right)$ and powder was added to the sample holder. Titanium hydride samples were $1+/-0.01 \mathrm{~g}$ while the 
zirconium hydride samples were $2+/-0.01 \mathrm{~g}$. These sample sizes are large compared to standard test specimens ${ }^{[63]}$, but due to the resolution of the scale and maximum estimated hydrogen mass losses, this large mass was necessary.

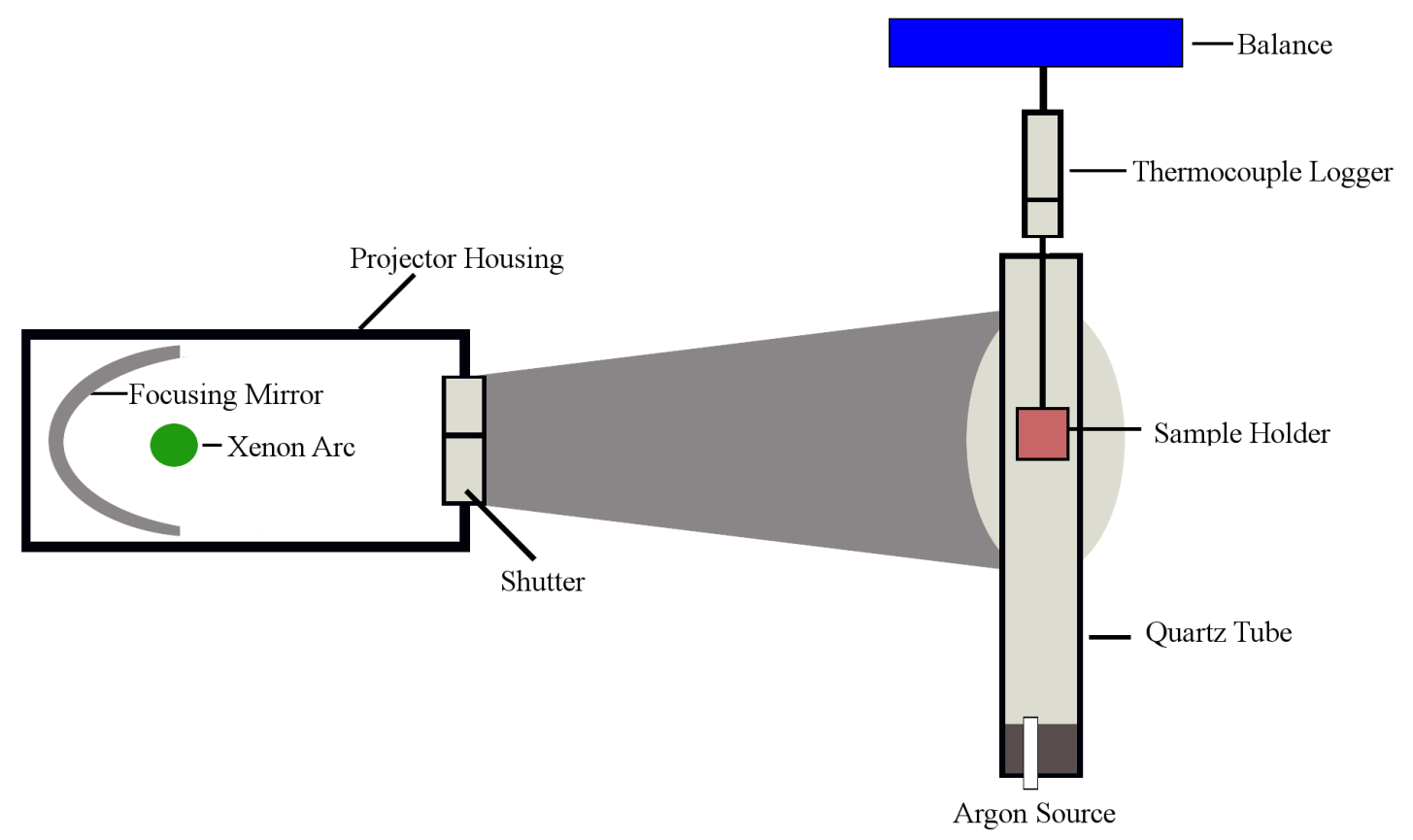

Figure 6.1: Schematic of the xenon arc image thermo-gravimetric analyzer. Temperature control for samples was maintained by adjusting the shutter.

The manual shutter on the xenon arc image heat source was completely opened to rapidly heat the powder to target temperatures. The powder test temperature was maintained by partially closing the shutter to deflect part of the xenon arc image allowing the temperature control within $5 \mathrm{~K}$ of the target.

Test temperatures and time were chosen to match the processing temperature range and times for gasarite foam processing. A summary of the powders and various target hold temperatures is included in Table 6.1. Sintering of the 1-5 $\mu \mathrm{m}$ titanium 
powders and destruction of two sample holders occurred at $1073 \mathrm{~K}\left(800^{\circ} \mathrm{C}\right)$, so this temperature was not used for further tests of titanium hydride. During preliminary testing, the oxidized and unoxidized $20-30 \mu \mathrm{m}$ powder showed nearly identical decomposition characteristics when compared to their $1-5 \mu \mathrm{m}$ counterparts therefore the 20-30 $\mu \mathrm{m}$ powders were only tested at $933 \mathrm{~K}\left(660^{\circ} \mathrm{C}\right)$. All powders were maintained at temperature for a period of 4-5 minutes. This time range corresponds to the range of solidification times for a thermal decomposition processed gasarite foam.

Table 6.1: Experimental test matrix for target hold temperatures.

\begin{tabular}{|c|c|c|c|c|}
\hline Material & $\begin{array}{c}873 \mathrm{~K} \\
\left(600^{\circ} \mathrm{C}\right)\end{array}$ & $\begin{array}{c}933 \mathrm{~K} \\
\left(660^{\circ} \mathrm{C}\right)\end{array}$ & $\begin{array}{l}1003 \mathrm{~K} \\
\left(730^{\circ} \mathrm{C}\right)\end{array}$ & $\begin{array}{l}1073 \mathrm{~K} \\
\left(800^{\circ} \mathrm{C}\right)\end{array}$ \\
\hline $1-5 \mu \mathrm{m} \mathrm{TiH}_{1.98}$ & $X$ & $\mathrm{X}$ & $\mathrm{X}$ & $\mathrm{X}$ \\
\hline $20-30 \mu \mathrm{m} \mathrm{TiH}_{1.98}$ & *1 & $\mathrm{X}$ & $*^{1}$ & $*^{1}$ \\
\hline Oxidized 1-5 $\mu \mathrm{m} \mathrm{TiH}{ }_{1.98}$ & $\mathrm{X}$ & $\mathrm{X}$ & $\mathrm{X}$ & $*^{2}$ \\
\hline Oxidized $20-30 \mu \mathrm{m} \mathrm{TiH}{ }_{1.98}$ & $* 1$ & $\mathrm{X}$ & $* 1$ & $*^{1}$ \\
\hline $\mathrm{ZrH}_{2}$ & $*^{3}$ & $\mathrm{X}$ & $\mathrm{X}$ & $\mathrm{X}$ \\
\hline
\end{tabular}

*1-Preliminary results indicated identical behavior therefore no further tests were conducted

*2-Not tested due to potential sintering

*3-Slow kinetics limited the ability to test

After cooling to $423 \mathrm{~K}\left(150^{\circ} \mathrm{C}\right)$ powders were removed from the argon atmosphere and placed in a dessicator to await further analysis. The hydride stoichiometries were determined via $\mathrm{x}$-ray diffraction using $\mathrm{Cu}-\mathrm{K}_{\alpha}$ radiation and a $2 \theta$ range of $20-90^{\circ}$. The stoichiometry of the as-received powders was used to find the weight percent of hydrogen bound in the material in order to find the maximum weight loss possible, $\mathrm{m}_{\max }$, for the thermogravimetric measurement.

The decomposition conversion fractions, $\alpha$, were calculated by dividing the recorded mass loss as a function of time, $\Delta \mathrm{m}(\mathrm{t})$, by the maximum hydrogen loss, $\mathrm{m}_{\max }$, according to Equation 6.1. 


$$
\alpha(t)=\frac{\Delta m(t)}{m_{\max }}
$$

In order to validate the TGA measurements, phase volume fractions in the decomposed hydrides were determined via the direct comparison method outlined in Cullity ${ }^{[64]}$ using $\mathrm{Cu}-\mathrm{K}_{\alpha}$ radiation over a $20-90^{\circ} 2 \theta$ range. Volume fraction estimates were converted to weight fractions using the densities of the constituents present. The peak positions and relative intensities were used to determine the stoichiometry and the amount of remaining hydride phases. X-ray diffraction from the oxidized powders (before decomposition) was used to adjust $\mathrm{m}_{\max }$ due to hydrogen loss during the heat treatment cycle.

Scanning electron microscopy was conducted on select hydride samples before and after the TGA analysis. An accelerating voltage of $25 \mathrm{KV}$ was used characterize the surface of the powders. The oxidized specimens were coated in carbon in order to avoid charging. Secondary electron images were used to examine both the macroscopic and microscopic surface characteristics and to identify evidence of cracks and fissures due to thermal shock.

\subsection{Results and Discussion}

Sieve separated 20-30 $\mu \mathrm{m}$ titanium and zirconium hydride powders before decomposition exhibited a significant number of fine particles surrounding the larger particles (Figure 6.2). The overlap between the 1-5 $\mu \mathrm{m}$ and 20-30 $\mu \mathrm{m}$ particle size distributions may result in similar decomposition behavior. Cracks and fissures were observed on the surface of all hydrides evaluated in this study, with an example shown 
for zirconium hydride (Figure 6.3). There was no topological difference between the non-oxidized and oxidized titanium hydride. The key difference was in the color of the powders after they were heat treated. The $20-30 \mu \mathrm{m}$ powder was gold to yellowish brown while the 1-5 $\mu \mathrm{m}$ powder was dark violet. These colors correspond to oxide layer thicknesses of $10 \mathrm{~nm}$ and $100 \mathrm{~nm}$ respectively according to color scales used in titanium anodization. ${ }^{[65]}$ The reason for these differences could be due in part to the difference in the surface area between the two particle sizes.

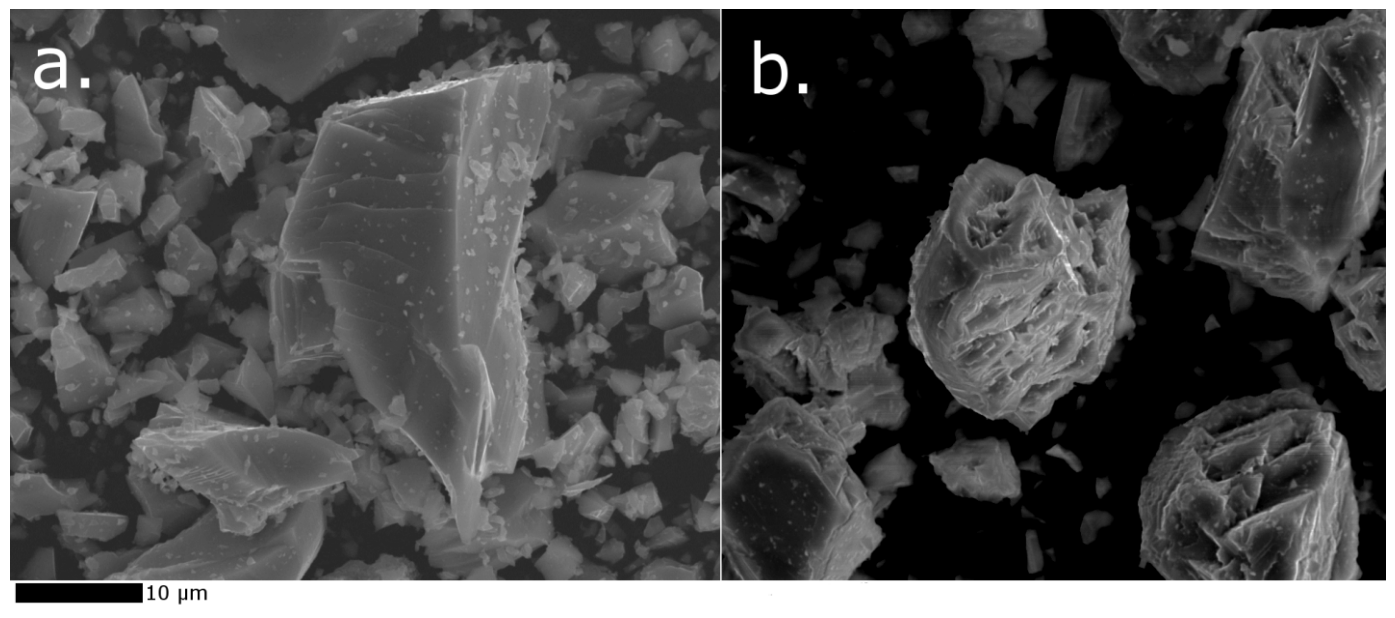

Figure 6.2: Secondary electron images of (a.) $20-30 \mu \mathrm{m} \mathrm{TiH} 2$ before decomposition. (b.) 20-30 $\mu \mathrm{m} \mathrm{ZrH}$ before decomposition. There was significant amounts of fine particulate in each case indicating that sieve separation was incomplete. 


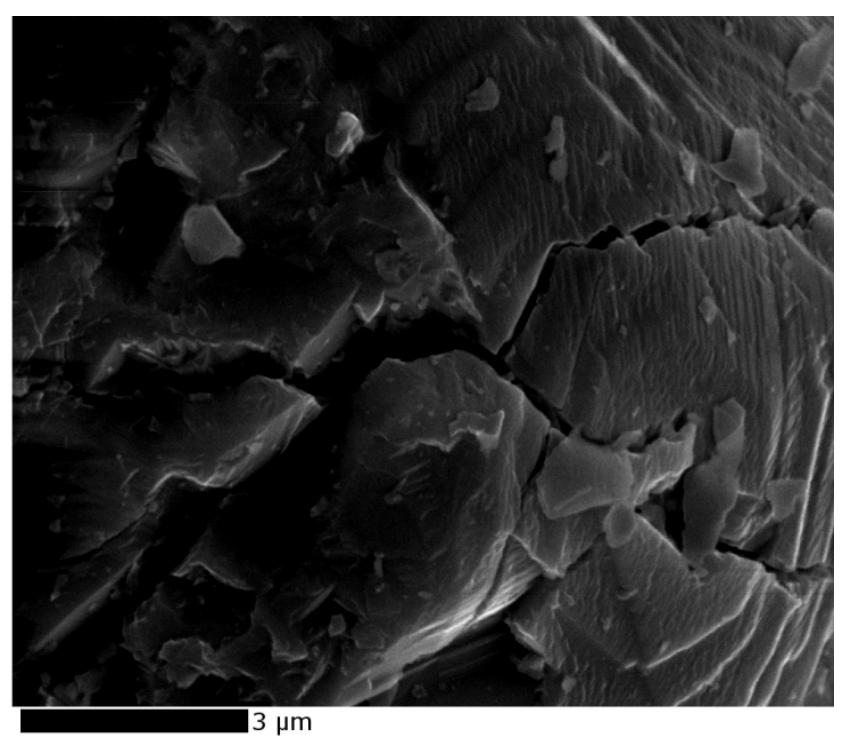

Figure 6.3: Secondary electron images of fissure in $\mathrm{ZrH}_{2}$ particle surface before decomposition. These feature present on both $\mathrm{TiH}_{2}$ and $\mathrm{ZrH}_{2}$ and may influence decomposition rate.

X-ray diffraction profiles of the as-received 1-5 $\mu \mathrm{m}$ and 20-30 $\mu \mathrm{m}$ titanium hydride match that reported for $\mathrm{TiH}_{1.98}$ compounds having a calcium fluoride prototype structure (Figure $6.4 \mathrm{a}-\mathrm{b}$ ). The x-ray diffraction pattern for as-received zirconium hydride matched that of $\mathrm{ZrH}_{2}$ having a thorium hydride structure (Figure 6.5). There was no evidence of any oxide peaks in x-ray diffraction scans of the as-received powders, but a thin amorphous oxide layer is expected to be present. Using the above hydride stoichiometries and sample masses of $1 \mathrm{~g} \mathrm{TiH}_{1.98}$ and $2 \mathrm{~g}$ of $\mathrm{ZrH}_{2}$, the maximum experimental mass losses were $0.040 \mathrm{~g}$ and $0.044 \mathrm{~g}$ respectively.

The oxidized titanium hydride 1-5 $\mu \mathrm{m}$ powders showed small peaks for rutile $\left(\mathrm{TiO}_{2}\right)$ as well as alpha titanium and $\mathrm{TiH}_{1.98}$ indicating that the oxide formation came at the cost of hydride (Figure $6.4 \mathrm{c}-\mathrm{d}$ ). The presence of $\alpha$-Ti was somewhat unexpected since the heat treatment temperature of $663 \mathrm{~K}\left(390^{\circ} \mathrm{C}\right)$ was well below the nominal 
decomposition point of $733 \mathrm{~K}\left(460^{\circ} \mathrm{C}\right)$ for titanium hydride ${ }^{[46]}$. According to the direct comparison methods used, the oxidized $1-5 \mu \mathrm{m}$ powders were composed of approximately $54 \%$ hydride by weight leading to a maximum hydrogen loss of $0.022 \mathrm{~g}$ in a $1 \mathrm{~g}$ sample. Although the oxidized 20-30 $\mu \mathrm{m} \mathrm{TiH}_{1.98}$ powders showed a change in surface color indicating a $10 \mathrm{~nm}$ oxide layer, there were no changes in the x-ray diffraction pattern compared to the as-received powder.

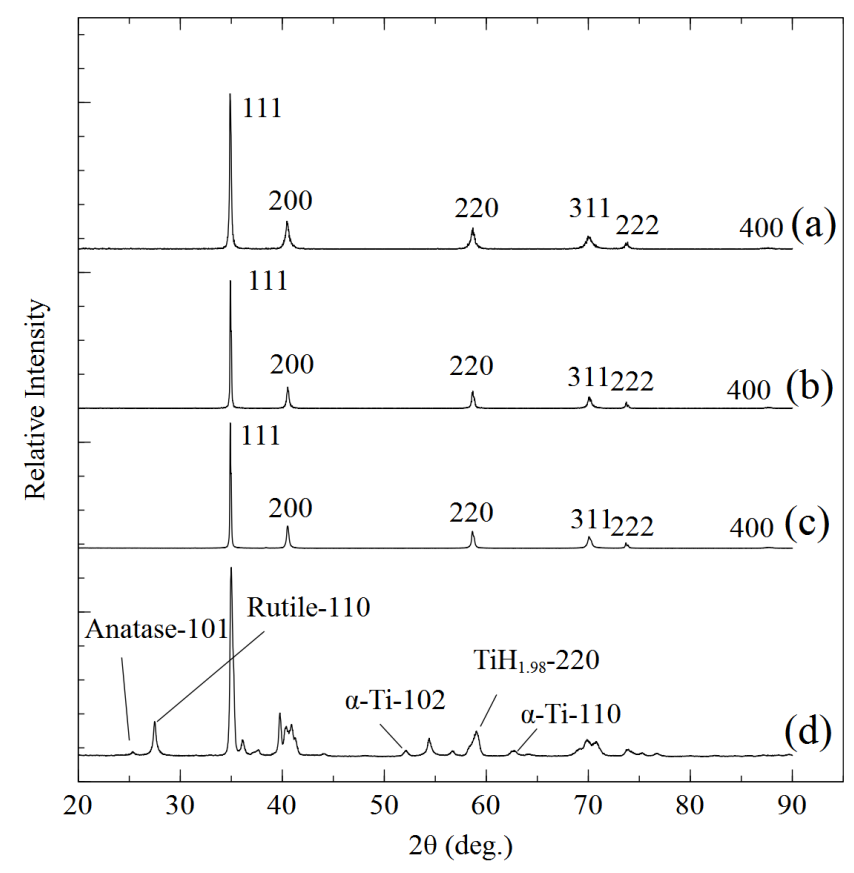

Figure 6.4: X-ray diffraction scans of 1-5 $\mu \mathrm{m}$ (a), 20-30 $\mu \mathrm{m}$ (b), oxidized 20-30 $\mu \mathrm{m}$ (c) and oxidized 1-5 $\mu \mathrm{m}$ (d) titanium hydride before decomposition. Peak labeled on scans (a)-(c) correspond to $\mathrm{TiH}_{1.98}$ characteristic peaks. 


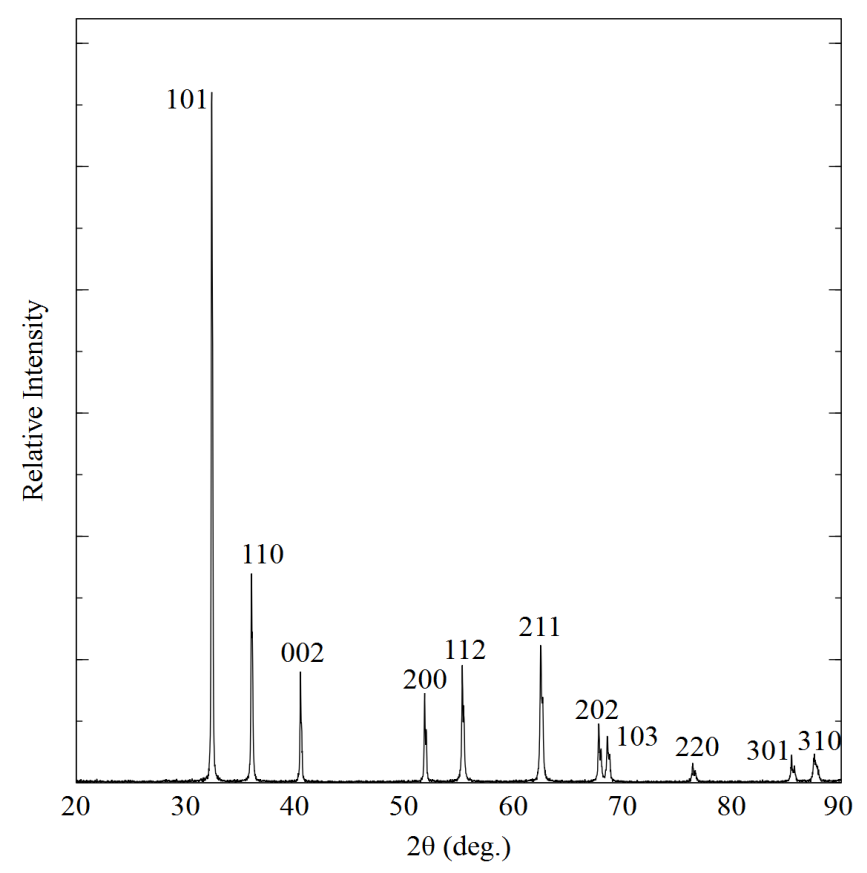

Figure 6.5: X-ray diffraction scan of as-received $20-30 \mu \mathrm{m} \mathrm{ZrH}$. Labeled peaks correspond to those of $\mathrm{ZrH}_{2}$ with a $\mathrm{ThH}_{2}$ structure.

Weight fractions calculated from x-ray diffraction of powders decomposed at 933 $\mathrm{K}\left(660^{\circ} \mathrm{C}\right)$ were used to validate the TGA experiments by comparing to thermogravimetric conversion fractions. The peaks labeled in Figure 6.6 were used in the direct comparison analysis. Due to a high degree of peak overlap there was a limited number of peaks used in direct comparison evaluations. Despite this limitation the x-ray diffraction volume fraction estimates had low errors and are in good agreement with the TGA results (Table 6.2). For the zirconium hydride powders, the observed diffraction scan (Figure 6.7) did not show a mixture of phases, but rather a range of stoichiometries corresponding to $\mathrm{ZrH}_{1.6-1.8}$ having the calcium fluoride structure. The comparison for this sample was made by calculating the theoretical mass lost for the midpoint of this range of 
stoichiometries and converting the weight fraction lost to volume fraction using the densities of the two hydrides.

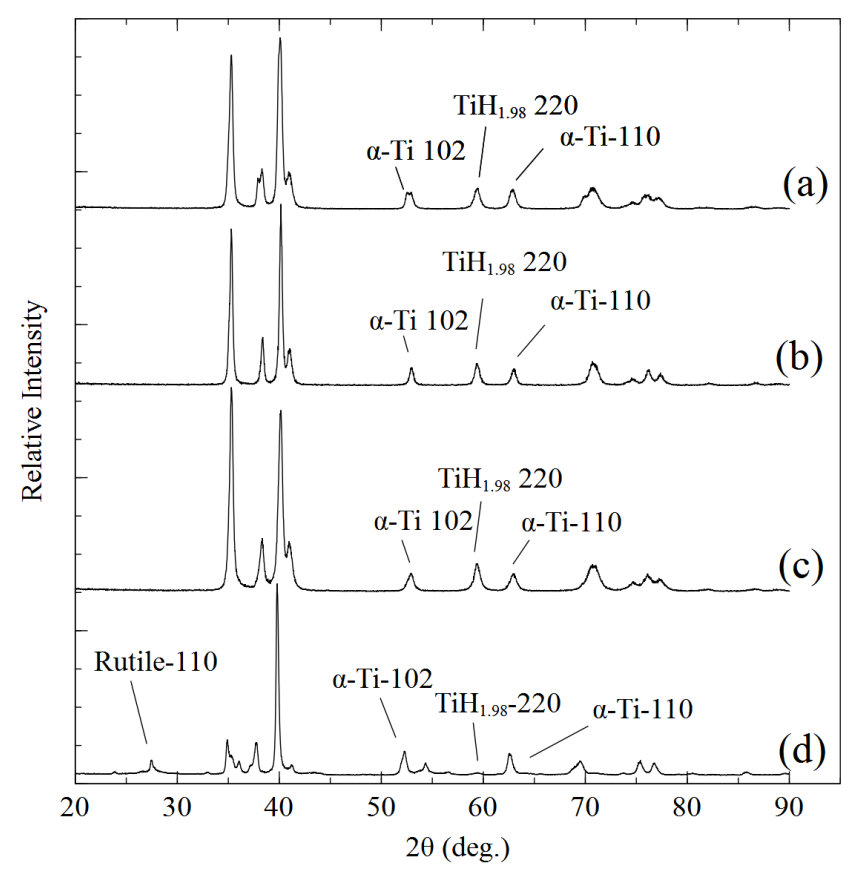

Figure 6.6: X-ray diffraction scans of 1-5 $\mu \mathrm{m}$ (a), 20-30 $\mu \mathrm{m}$ (b), oxidized 20-30 $\mu \mathrm{m}$ (c) and oxidized 1-5 $\mu \mathrm{m}(\mathrm{d})$ titanium hydride after decomposition at $933 \mathrm{~K}\left(660^{\circ} \mathrm{C}\right)$. Peak labeled correspond to those used in direct comparison method.

Table 6.2: Comparison of weight fraction transformation estimates from TGA and XRD Data. Estimates between the TGA data and XRD data showed agreement within experimental error.

\begin{tabular}{ccccc}
\hline Sample Material & $\begin{array}{c}\text { XRD Wt. } \\
\text { Fraction } \\
\text { Transformed }\end{array}$ & $\begin{array}{c}\text { Standard } \\
\text { Error }\end{array}$ & $\begin{array}{c}\text { TGA Wt. } \\
\text { Fraction } \\
\text { Transformed }\end{array}$ & $\begin{array}{c}\text { Standard } \\
\text { Error }\end{array}$ \\
\hline $1-5 \mu \mathrm{m} \mathrm{TiH}_{2}$ & 0.63 & 0.02 & 0.67 & 0.02 \\
$20-30 \mu \mathrm{m} \mathrm{TiH}_{2}$ & 0.62 & 0.02 & 0.67 & 0.05 \\
$20-30 \mu \mathrm{m} \mathrm{ZrH}$ & N/A & 0.16 & 0.05 \\
\hline Zirconium XRD weight fraction estimated from stoichiometry change, not from direct comparison
\end{tabular}




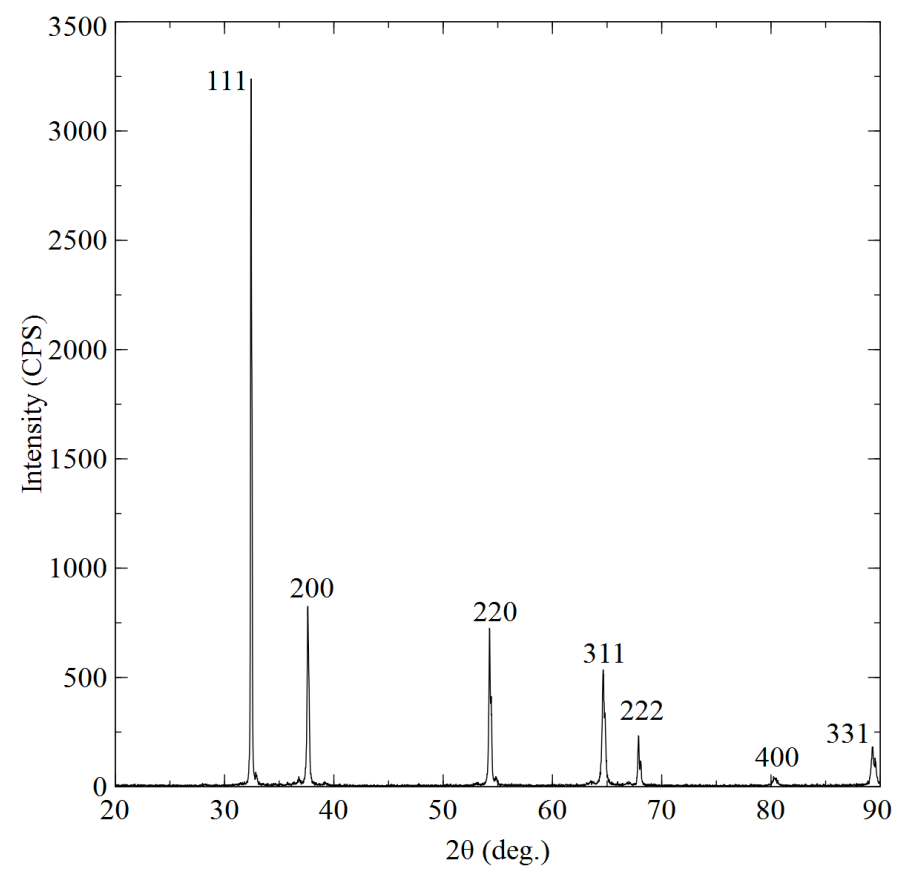

Figure 6.7: X-ray diffraction scan of $20-30 \mu \mathrm{m} \mathrm{ZrH}_{2}$ powder after a 300 second hold at $933 \mathrm{~K}\left(660^{\circ} \mathrm{C}\right)$. Peaks labeled correspond to $\mathrm{ZrH}_{2-\mathrm{x}}$ with a $\mathrm{CaF}_{2}$ structure.

Representative decomposition data for trials conducted for various hydrides and temperature profiles are provided in the Figures 8-12. Data markers were thinned on all graphs so that marker shapes could be distinguished. Over 2000 data points compose each graph. The average linear heating rates and confidence intervals for each target hold temperature are included in Table 6.3. Due to sensitivity to sample position within the focal point of the arc image, heating rates varied by roughly $80 \mathrm{~K} / \mathrm{min}$ about the average heating rate. The heating rates near $1003 \mathrm{~K}\left(730^{\circ} \mathrm{C}\right)$ and $1073 \mathrm{~K}\left(800^{\circ} \mathrm{C}\right)$ were significantly lower than those at lower temperatures, most likely resulting from limitations of the arc image refiner to maintain a constant heating rate at the high end of this temperature range. This is reflected in some non-linearity in the heating curves. Repeatability between runs was typically very consistent with the exception being for 20- 
$30 \mu \mathrm{m} \mathrm{ZrH} 2$ at both $933 \mathrm{~K}\left(660^{\circ} \mathrm{C}\right)$ and $1003 \mathrm{~K}\left(730^{\circ} \mathrm{C}\right)$ hold temperatures. These differences may have been due to contamination of the samples by moisture or other volatile materials despite efforts to maintain clean powders.

Table 6.3: Heating rates for different target hold temperatures.

\begin{tabular}{lcc}
\hline \multicolumn{1}{c}{ Hold Temperature } & $\begin{array}{c}\text { Avg. Heating Rate } \\
(\text { K/min) }\end{array}$ & $\begin{array}{c}+/- \\
(\mathbf{K} / \mathbf{m i n})\end{array}$ \\
\hline $873 \mathrm{~K}\left(600^{\circ} \mathrm{C}\right)$ & 955 & 146 \\
$933 \mathrm{~K}\left(660^{\circ} \mathrm{C}\right)$ & 909 & 102 \\
$1003 \mathrm{~K}\left(730^{\circ} \mathrm{C}\right)$ & 552 & 91 \\
$1073 \mathrm{~K}\left(800^{\circ} \mathrm{C}\right)$ & 606 & 104 \\
\hline Overall & $\mathbf{7 9 5}$ & $\mathbf{8 0}$ \\
\hline
\end{tabular}

$*_{+}$/- values represent $95 \%$ confidence intervals

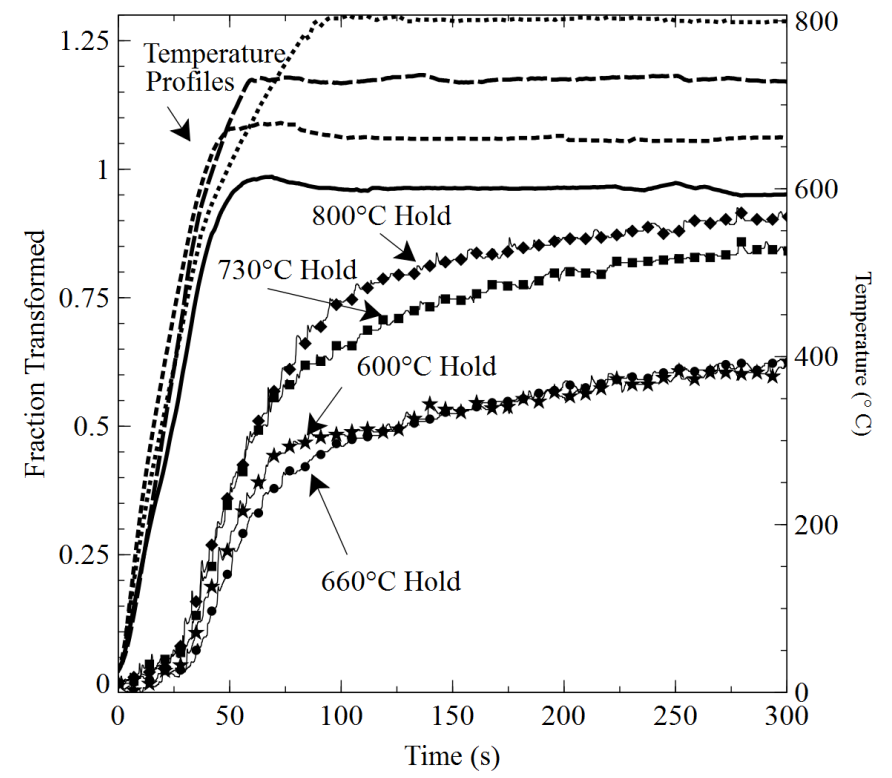

Figure 6.8: Decomposition data for 1-5 $\mu \mathrm{miH}_{1.98}$. There is little difference between the decomposition behavior at $873 \mathrm{~K}\left(600^{\circ} \mathrm{C}\right)$ and $933 \mathrm{~K}\left(660^{\circ} \mathrm{C}\right)$ 


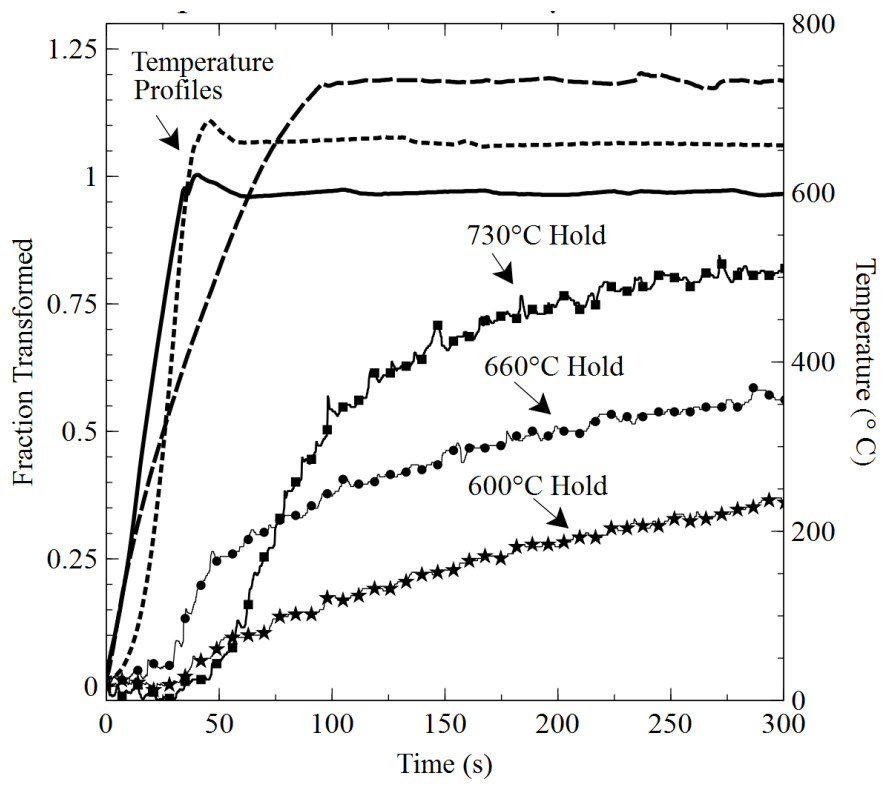

Figure 6.9: Decomposition data for oxidized 1-5 $\mu \mathrm{m} \mathrm{TiH}_{1.98}$. The delay in decomposition for the $1003 \mathrm{~K}\left(730^{\circ} \mathrm{C}\right)$ hold was most likely due to sample misalignment within the arc image.

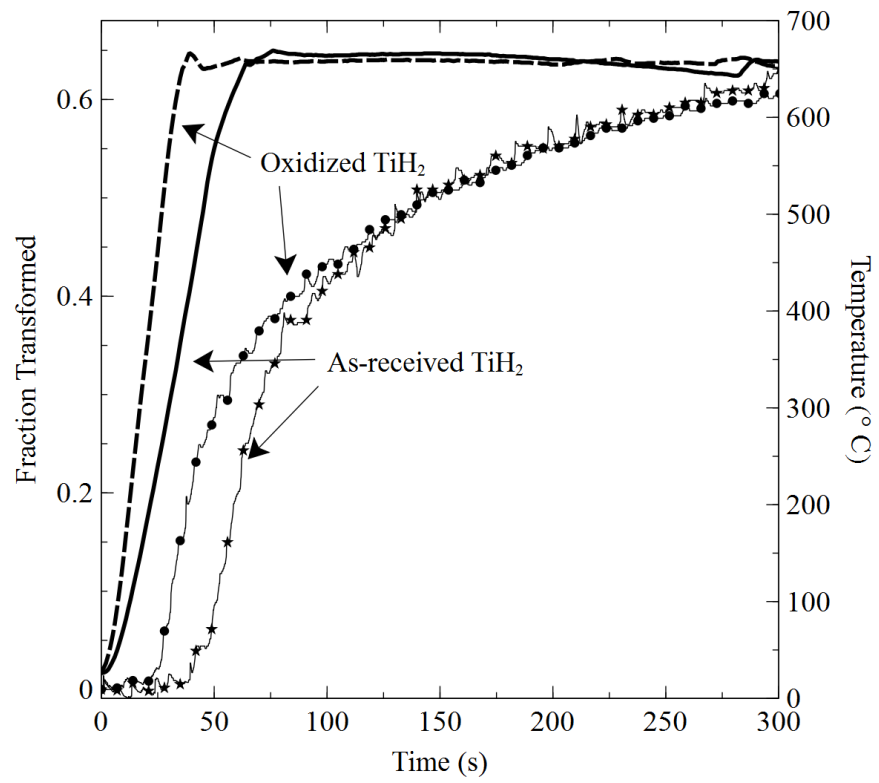

Figure 6.10: Representative decomposition data for both as-received and oxidized 20-30 $\mu \mathrm{m} \mathrm{TiH}_{1.98}$ held at $933 \mathrm{~K}\left(660^{\circ} \mathrm{C}\right)$. Very little observed difference is apparent at longer hold times. 


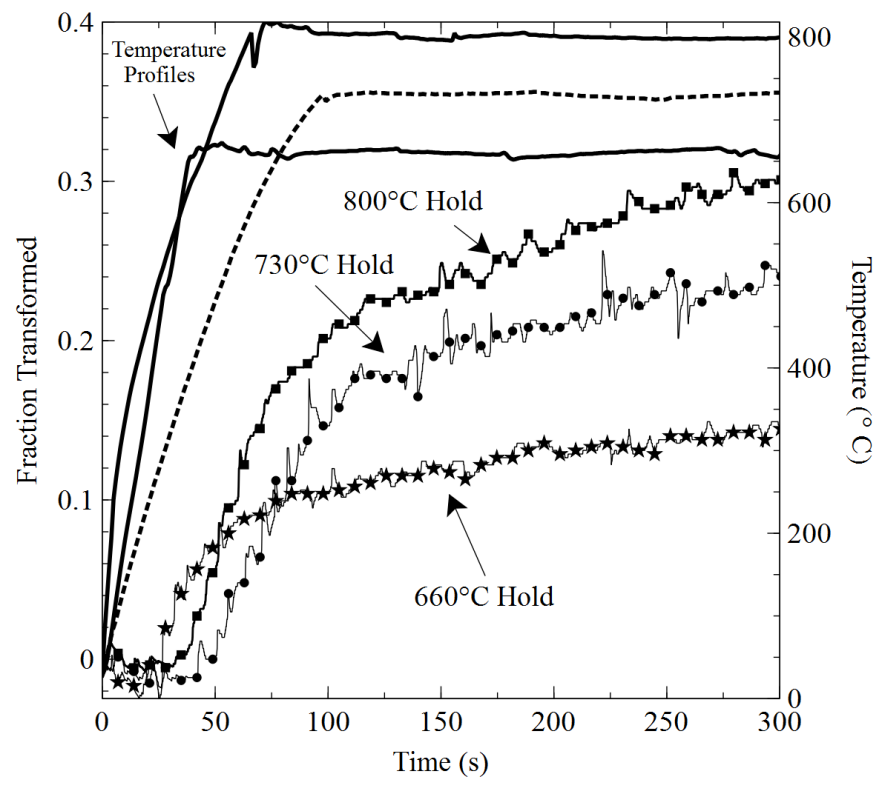

Figure 6.11: Representative decomposition data for 20-30 $\mu \mathrm{m} \mathrm{ZrH}_{2}$. As expected at high temperatures, decomposition proceeds more rapidly.

For ease of comparison, representative runs for all materials were combined into the figures below at the targeted hold temperatures (Figures 37-40). At $873 \mathrm{~K}\left(600^{\circ} \mathrm{C}\right)$, the oxidized titanium hydride powder had a significantly lower decomposition rate than that of the as-received $\mathrm{TiH}_{1.98}$ powder, in agreement with previous work. ${ }^{[47]}$ At $933 \mathrm{~K}$ $\left(660^{\circ} \mathrm{C}\right)$ and above, the as-received and oxidized titanium hydride decomposition rates were more similar to one another, but the oxidized powders still decomposed more slowly. The zirconium hydride powder tested at $933 \mathrm{~K}\left(660^{\circ} \mathrm{C}\right), 1003 \mathrm{~K}\left(730^{\circ} \mathrm{C}\right)$, and $1073 \mathrm{~K}\left(800^{\circ} \mathrm{C}\right)$ showed a markedly slower decomposition rate than all other powders as is expected from the results of previous studies at lower heating rates. ${ }^{[54]}$

There were no significant differences in the titanium hydride decomposition kinetics as a function of particle size at $933 \mathrm{~K}\left(660^{\circ} \mathrm{C}\right)$. At slow heating rates, a diffusion limited Jander model was found to fit the titanium hydride decomposition results yielding 
an inverse square relation between average particle size and the extent of decomposition. ${ }^{[47]}$ If the Jander model were valid in this case, the size difference between the $1-5 \mu \mathrm{m}$ particles and $20-30 \mu \mathrm{m}$ particles should produce a significant difference in decomposition rates. Some fine particulate was observed in the 20-30 $\mu \mathrm{m}$ powders, which could have resulted in similar decomposition rates to the 1-5 $\mu \mathrm{m}$ powders. Another possible explanation for the independence of decomposition to particle size is thermal shock of the brittle hydride powders as they are heated rapidly, however no evidence of increased quantities of fine particulate was found in the SEM images taken of the powders after decomposition (Figure 6.17).

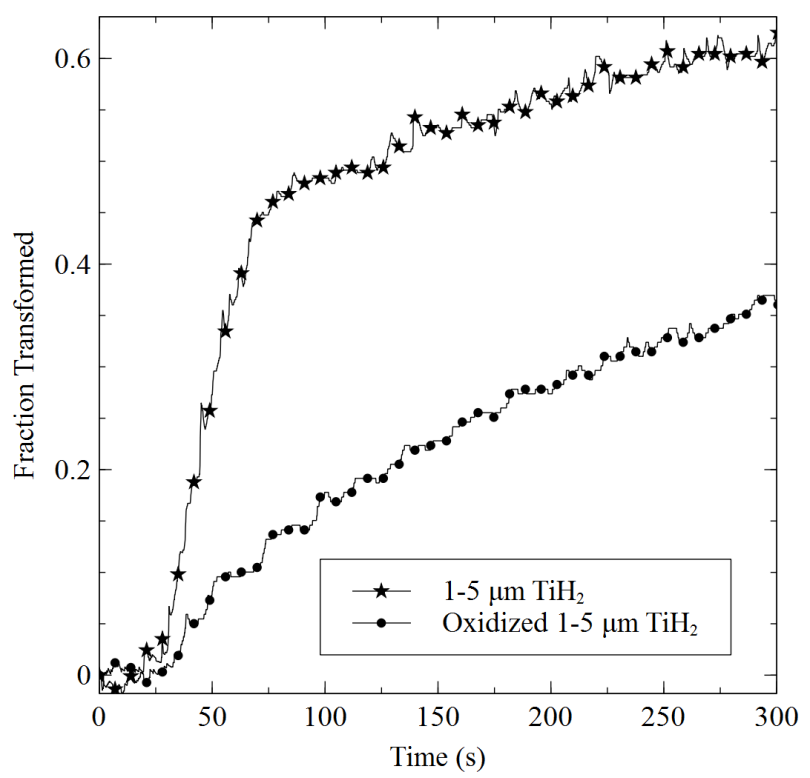

Figure 6.12: Comparison of all materials run at $873 \mathrm{~K}\left(600^{\circ} \mathrm{C}\right)$ hold temperatures. The oxide barrier has a large influence at this hold temperature. 


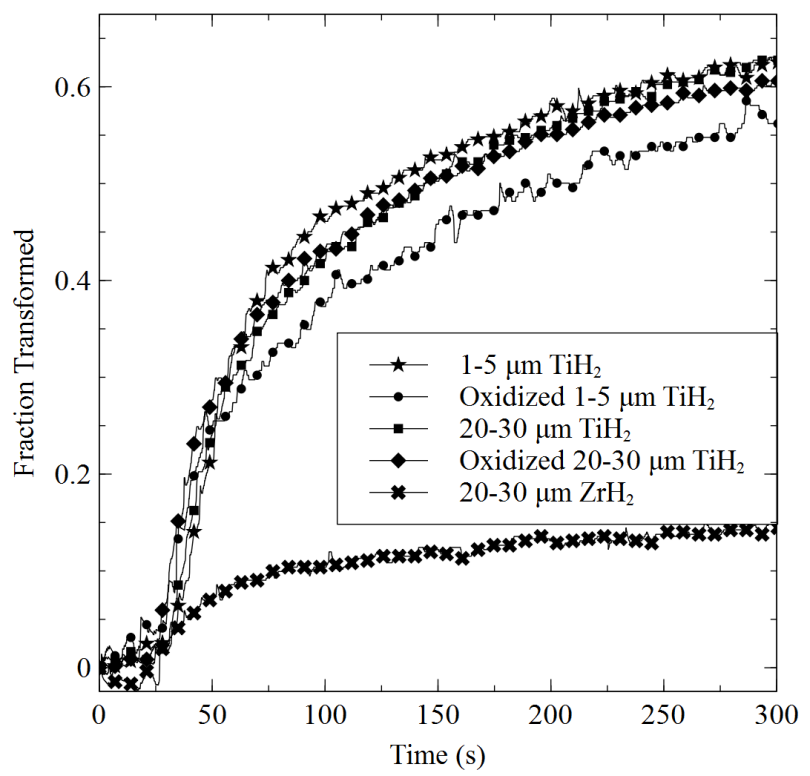

Figure 6.13: Comparison of all materials run at $933 \mathrm{~K}\left(660^{\circ} \mathrm{C}\right)$ hold temperatures. Only the $\mathrm{ZrH}_{2}$ exhibited different decomposition characteristics.



Figure 6.14: Comparison of all materials run at $1003 \mathrm{~K}\left(730^{\circ} \mathrm{C}\right)$ hold temperatures. Only $\mathrm{ZrH}_{2}$ exhibited significantly different decomposition characteristics. 


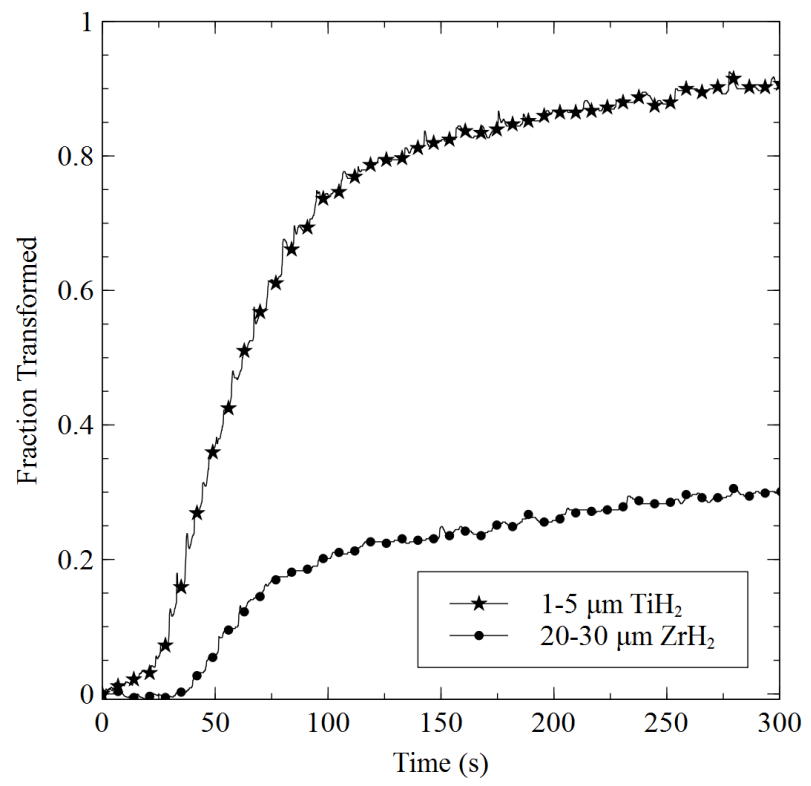

Figure 6.15: Comparison of all materials run at $1073 \mathrm{~K}\left(800^{\circ} \mathrm{C}\right)$ hold temperatures. $\mathrm{ZrH}_{2}$ decomposed much more slowly than $\mathrm{TiH}_{2}$.

Examining the powders under SEM after decomposition, several very large agglomerations of particles were observed in the $1-5 \mu \mathrm{m} \mathrm{TiH}_{1.98}$ powders at $933 \mathrm{~K}$ $\left(660^{\circ} \mathrm{C}\right)$ (Figure 6.16), indicating that sintering may be occurring. As with the initial powders, all decomposed hydrides exhibited cracks and fissures in addition to varying amounts of fine particulate. No direct evidence of thermal shock damage to the powders was manifested through additional cracks or a higher number of fine particulate. The fine particulate appeared more globular and in the case of the $20-30 \mu \mathrm{m} \mathrm{TiH}_{1.98}$ powders processed at $933 \mathrm{~K}\left(660^{\circ} \mathrm{C}\right)$, the fine particulate bonded to the larger particles (Figure $6.17)$. 


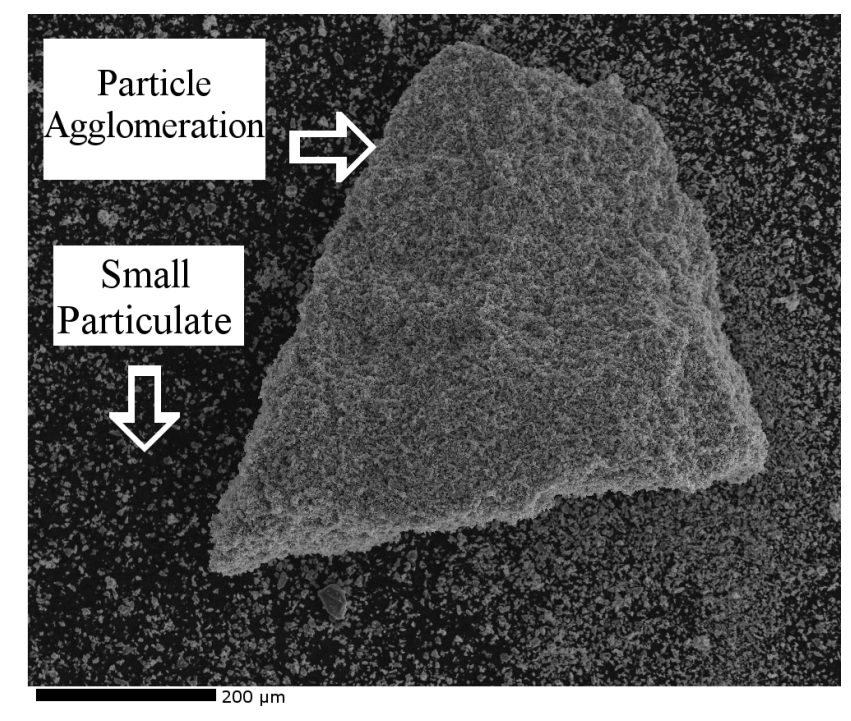

Figure 6.16: Agglomeration of 1-5 $\mu \mathrm{m} \mathrm{TiH}_{1.98}$ after decomposition at $933 \mathrm{~K}\left(660^{\circ} \mathrm{C}\right)$ for 300 seconds. These agglomerations indicate some degree of sintering during testing which may influence decomposition behavior via reduction of particle surface area to volume ratios.

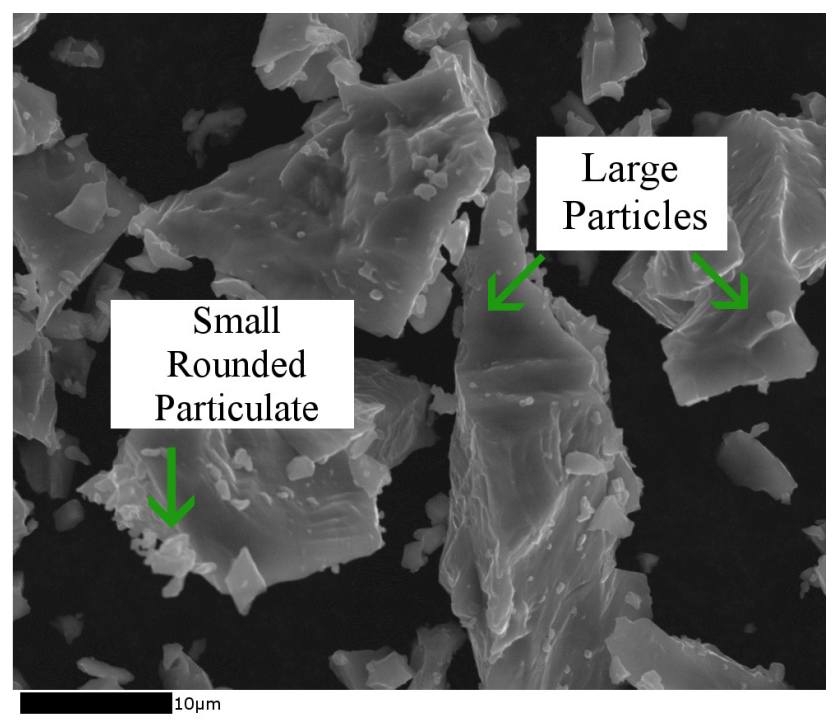

Figure 6.17: Rounded particulate attached to larger particles in 20-30 $\mu \mathrm{m} \mathrm{TiH}_{1.98}$ decomposed at $933 \mathrm{~K}\left(660^{\circ} \mathrm{C}\right)$ for 300 seconds. This is evidence that the morphology of particles change during decomposition at elevated temperature, and may influence decomposition. 


\subsection{Kinetic Modeling}

While the raw data helps to illustrate key differences in hydride decomposition kinetics between materials, it is necessary estimate kinetic behavior for more general cases through application of modeling techniques. There are several methodologies available for generating models from experimental data with the goal of determining the so called kinetic triplet which includes the reaction model, $f(\alpha)$, pre-exponential factor, A, and activation energy, $\mathrm{E}_{\mathrm{a}}$. The currently favored technique suggested by the International Confederation for Thermal Analysis and Calorimetry (ICTAC) is to make use of model

free analysis methods. ${ }^{[63]}$ In model free methods, it is assumed that the decomposition model is independent of decomposition temperature enabling the calculation of activation energies as a function of conversion fraction, $\alpha$. This methodology requires the ability to actively control heating rates during experiments in order to solve for activation energies and extremely repeatable data.

Unfortunately, in the current study, the arc image analyzer was not capable of repeatable heating rate control. Another limitation on the equipment was lack of automated control. This made it impractical to run tests at lower hold temperatures to achieve half life time estimations for use in isoconversional methods. As a result of this, a force fitting approach was used in order to provide rough estimates of the kinetic triplets. While this methodology suffers from statistical limitations ${ }^{[66]}$, due to the nature of the data gathered it was the most appropriate method for analyzing the data. 
In order to model experimental kinetic data, the first derivative of the conversion fraction, $\alpha$, with time is assumed to follow an Arrhenius type relation multiplied by a reaction model, $\mathrm{f}(\alpha)$ (Equation 6.2).

$$
\frac{d \alpha}{d t}=A e^{\left(-E_{a} / R T\right)} f(\alpha)
$$

where $\mathrm{A}$ is the pre-exponential factor, $\mathrm{E}_{\mathrm{a}}$ is the activation energy, $\mathrm{R}$ is the ideal gas constant, and $\mathrm{T}$ is the temperature. In the case of the current study, the thermogravimetric mass loss was converted to conversion fraction, $\alpha$, through use of Equation 6.1.

For non-isothermal experiments of constant heating rate, $\beta$, Equation 6.2 may be rearranged with a change of variable (from time to temperature) to give the nonisothermal reaction relation, Equation 6.3.

$$
\frac{d \alpha}{d T}=\frac{A}{\beta} e^{\left(-E_{a} / R T\right)} f(\alpha)
$$

In order to analyze thermogravimetric data it is more convenient to utilize the integral form of Equations 6.2-6.3 which may be obtained by separating variables and integrating. In the case of isothermal experiments the resulting equation has a straightforward form (Equation 6.4).

$$
g(\alpha)=A e^{\left(-E_{a} / R T\right)} t
$$

for non-isothermal experiments the integral form is (Equation 6.5), 


$$
g(\alpha)=\frac{A}{\beta} \int_{0}^{T} e^{\left(-E_{a} / R T\right)} d T
$$

In Equations 6.4-6.5, $\mathrm{g}(\alpha)$ is the integral form of the reaction model $\mathrm{f}(\alpha)$. The Senum Yang approximation ${ }^{[67]}$ was used to calculated the integral quantity in Equation 6.5 and allow convergence to realistic fit parameters. Table 6.4 summarizes integral forms of the reaction models used to fit the data generated in the current study.

Table 6.4: Integral forms of the models used to fit data in the current study. ${ }^{[6]}$

\begin{tabular}{lcc}
\hline Model & Designation & $\mathbf{g}(\boldsymbol{\alpha})$ \\
\hline Power Law (2nd order) & P2 & $\alpha^{1 / 2}$ \\
Power Law (3rd order) & P3 & $\alpha^{1 / 3}$ \\
Power Law (4th order) & P4 & $\alpha^{1 / 4}$ \\
Avrami-Erofeyev (n=2) & A2 & {$[-\ln (1-\alpha)]^{1 / 2}$} \\
Avrami-Erofeyev (n=3) & A3 & {$[-\ln (1-\alpha)]^{1 / 3}$} \\
Avrami-Erofeyev (n=4) & A4 & {$[-\ln (1-\alpha)]^{1 / 4}$} \\
Contracting Area & R2 & $1-(1-\alpha)^{1 / 2}$ \\
Contracting Sphere & R3 & $1-(1-\alpha)^{1 / 3}$ \\
1D-Diffusion & D1 & $\alpha^{2}$ \\
2D-Diffusion & D2 & $((1-\alpha) \ln (1-\alpha))+\alpha$ \\
3D-Diffusion (Jander) & D3 & $\left(1-(1-\alpha)^{1 / 3}\right)^{2}$ \\
Ginstling-Brounshtein & D4 & $1-(2 / 3) \alpha-(1-\alpha)^{2-3}$ \\
Zero Order Reaction & F0 & $\alpha$ \\
First Order Reaction & F1 & $-\ln (1-\alpha)$ \\
Second Order Reaction & F2 & {$[1 /(1-\alpha)]-1$} \\
Third Order Reaction & F3 & $(1 / 2)\left[(1-\alpha)^{-2}-1\right]$ \\
\hline
\end{tabular}

Due to the fact that the thermal profile used in all trials consisted of a nonisothermal ramp and isothermal hold, data sets were subdivided into these respective portions, transformed according to the various reaction models in Table 6.4 and fit using Wolfram Mathematica's nonlinear model fitting algorithms in order to find estimates of $A$ and $E_{a}$ according to Equations 6.4-6.5. Since the reaction had proceeded moderately before the isothermal hold, the isothermal data were shifted down to zero in order to 
account for this and provide a more accurate fit without introducing additional fit terms. The ranges of conversion over which the data were fit are included since this may have an impact on the applicability of the kinetic triplets obtained. The $\mathrm{R}^{2}$ value was used as the measure for best fit, along with visually checking every fit alongside the experimental data.

The average range of conversion fractions over which both the non-isothermal and isothermal data were fit are summarized in Table 6.5. The non-isothermal data were subjected to a considerable amount of scatter due to the low signal to noise ratio at small mass losses. Due to this fact, the kinetic triplets for this section of the curve are relatively unreliable and did not show a consistent trend.

Table 6.5: Average conversion fractions ranges over which model fits were employed.

\begin{tabular}{|l|c|c|c|c|c|}
\cline { 3 - 6 } \multicolumn{2}{c|}{} & \multicolumn{2}{c|}{ Non-Isothermal } & \multicolumn{2}{c|}{ Isothermal } \\
\hline \multirow{3}{*}{ Material } & $\mathrm{T}_{\text {Hold }}(\mathrm{K})$ & $\alpha_{\text {Min }}$ & $\alpha_{\text {Max }}$ & $\alpha_{\text {Min }}$ & $\alpha_{\text {Max }}$ \\
\cline { 2 - 6 } $\mathrm{TiH}_{2}$ & 873 & 0 & 0.25 & 0.25 & 0.64 \\
\cline { 2 - 6 } & 933 & 0 & 0.18 & 0.18 & 0.65 \\
\cline { 2 - 6 } & 1003 & 0 & 0.44 & 0.44 & 0.82 \\
\hline $20-30 \mu \mathrm{m} \mathrm{TiH}$ & 1073 & 0 & 0.67 & 0.67 & 0.94 \\
\hline Oxidized 1-5 $\mu \mathrm{m} \mathrm{TiH}_{2}$ & 933 & 0 & 0.22 & 0.22 & 0.65 \\
\cline { 2 - 6 } & 873 & 0 & 0.04 & 0.04 & 0.45 \\
\cline { 2 - 6 } & 933 & 0 & 0.10 & 0.10 & 0.60 \\
\hline Oxidized 20-30 $\mu \mathrm{m} \mathrm{TiH}_{2}$ & 1003 & 0 & 0.45 & 0.45 & 0.86 \\
\hline \multirow{2}{*}{$20-30 \mu \mathrm{m} \mathrm{ZrH}_{2}$} & 933 & 0 & 0.19 & 0.19 & 0.64 \\
\cline { 2 - 6 } & 933 & 0 & 0.12 & 0.12 & 0.21 \\
\cline { 2 - 6 } & 1003 & 0 & 0.15 & 0.15 & 0.24 \\
\hline
\end{tabular}

The isothermal data fit very consistently to a 3-D diffusion limited Jander model for the $\mathrm{TiH}_{1.98}$ samples of all particle size and treatments. . A 1-D diffusion limited model for the $\mathrm{ZrH}_{2}$ specimens was found in all cases to be the best fit for this data set. 
Though not all $\mathrm{TiH}_{1.98}$ trials followed the Jander equations these fits were still very good and were used in the determination of average activation energies and pre-exponential factors. An example model construction is provided in Figure 6.18 for a $1-5 \mu \mathrm{m} \mathrm{TiH} 1.98$ trial. There was some systematic underestimation of the experimental data potentially resulting from round off error propagating through the exponential terms.

The averages for both activation energy and pre-exponential factors are included in Table 6.6. In alignment with experimental decomposition curves, there were no statistically significant differences between 1-5 $\mu \mathrm{miH}_{1.98}, 20-30 \mu \mathrm{m} \mathrm{TiH}{ }_{1.98}$ and oxidized 20-30 $\mu \mathrm{m} \mathrm{TiH} \mathrm{H}_{1.98}$ activation energies or pre-exponential factors. The activation energies range for these model fits $(35-38 \mathrm{~kJ} / \mathrm{mol})$ are significantly lower than values reported in other works as shown in Table 6.6. The activation energies found for hydrogen diffusion in $\alpha$-Ti is estimated between $40-50 \mathrm{~kJ} / \mathrm{mol}^{\left[{ }^{[68]}\right.}$ The estimated activation energies for $\mathrm{TiH}_{1.98}$ are very close to this value indicating that diffusion controlled decomposition takes place.

In the case of oxidized 1-5 $\mu \mathrm{m} \mathrm{TiH}_{1.98}$, the activation energy and pre-exponential factors were higher than other $\mathrm{TiH}_{1.98}$ specimens. This trend is in agreement with the results of others ${ }^{[47]}$ and supports the intended effect of oxidizing treatments, i.e. the minimization of gas evolution rate and associated turbulence during foam processing. The $\mathrm{ZrH}_{2}$ specimens obeyed a different reaction model than $\mathrm{TiH}_{2}$ as well as results from literature for its low ramp rate decomposition ${ }^{[54,59]}$, therefore direct comparisons of kinetic parameters are not valid; however the activation energy and pre-exponential factor were such that the comparatively sluggish decomposition kinetics were apparent. 
With regard to foam processing, the results above indicate that hydride decomposition kinetics are sensitive to heating rate. Heating rate was not a controllable factor in the current study, therefore it is suggested for future work that hydride decomposition be studied at intermediate heating rates $(100-500 \mathrm{~K} / \mathrm{min})$ in order to better elucidate the influence of heating rate on decomposition kinetics. This data could then be used to extrapolate decomposition behavior to aluminum foam processing conditions.

Table 6.6: Average values for pre-exponential factors and activation energies for modeled isothermal portions of kinetic data. (+/-) values represent $95 \%$ confidence interval constructions.

\begin{tabular}{|c|c|c|c|c|c|c|}
\hline Powder Type & Model & $\begin{array}{c}\operatorname{Avg} . A \\
\left(s^{-1}\right)\end{array}$ & $\begin{array}{l}+/- \\
\left(s^{-1}\right)\end{array}$ & $\begin{array}{r}\text { Avg. } E_{a} \\
(\mathrm{~kJ} / \mathrm{mol})\end{array}$ & $\begin{array}{c}+/- \\
(\mathrm{kJ} / \mathrm{mol})\end{array}$ & $\begin{array}{c}\text { Lit. } \mathbf{E}_{\mathbf{a}} \\
(\mathbf{k J} / \mathbf{m o l})^{*}\end{array}$ \\
\hline $1-5 \mu \mathrm{m} \mathrm{TiH}_{1.98}$ & D3 & 0.0091 & 0.0059 & 35 & 3.5 & $\begin{array}{c}63-100^{[28}, \\
47,69]\end{array}$ \\
\hline $\begin{array}{l}\text { Oxidized } \\
1-5 \mu \mathrm{m} \mathrm{TiH} \mathrm{T}_{1.98}\end{array}$ & D3 & 0.027 & 0.0090 & 47 & 7.9 & $120^{\lfloor 47]}$ \\
\hline $\begin{array}{l}20-30 \mu \mathrm{m} \\
\mathrm{TiH}_{1.98}\end{array}$ & D3 & 0.025 & $0.036^{*}$ & 38 & 8.5 & $63-100$ \\
\hline $\begin{array}{l}\text { Oxidized } \\
20-30 \mu \mathrm{m} \\
\mathrm{TiH}_{1.98}\end{array}$ & D3 & 0.011 & 0.0066 & 36 & 0.21 & 120 \\
\hline $20-30 \mu \mathrm{m} \mathrm{ZrH}_{2}$ & D1 & 0.0082 & 0.0043 & 40 & 3.2 & 205 \\
\hline
\end{tabular}




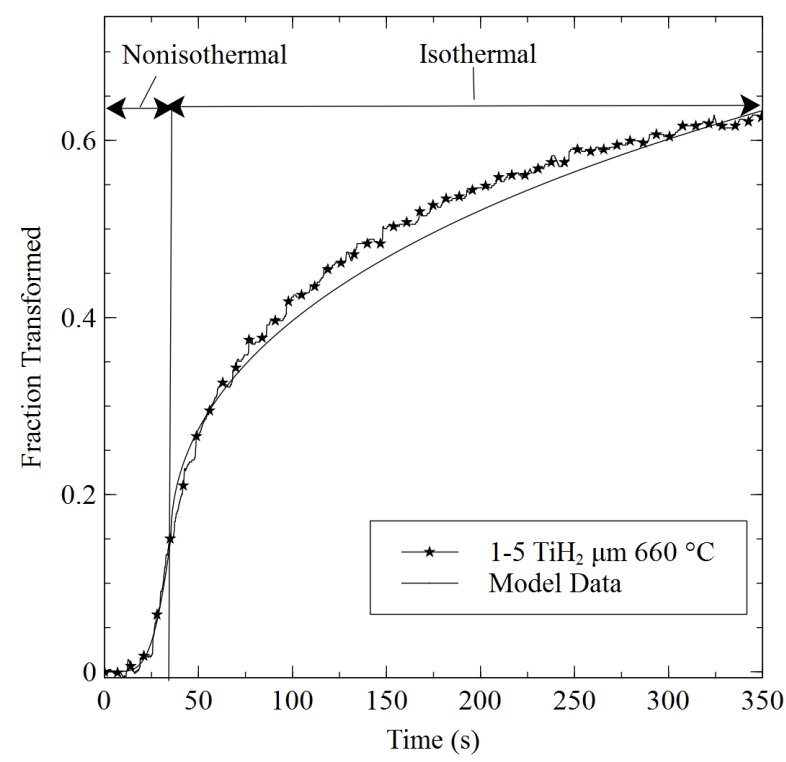

Figure 6.18: Example fit of raw data using force fitting procedures. Run 3-3 corresponds to $1-5 \mu \mathrm{m} \mathrm{TiH}{ }_{1.98}$ held at $933 \mathrm{~K}\left(660^{\circ} \mathrm{C}\right)$.

\subsection{Summary and Conclusions}

The high heating rate decomposition of several hydrides important to metal foam processing has been characterized using a unique thermo-gravimetric analyzer. The experimental data agree with decomposition models found throughout the literature, however the magnitude of the decomposition rates are significantly greater than most reported values. Modeling results of non-isothermal sections of the data yielded limited agreement from sample to sample on kinetic triplet, but isothermal data yielded very consistent model fits allowing the determination of kinetic parameters for comparison to other studies. The models that were found to fit the isothermal data were in agreement with other works on the same materials; however the activation energy and preexponential frequency factors were such that decomposition progressed more quickly. It 
is recommended that intermediate heating rate experiments be carried out in order to elucidate decomposition responses to different heating rates. 


\subsection{General Model of Gasarite Growth via Thermal Decomposition}

\subsection{Introduction}

As outlined in the preliminary model, there are three different mechanisms that promote pore formation and growth in thermal decomposition processing. These formation mechanisms include gas-metal eutectic growth, bubble capture, and direct gas evolution. Each pore growth mechanism is governed by different physical relations. As shown in Chapter 2, all three pore formation modes rely heavily on the determination of the gas evolution rate from the decomposing particulate. The gas evolution rate may be estimated by utilizing model fits for decomposition data produced in Chapter 6 and experimental thermocouple data from the first five $12.7 \mathrm{~mm}$ sections from the chill surface. Maximum porosity levels were estimated through the physical relations that govern each pore formation mode and compared to experimental values. Porosity estimates were then used to weigh the contribution of each pore formation mode to overall pore formation by comparison to experiments.

\subsection{Gas Evolution Quantification}

Before presenting the physical relations for different pore formation modes, it is necessary to obtain estimates for the fraction of hydride that transforms to produce gas. These estimates were determined from experimental cooling curves (Figure 7.1) in conjunction with the model parameters from Chapter 6 (Table 6.6). It is assumed that

any hydride that is introduced from the crucible additions evolves gas at the same rate as hydride that comes from the mold packet. The implication of this assumption is that the 
crucible hydrides are still in the early stages of decomposition, which is not likely. Since no reliable thermal data within the crucible (due to radiation of graphite causing temperature overestimation and no pyrometer data logging capability) this is a necessary assumption.

The cooling curves were taken from data sets used to calculate solidification velocities in Chapter 3 (Figure 3.3). Since there were only five thermocouple attachments available only the first five sections will be evaluated in the current treatment. In order to estimate the extent of conversion ( $\alpha$ in wt.\%), thermal profiles were broken into a series of isothermal steps. Within each of the five sections, the temperature profile is assumed to be uniform. It is also assumed that no transport of hydride occurs between sections. Unless otherwise stated hydride is assumed to distribute evenly across all ten $12.7 \mathrm{~mm}$ thick sections ( $0.04 \mathrm{~g} / \mathrm{section})$. The decomposition point of $\mathrm{TiH}_{2}$ is $733 \mathrm{~K}\left(460^{\circ} \mathrm{C}\right)$ and that of $\mathrm{ZrH}_{2}$ is $773 \mathrm{~K}\left(530^{\circ} \mathrm{C}\right) .{ }^{[28,70]}$ These values served to limit the time interval of hydride decomposition. Gas production begins when the hydride is raised above its decomposition point and halts when the thermocouple data falls below this value. 


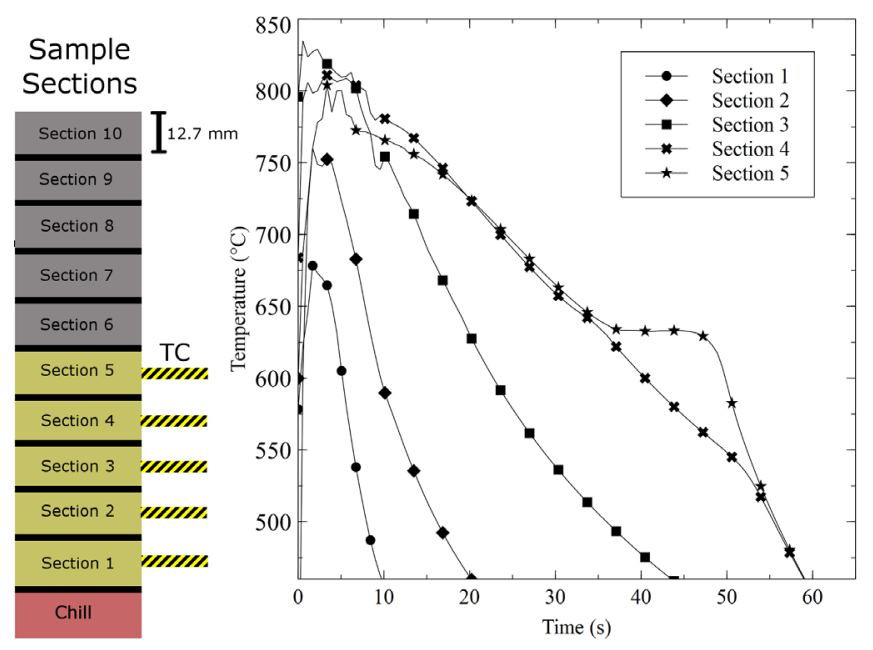

Figure 7.1: Schematic of sample sections and thermocouple profiles used for estimation of gas evolution. Data point markers on the graph are thinned so they are easily identified.

From Chapter 6, the integral form of the reaction model is expressed as (Equation $7.1)$

$$
g(\alpha)=A e^{\left(-E_{a} / R T\right)} t
$$

Using the best fit models from experiments, the conversion fraction may be determined by solving $\mathrm{g}(\alpha)$ in terms of the activation energy, pre-exponential factor, time and temperature (Equation 7.2).

$$
\alpha=f_{\text {Model }}(T, t)
$$

where $f_{\text {Model }}(T, t)$ is the integral form of the reaction model solved for conversion fraction. For the D3 (three dimensional diffusion), and D1 (one dimensional diffusion) models that fit the $\mathrm{TiH}_{2}$ and $\mathrm{ZrH}_{2}$ decomposition respectively, $\mathrm{f}_{\text {Model }}(\mathrm{T}, \mathrm{t})$ takes the form shown below (Equations 7.3-7.4), 


$$
\begin{aligned}
f_{D 3}(T, t) & =1-\left(1-\sqrt{A e^{\left(-E_{a} / R T\right)} t}\right)^{3} \\
f_{D 1}(T, t) & =\sqrt{A e^{\left(-E_{a} / R T\right)} t}
\end{aligned}
$$

Changes in conversion fraction, $\Delta \alpha_{\mathrm{i}}$, may be calculated as shown in Equation 7.5. The time span (Equation 7.6), and temperature, $\mathrm{T}_{\mathrm{i}}$, used to calculate change in conversion fraction was determined by the thermocouple sampling rate ( $0.56 \mathrm{~s})$ and cooling curve data.

$$
\begin{gathered}
\Delta \alpha_{i}=f_{\text {Model }}\left(T_{i}, t_{i+1}\right)-f_{\text {Model }}\left(T_{i}, t_{i}\right) \\
\Delta t=t_{i+1}-t_{i}=0.56 \mathrm{~s}
\end{gathered}
$$

The total fraction transformed is equal to the sum of all $\Delta \alpha_{i}$ for which $T_{i}$ remains above the decomposition point of the material (Equation 7.7).

$$
\alpha_{T}=\sum_{i} \Delta \alpha_{i},\left(T_{i} \geq T_{D}\right)
$$

Using these equations and the kinetic data for $20-30 \mu \mathrm{m} \mathrm{TiH}_{2}$ and $\mathrm{ZrH}_{2}$ from Table 6.6, the conversion fraction for hydrides contained within the first five $12.7 \mathrm{~mm}$ thick sections were estimated and compared to experimental porosity levels. (Figure 7.2-Figure 7.3). 


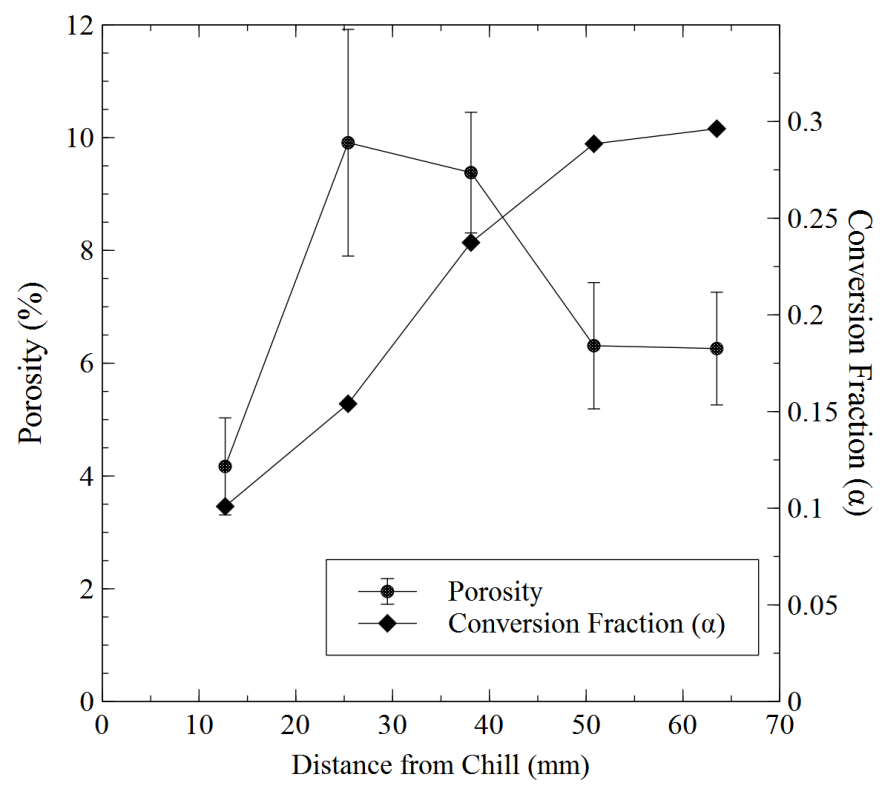

Figure 7.2: Calculated conversion fractions compared to sectional porosities for $\mathrm{TiH}_{2}$ specimens.

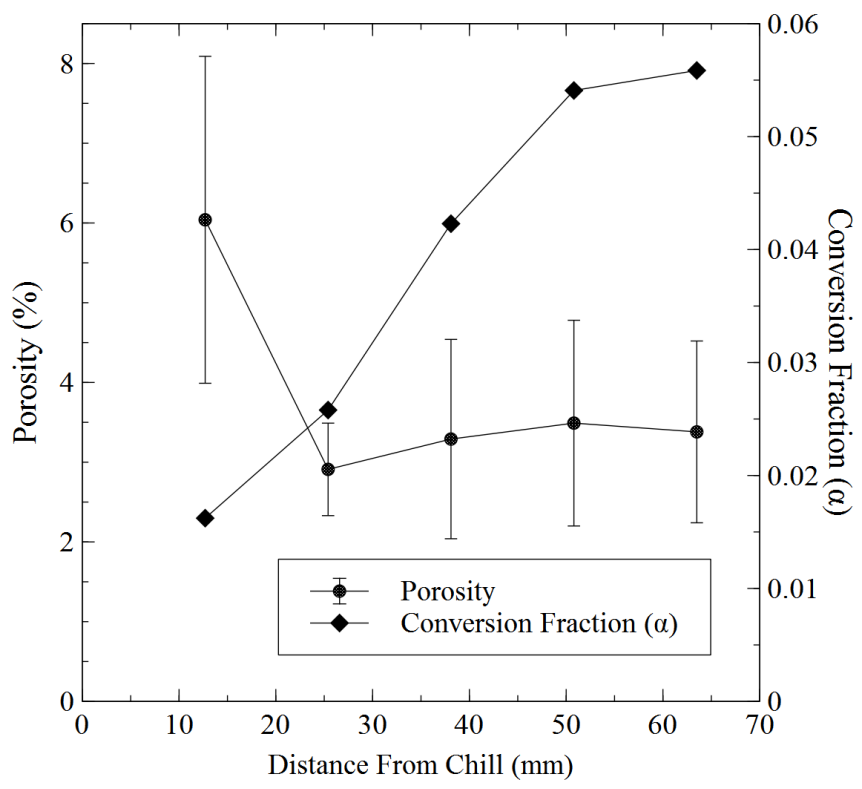

Figure 7.3: Calculated conversion fractions compared to sectional porosities for $\mathrm{ZrH}_{2}$. Error bars on experimental data are standard errors.

The porosity profiles do not correlate directly to conversion fraction profiles for either powder type. For $\mathrm{TiH}_{2}$ the porosity profile reaches a maximum of $9.9 \%$ at 25.4 
$\mathrm{mm}$ from the chill, then drops to $6 \%$ in sections above $38.1 \mathrm{~mm}$ from the chill. The conversion fraction continuously increases with distance from the chill plate due to the longer times above the hydride decomposition temperature. In the case of $\mathrm{TiH}_{2}$, porosity decreases at $38.1 \mathrm{~mm}$ from the chill despite higher estimated conversion fraction in this section, which may indicate gas escape due to slow solidification (see Figure 3.3). Higher porosity in the $25.4-38.1 \mathrm{~mm}$ sections may also indicate that greater amounts of $\mathrm{TiH}_{2}$ settled into these sections. For $\mathrm{ZrH}_{2}$, porosity levels are high within the first 12.7 $\mathrm{mm}$ section then fall significantly in all subsequent sections. Again conversion fraction is constantly increasing as a function of distance from the chill plate, but at magnitudes much less than $\mathrm{TiH}_{2}$. The porosity level in the first section of $\mathrm{ZrH}_{2}$ specimens was significantly higher than all other sections despite much smaller conversion fractions. This indicates that more hydride mass must have resided in this section assuming all other factors (gas escape etc) are equal. This indicates that $\mathrm{ZrH}_{2}$ does not disperse as well as $\mathrm{TiH}_{2}$. This is most likely due to the higher density $\left(5.60 \mathrm{~g} / \mathrm{cm}^{3}\right)$ of this particle type than $\mathrm{TiH}_{2}\left(3.75 \mathrm{~g} / \mathrm{cm}^{3}\right)$.

It is possible to estimate the amount of gas within each section by multiplying the Archimedes sectional porosity determined in Chapter $5, \mathrm{f}_{\mathrm{p}-\mathrm{s}}$, by the section volume $\left(\mathrm{V}_{\mathrm{s}}\right)$ (Equation 7.8).

$$
V_{p-s}=f_{p-s} V_{s}=f_{p} \pi r_{s}^{2} h_{s}
$$

where $\mathrm{r}_{\mathrm{s}}=\mathrm{h}_{\mathrm{s}}=12.7 \mathrm{~mm}$ for samples analyzed in the current study. The calculated conversion fractions may then be used to determine the hydride mass required to produce 
gas volumes consistent with porosity levels. This method may be used to assess the assumption of uniform powder dispersion directly by determining the hydride mass profile.

Assuming pores form at the melting temperature of aluminum $\left(\mathrm{T}_{\mathrm{m}}=933 \mathrm{~K}\right)$ under the sum of the inert gas pressure $\left(\mathrm{P}_{\mathrm{Ext}}=0.05 \mathrm{~atm}\right)$ plus the section's hydrostatic head(Equation 2.3); the number of moles of gas contained within the pores, $\mathrm{n}_{\mathrm{s}}$, may be estimated using the ideal gas law (Equation 7.9). It is also assumed that no gas escape occurs.

$$
n_{s}=\frac{P_{s} V_{p-s}}{R T_{m}}
$$

The mass of hydride $\left(\mathrm{m}_{\mathrm{s}}\right)$ contained within each section may be estimated using the molar mass of the hydride $\left(\mathrm{m}_{\mathrm{M}}=49.9 \mathrm{~g} / \mathrm{mol}\right.$ for $\mathrm{TiH}_{2}, 93.2 \mathrm{~g} / \mathrm{mol}$ for $\left.\mathrm{ZrH}_{2}\right)$ and the extent of conversion for the section, $\alpha_{\mathrm{s}}$ (Equation 7.10).

$$
m_{s}=\frac{n_{s} m_{M}}{\alpha_{s}}
$$

The use of molar mass above implies a single step decomposition reaction with each mole of $\mathrm{TiH}_{2}$ yielding one mole of $\mathrm{H}_{2}$ gas. Using Equation 7.10, mass estimates have been calculated for both $\mathrm{TiH}_{2}$ and $\mathrm{ZrH}_{2}$ foamed specimens (Figure 7.4). Sectional masses calculated for $\mathrm{TiH}_{2}$ are much more uniform than those for $\mathrm{ZrH}_{2}$ in which the first 
sectional mass was a factor of ten greater than other sections. In the case of $\mathrm{ZrH}_{2}$ this calculation provides further indication of incomplete dispersion.

The total mass of hydride calculated above is significantly lower than the mass added to the system $\left(0.4 \mathrm{~g}\right.$ added vs. $0.0006 \mathrm{~g}$ to form pores using $\mathrm{TiH}_{2}$ and $0.74 \mathrm{~g}$ added vs. $0.004 \mathrm{~g}$ to form pores using $\mathrm{ZrH}_{2}$ ). The influence of hydride mass on porosity has been investigated ${ }^{[20]}$ and was shown to plateau with increasing hydride mass (from 0.05$0.2 \mathrm{~g}$ ). The above calculations disagree with this result, indicating that much more hydride has been added than necessary. One explanation for disagreement between experiments and the calculations above is that gas escape occurs during pore formation. In order to compensate for gas escape, additional hydride additions are likely required explaining the need for much higher additions. Gas escape was clearly observed during of the decomposition reaction after pouring and will be quantified when examining the bubble capture mechanism below.

With estimates of conversion fractions, it is possible to estimate porosity levels for each pore formation mode. Due to the calculated homogeneity of $\mathrm{TiH}_{2}$ within foamed samples above (allowing the assumption of uniform dispersion) and its use as the primary hydride gas source throughout the current study, each pore formation mode will be evaluated using $\mathrm{TiH}_{2}$ based calculations and experimental data. 


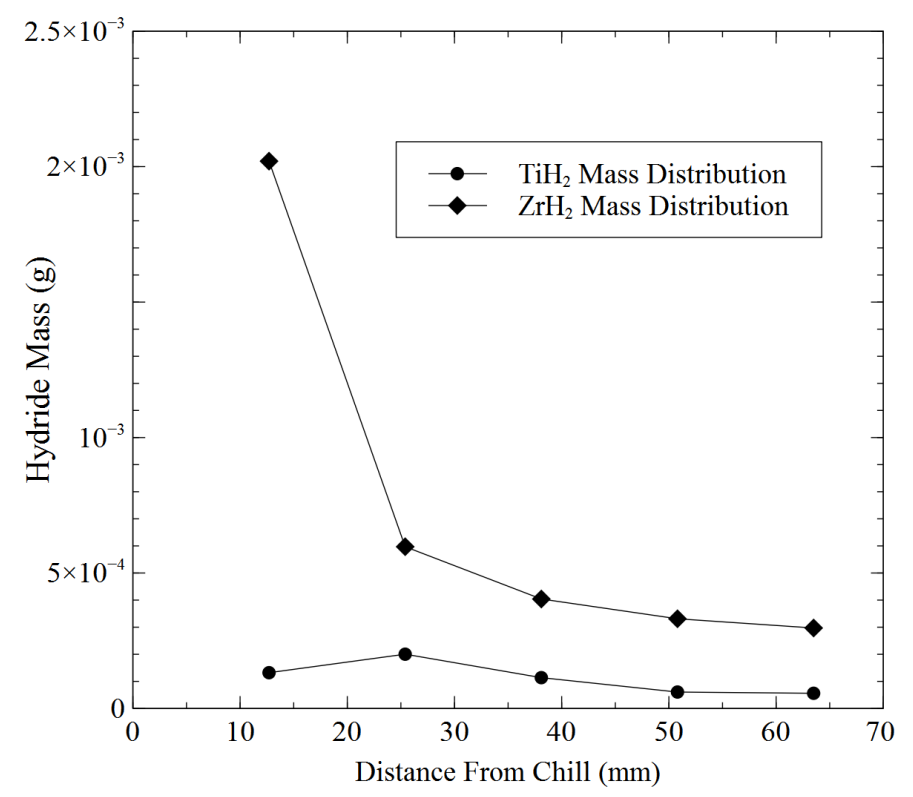

Figure 7.4: Estimate of the required hydride mass to produce the observed porosity in the first five sections above the chill plate. It appears that $\mathrm{TiH}_{2}$ has a more homogeneous mass distribution than $\mathrm{ZrH}_{2}$. Total masses were low compared to the hydride additions during processing.

\subsection{Gas-metal Eutectic Growth}

The classical model for eutectic growth is that of Jackson and Hunt originally published in 1966 and refined multiple times over the course of the past several decades. ${ }^{[71-73]}$ Both Drenchev and Liu have proposed applications of this model to gas metal eutectic growth by combining it with the ideal gas law in order to estimate pore volumes, sizes, and spacing. ${ }^{[56,74]}$ Due to the stochastic nature of the thermal decomposition process, the application of these methods to the current study is invalid. This was apparent from the lack of experimental trends linking pore spacing to solidification front velocity in Chapter 5. The method that will be used to evaluate gasmetal eutectic growth in the current study involves its link to the solubility of gas within 
the molten metal. As stated in Chapter 2, many gases (including hydrogen) dissolve into molten metal according to Sieverts' Law (Equation 7.11). Porosity levels may then be estimated by applying the set of equations (Equations 7.12-15) below.

$$
\begin{gathered}
C_{H-\text { local }}=K_{H-A l} \sqrt{P_{H}} \\
P_{H}=P_{\text {Head }}+P_{E x t} \\
P_{\text {Head }}=\rho_{f} g z \\
C_{H-\text { Operating }}=C_{H}\left(\frac{T_{m}}{298 K}\right)\left(\frac{1 \text { atm }}{P_{\text {Ext }}+P_{\text {Head }}}\right) \\
f_{p}=\frac{V_{p}}{V_{p}+V_{m}}=\frac{C_{H-\text { Operating }}}{C_{H-\text { Operating }}+\frac{1}{\rho_{l}}}
\end{gathered}
$$

It is first necessary to determine if enough gas has been generated from hydride to saturate the molten aluminum. In order to calculate this, the conversion fraction calculation from above is utilized, but only calculated for the range of time over which the aluminum was molten (i.e. none of the gas evolved after solidification can go into solution). The total number of moles of gas necessary to saturate a section may be calculated using Equation 7.16.

$$
n_{s}=\frac{C_{H-\text { Operating }} \rho_{l} V_{s} P_{s}}{R T_{m}}
$$


Using this equation and conversion fraction calculations with the assumption of uniform dispersion (i.e. $\mathrm{m}_{\mathrm{s}}=0.4 \mathrm{~g} / 10=0.04 \mathrm{~g}$ ), the amount of gas required to saturated each section is presented alongside the number of moles of gas released (Figure 7.5).

According to these estimations the amount of gas evolved is roughly 100-500 times that needed to saturate each section making the gas metal eutectic growth a possibility.

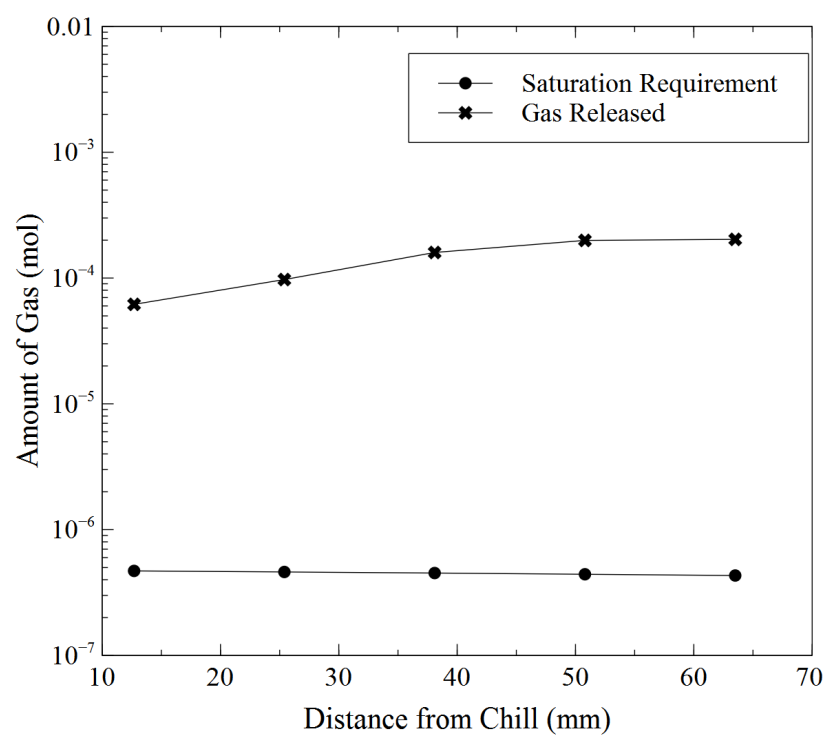

Figure 7.5: Calculated solubility requirements (in moles of gas) plotted alongside the number of moles of gas evolved from $\mathrm{TiH}_{2}$ assuming uniform powder dispersion over the entire $127 \mathrm{~mm}$ long sample. The gas released is approximately 100-500 times that necessary to saturate the solution.

Once again operating under the assumption of zero gas escape for simplicity, the porosity levels predicted by the equations for each section (with an inert gas pressure of $0.05 \mathrm{~atm}$ and pore formation at the melting point of aluminum, $933 \mathrm{~K}$ ) are presented below (Figure 7.6). Within the first three sections there is significant disagreement between calculated porosity levels and those observed during experiments. The first 
section significantly overestimates porosity, while porosity levels in the next two sections are well above estimations. Under the assumption of no gas escape, the calculations should overestimate porosity; therefore it is likely in these sections other pore formation modes are contributing. In sections further from the chill, which may have more opportunity to achieve steady state growth, the experimental porosity levels and estimations are more aligned which could indicate the dominance of pore formation via gas-metal eutectic growth. It should be noted that diffusion limited spacing and size trends were not experimentally observed therefore a non-equilibrium growth mode would be expected if gas metal eutectic growth occurs. Under the assumption of nonequilibrium growth conditions it appears as though gas metal eutectic may contribute to pore formation; however additional pore growth modes must be examined in order to determine whether they may also reflect experimental trends.

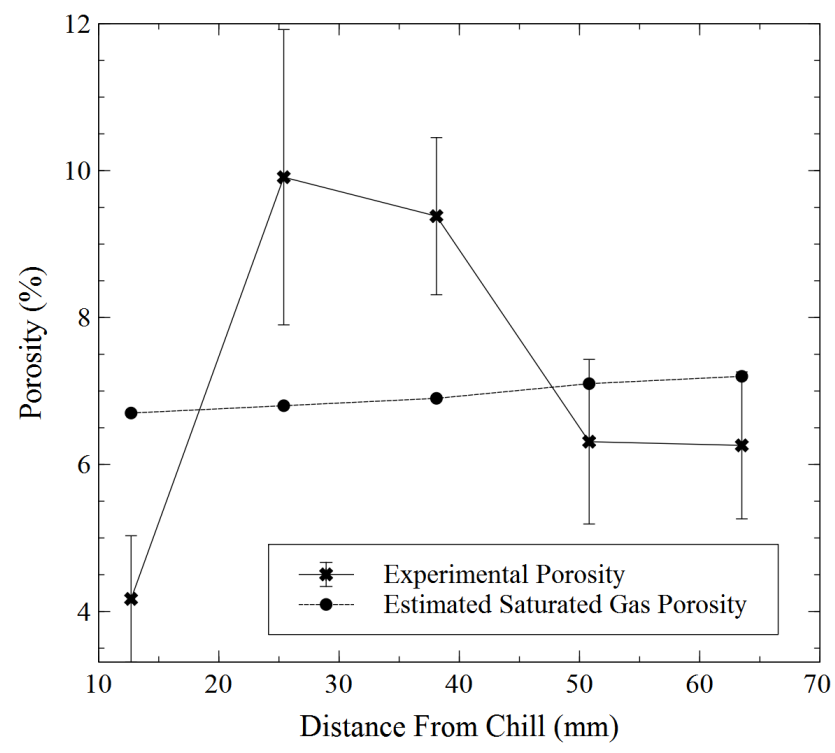

Figure 7.6: Comparison of porosity levels observed in $\mathrm{TiH}_{2}$ experiments with those estimated using the saturation limits of hydrogen in molten aluminum. Error bars 
represent standard errors. Initially there is some disagreement with calculations, but as distance from the chill is increased, the differences between calculations and experiments decreases.

\subsection{Bubble Capture}

As shown in Chapter 2, the bubble capture pore growth mode is highly dependent on the balance between solidification front velocity and bubble velocity. Specifically, this pore growth mode dictates that the path of the bubble and path of the solidification front must intersect over time in order to form tubular pores. For the current treatment, analogous treatments of bubble rise within aqueous systems will be utilized to estimate whether or not this can occur. A review of these treatments has been recently published. ${ }^{[75]}$ The geometry utilized in these treatments involves a submerged orifice as the gas source as opposed to decomposing particulate. In order to apply these treatments to a decomposing particle, the bubble the configuration shown in Figure 7.7 is assumed yielding similar conditions similar to those found for submerged orifices.

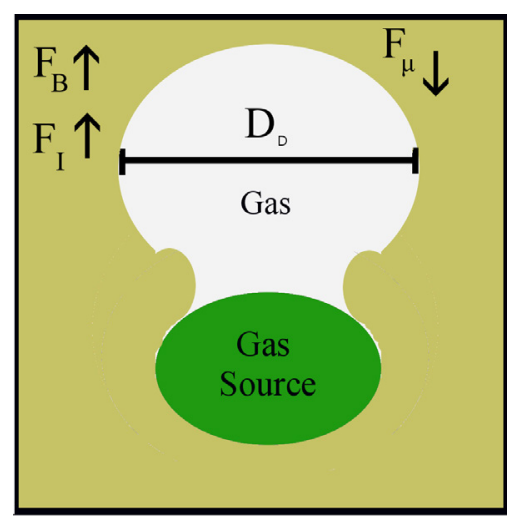

Figure 7.7: Schematic of a gas bubble just before detachment from the gas source. $D_{D}$ is the diameter of the bubble when it detaches from the particle, $F_{B}$ is buoyancy force, $F_{I}$ is inertial force, and $F_{\mu}$ is viscous drag. 
The treatment below was originally derived by Kumar et al. ${ }^{[76]}$ and entails the following assumptions:

1. Bubble formation is two staged (expansion followed by detachment)

2. Carrier mass of liquid is constant during bubble growth (i.e. gas saturation level is constant)

3. No transport of zero viscosity fluids into or out of the system (drag simplification)

4. Bubble motion is not influenced by the presence of other bubbles

5. Surface tension has no effect on bubble size

6. Interfacial surface tension is constant and uniform

7. No mass transfer or energy is transferred through the gas-liquid interface

8. Ideal gas behavior is exhibited

9. Gas density is negligible compared to liquid metal density

10. The particle or orifice is stationary relative to the gas bubble

The detachment condition is determined by a force balance. The buoyancy force, which promotes detachment from the particle is estimated as (Equation 7.17),

$$
F_{B}=V_{B}\left(\rho_{l}\right) g
$$

where $V_{B}$ is the bubble volume, $\rho_{1}$ is the density of molten aluminum $\left(2.3 \mathrm{~g} / \mathrm{cm}^{3}\right)$ and $\mathrm{g}$ is gravitational acceleration $\left(9.81 \mathrm{~m} / \mathrm{s}^{2}\right)$. The next force, viscous drag force, inhibits bubble motion (Equation 7.18),

$$
F_{\mu}=6 \pi \mu v_{e} r_{e}
$$


where $\mu$ is dynamic viscosity $\left(1.3 \mathrm{mPa}\right.$-s for molten aluminum $\left.{ }^{[50]}\right)$. The terms $\mathrm{v}_{\mathrm{e}}$ and $\mathrm{r}_{\mathrm{e}}$ correspond to the bubble instantaneous expansion velocity and radius respectively. The final force term considered is inertial force (Equation 7.19),

$$
F_{I}=\frac{Q^{2}\left(\rho_{g}+\frac{11}{16} \rho_{l}\right)}{12 \pi\left(\frac{3}{4 \pi} V_{B}\right)^{\frac{2}{3}}}
$$

where $\mathrm{Q}$ is the volumetric gas flow rate determined from decomposition data.

Balancing the forces, the detachment volume of a bubble is expressed as (Equation 7.20),

$$
V_{D}=(2 \pi)^{0.25}\left(\frac{15 \mu Q}{2 \rho_{l} g}\right)^{0.75}
$$

In order to calculate values of $\mathrm{Q}$ for each section and determine the size of bubbles that may detach from well dispersed, uniform particle distributions, the conversion fractions were applied to individual particle masses, $\mathrm{m}_{\mathrm{p}}$, of $\mathrm{TiH}_{2}$. The particle mass was calculated by assumed gas source particles were spherical (Equation 7.21).

$$
m_{p}=\rho_{T i H_{2}} \frac{4}{3} \pi r_{p}^{3}
$$

where the density of $\mathrm{TiH}_{2}$ is $3.75 \mathrm{~g} / \mathrm{cm}^{3}$ and the particle radius, $\mathrm{r}_{\mathrm{p}}$, is assumed to be 12.5 $\mu \mathrm{m}$ since this is the midpoint of the sieve range. The detachment volume as a function of 113 
time was then calculated for each section per Equation 7.20. The radii of these bubbles were then used in Stokes' law (Equation 7.21) to estimate bubble terminal velocities (assuming low gas density, i.e. $\rho_{\mathrm{l}}-\rho_{\mathrm{g}}=\rho_{\mathrm{l}}$ ) and compare them to experimental solidification velocities (Figure 7.8). It is implied by use of Stokes' law that bubbles are allowed enough time to attain their terminal velocities.

$$
v_{B}=\frac{-2\left(\rho_{l}-\rho_{g}\right) g r_{B}^{2}}{9 \mu}
$$

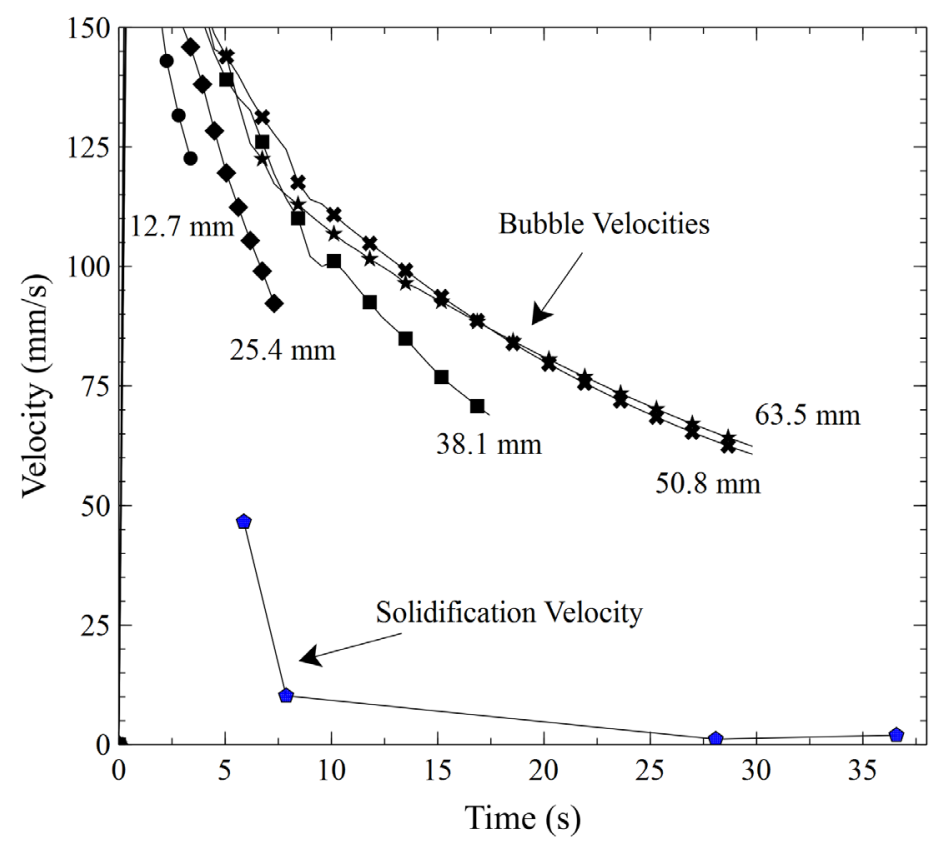

Figure 7.8: Comparison between the solidification front velocity and bubble velocities that detach from particles held within the first five $12.7 \mathrm{~mm}$ thick sections of the sample.

The results of these calculations reveal that bubbles evolving from any particle throughout the first five sections will have a velocity that is greater than the solidification 
front velocity (i.e. all gas bubbles will escape). This causes the estimated contribution of bubble capture to porosity levels to be zero under the assumptions of the current model.

Dividing the volume of gas produced by detachment volumes yields an estimate of 1000-10000 bubbles released per particle. Multiplying this by the number of particles $\left(\sim 10^{7}\right)$ added to the system results in a high number density of bubbles released to the system. This means that assumption 4 (bubbles do not interact) breaks down. The result of bubble interactions in this case would most likely entail coalescence. Bubble coalescence always serves to increase bubble velocity making the bubble capture mechanism even less likely.

Although calculated bubble velocities were high by comparison to the solidification front velocity, they may be slowed considerably if the alumina additions are taken into account. Pore interactions with alumina are likely to be highly stochastic in nature and are difficult to quantify in the current treatment or via experiments. A rough means by which to take this effect into consideration is to assume that the alumina covers some fraction, $\mathrm{f}_{\mathrm{st}}$ of the surface of a detached bubble at a thickness of $\mathrm{t}_{\mathrm{st}}$. It is also assumed that the stabilizer has a strong attraction to the bubble surface making it effectively a part of the bubble. Assuming the density of alumina is $3.94 \mathrm{~g} / \mathrm{cm}^{3}$, the effective increase in bubble density (decreasing buoyancy force) may be calculated (Equation 7.23).

$$
\rho_{g-e f f}=\frac{f_{s t} 4 \pi r_{D}{ }^{2} t_{s t} \rho_{A l_{2} 0_{3}}}{V_{D}}
$$


This density may be subtracted from the liquid aluminum density in Equation 7.22, to estimate new bubble terminal velocity profiles. The influence of stabilization was examined by varying stabilizer fractions and thicknesses independently, estimating new bubble velocity profiles, and again comparing them to the solidification front velocity (Figure 7.9). With $50 \%$ of the bubble surface covered in stabilizer and a coating thickness of $50 \mu \mathrm{m}(\sim 150$ particles thick assuming an alumina particle size of $0.3 \mu \mathrm{m})$ the bubbles move slowly enough to be captured by the solidification front. This is a large degree of stabilizer interaction. According to images taken from pore surfaces (Figure 4.6) fractional coverage is well below 0.5. In the current study, the thickness of segregated alumina was not directly measured. Given the amount of alumina added and its orientation ahead of the hydride, inside of the mold packet, it is reasonable to assume that bubbles will have ample interactions with alumina particles leading to bubble capture. A thickness of 150 particles is too great however making this mechanism of promoting bubble capture unlikely.

One piece of experimental evidence that helps to support some relation between pore growth and bubble capture is that the average detached bubble radius calculated from the Equation 7.20 was $300 \mu \mathrm{m}$. This value is within pore radius confidence interval (190-500 $\mu \mathrm{m}$ ) found in Chapter 5 (Figure 5.1) for $\mathrm{TiH}_{2}$. While potentially coincidental, this may indicate that bubble capture plays a role in bubble formation, but continued growth may be governed by other pore formation mechanisms including gas metal eutectic growth and direct gas evolution. 


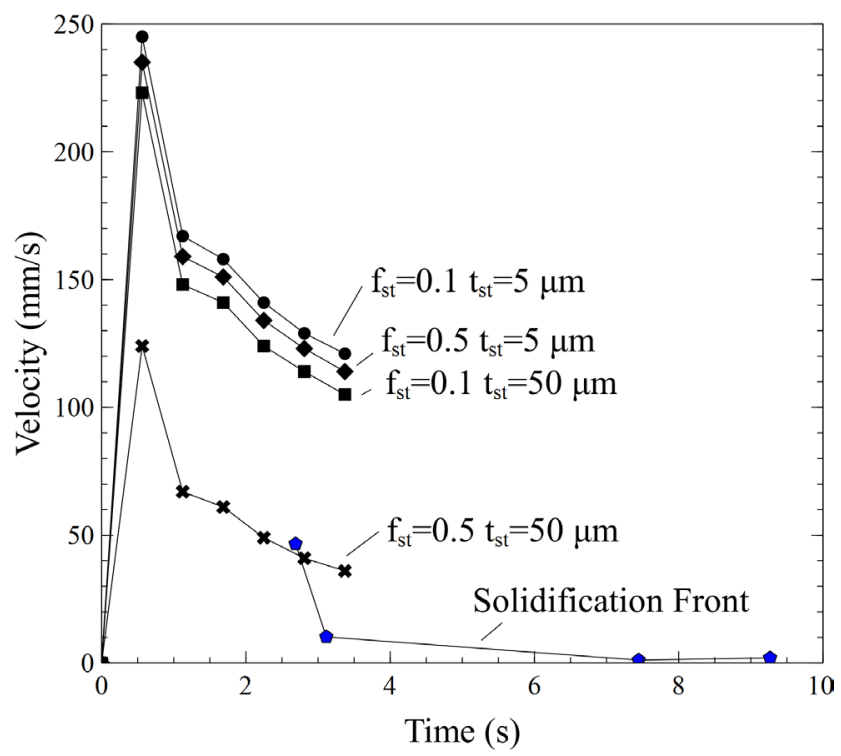

Figure 7.9: Stabilization effects for the bubbles produced in the first section of the mold $(12.7 \mathrm{~mm})$.

\subsection{Direct Gas Evolution}

Direct gas pore formation begins when the solidification front comes into contact with actively decomposing hydride particles as shown in Figure 7.10. When the solidification front continues to move upward a cylindrical gas volume will be encompassed as shown in Figure 7.11. Pores formed in this fashion are assumed to have a radius of approximately $300 \mu \mathrm{m}$ (average pore radius from experiments). Pores will continuously grow as long as the volume created by movement of the solidification front does not exceed the volume of gas released by the decomposing hydride. Assuming constant pore radius of $300 \mu \mathrm{m}$ (the average pore radius from experiments) and utilizing solidification front velocity profiles (Figure 3.3), the solidification driven pore volume increases were calculated using Equation 7.24 below. The gas expansion volumes were 
also calculated utilizing Equation 7.25. Only calculations for mold Section 3 will be presented due to its longer decomposition time and higher porosity levels.

$$
\begin{aligned}
\Delta V_{i} & =v_{s}\left(t_{i}-t_{i-1}\right) \pi r_{p}^{2} \\
\Delta V_{i-\text { gas }} & =N_{P} \frac{m_{p}}{m_{M}}\left(\alpha_{i}-\alpha_{i-1}\right) \frac{R T_{i}}{P_{i}}
\end{aligned}
$$

The value, $\mathrm{v}_{\mathrm{s}}$, is the solidification front velocity in Section 3, and $\mathrm{r}_{\mathrm{p}}$ is the radius of the pore. The radius of the pore is assumed to remain constant for simplicity. Uniform particle dispersion and an average of 100 pores per section were assumed (based on experimental averages) giving a total of 15000 particles $\left(\mathrm{N}_{\mathrm{p}}\right)$ attached to each growing pore per section. The sectional pressures $\left(\mathrm{P}_{\mathrm{i}}\right)$ were assumed to be equal to the sum of the inert gas and head pressure terms as in previous treatments. The results of these calculations were then directly compared (Figure 7.12). In Section 3, the volume of gas evolved from titanium hydride exceeded solidification driven pore growth by several orders of magnitude. Due to high gas evolution volumes, pore growth via direct gas evolution most likely takes on the appearance of a chimney plume with all excess gas escaping to the open liquid as shown in Figure 7.11. Despite the assumption that pore radius are constant, they increase considerably throughout the growth process due to excess gas supply. This is supported in previous metallographic images (Figure 5.3) showing pore radii increasing in the growth direction. Pore size variation could be estimated if more advanced solidification and fluid dynamics modeling techniques were utilized. Such techniques would need to quantify the precise thermal profiles across 
pores, as well as the expansion and contraction of the gas volume that occurs when bubbles escape from the pore tip. In the current treatment, the only means by which pore radius increases could be estimated is to assume a direct correlation between pore radius change and the volumetric gas evolution rate. Under this assumption pores undergo extreme expansion which does not reflect experimentally observed pore radii It is likely that the increase in pore radius involves some competition between solidification and gas evolution leading to limitations on pore size increases.

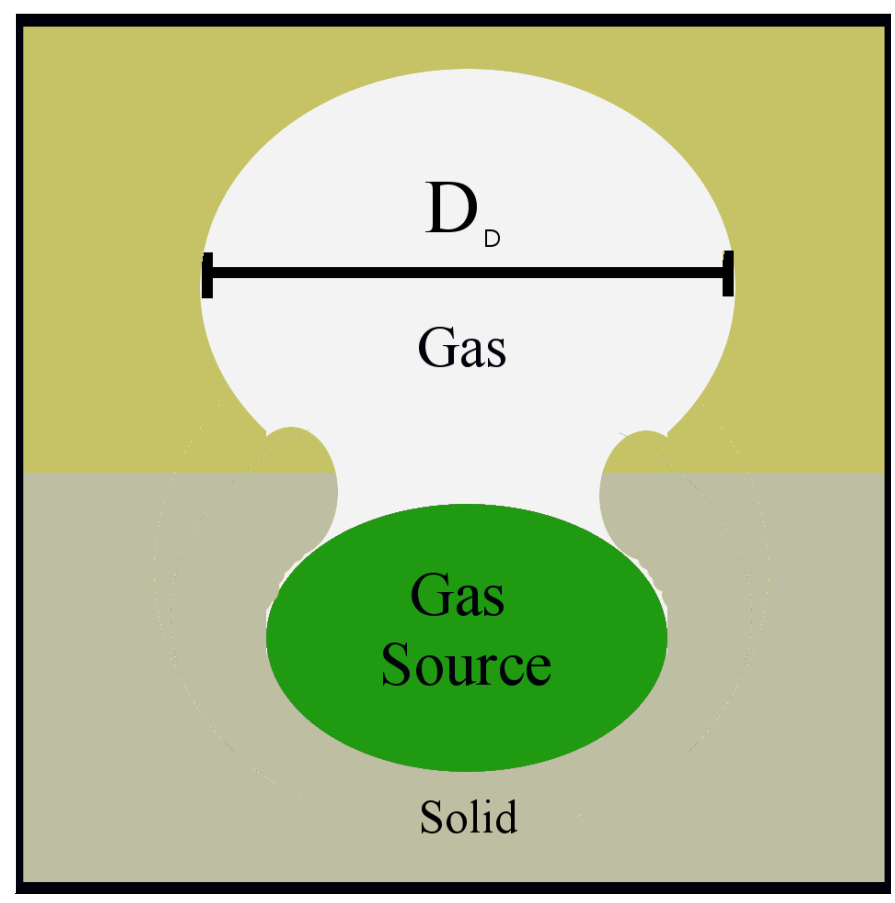

Figure 7.10: Beginning of direct gas evolution based on the bubble capture treatment. The solidification front encapsulats the gas source creating a cylindrical pore volume. 


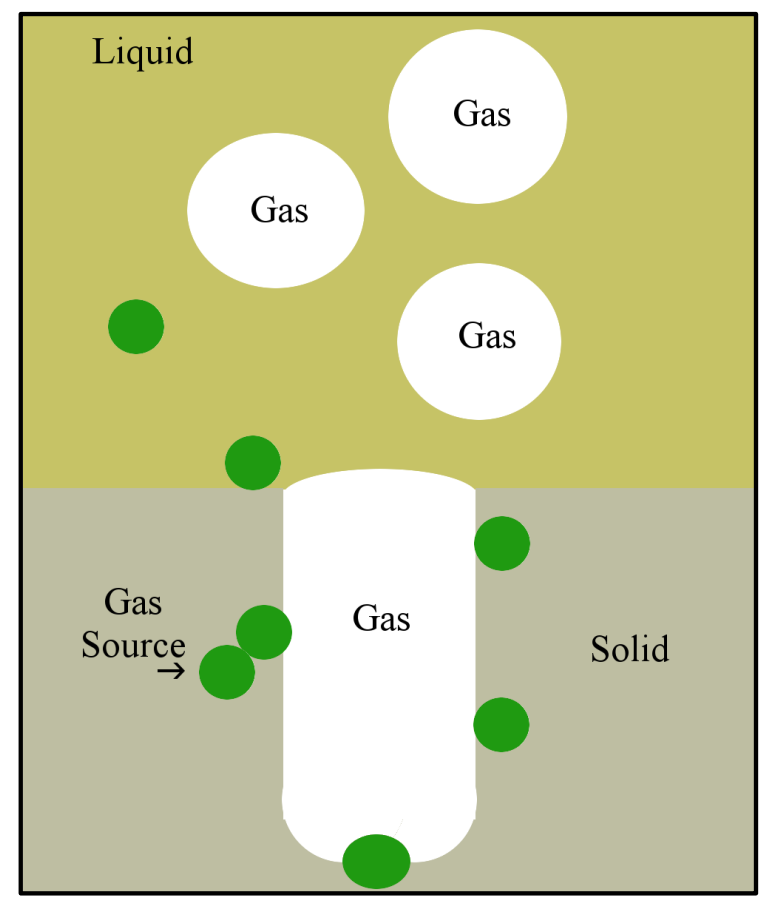

Figure 7.11: Stable direct gas evolution growth with gas escape from the top of the growing cylindrical pore.

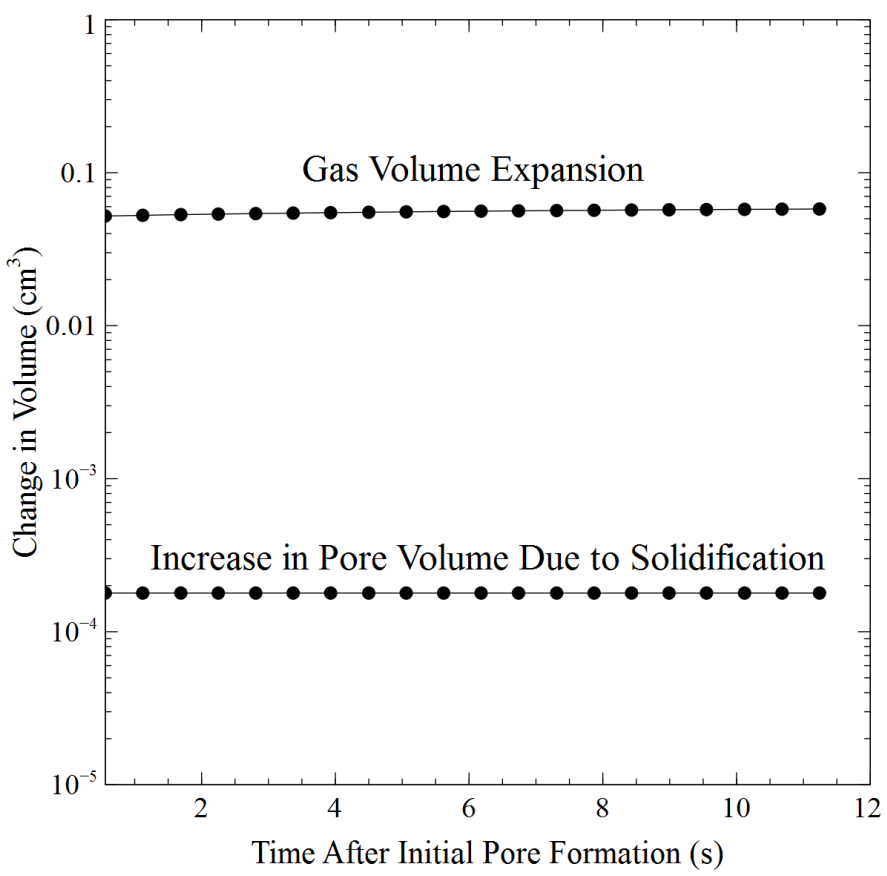

Figure 7.12: Calculation of the volume of gas evolved from titanium hydride (log scale) versus the pore volume that can be formed by solidification in Section 3. 
If large gas volumes are released from the top of the "chimney" it is possible that the liquid may fall into the pore as shown in Figure 7.13. Such large volumes may be released if the network of hydride connected to the pore surface builds up sufficient pressure and decompresses by venting into the larger pores. This is analogous to the fracking process used to extract oil or natural gas. ${ }^{[77]}$ When the liquid drops down into the pore and comes into contact with the solidified metal on the pore edges, the liquid may cool enough so that lateral solidification occurs as shown in Figure 7.13. Assuming the lateral solid growth occurs at roughly the same rate as directional solidification 300 $\mu \mathrm{m}$ pore may be sealed in $0.18 \mathrm{~s}$. If gas continues to evolve from the hydride it will it cause the laterally solidified film to deflect upwards. The cycle of gas escape, liquid infiltration and solid deflection will repeat until no opening remains from which the gas may escape (Figure 7.14). The deformation cycle is the most likely cause of the head section of the "tadpole" pores shown in experiments. Pore growth will terminate when either the hydride stops evolving gas, or the solid forms a continuous layer during which creep deformation may take place. Before assuming no further expansion occurs it is necessary to estimate the magnitude of creep expansion. 


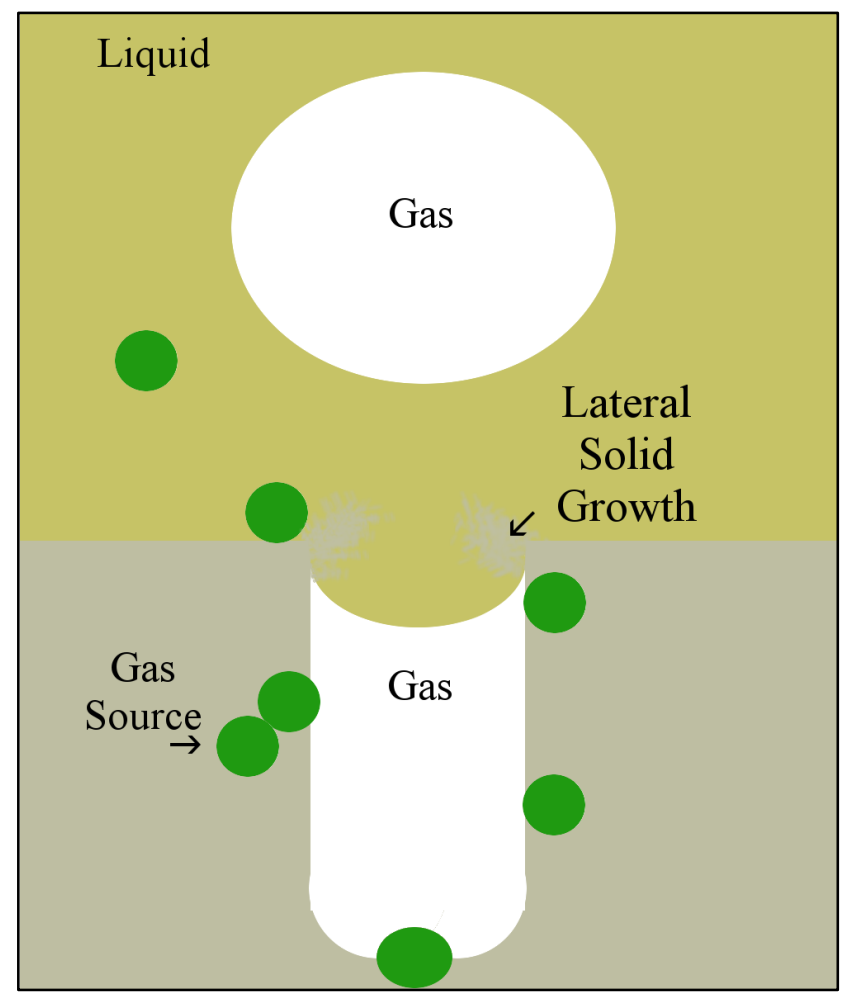

Figure 7.13: Lateral solidification from variable gas escape causing solid to protrude ahead of the gas expansion front. Newly formed solid is likely to be thrust upward leading to deformation and partial remelt. 


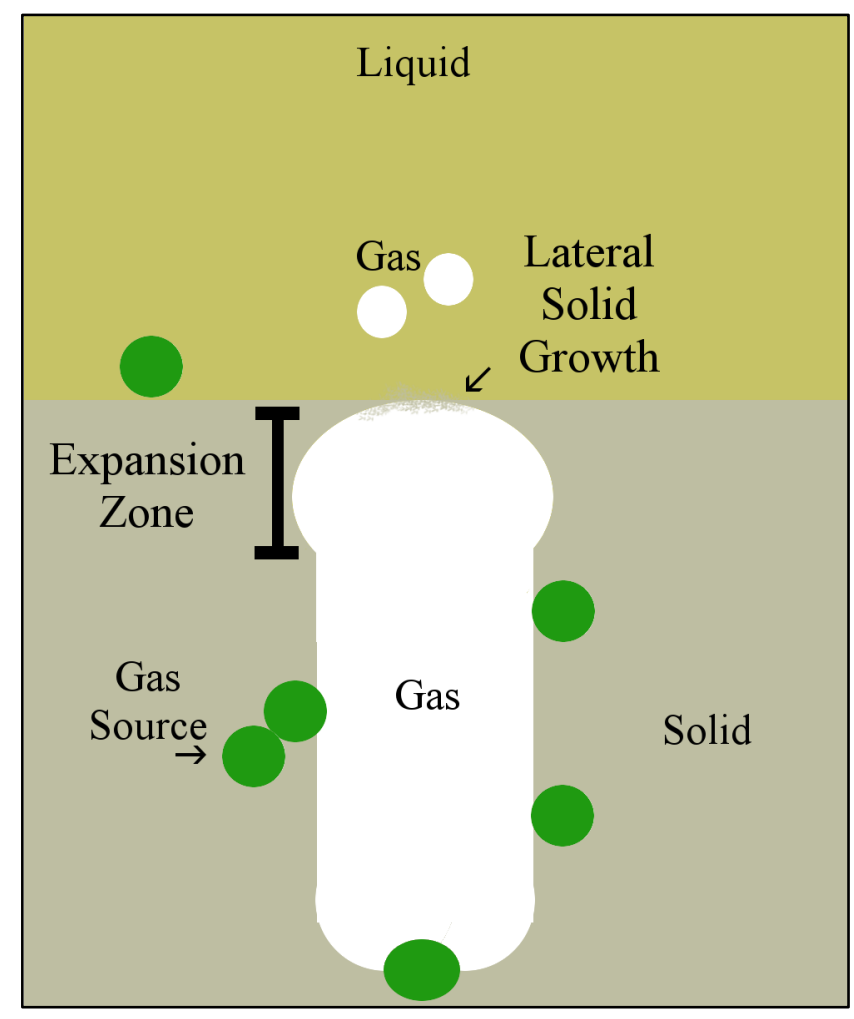

Figure 7.14: Encapsulation of gas volume by lateral solidification showing the formation of the characteristic "tadpole" pore. Small bubbles above the pore were released rapidly before the pore is sealed.

Rough estimates of the expansion due to creep are possible if it is assumed that one dimensional Nabarro-Herring, (high temperature, bulk diffusion) creep takes place at the temperatures and stress levels under consideration. In order to estimate the influence of creep on bubble expansion, the configuration shown in Figure 7.15 was constructed. Linear creep was assumed to stretch the solidified metal as shown. It was also assumed that particles start on the lowest planar surface of each section (i.e. they have $12.7 \mathrm{~mm}$ to grow upward before intersecting with the next section under consideration). 


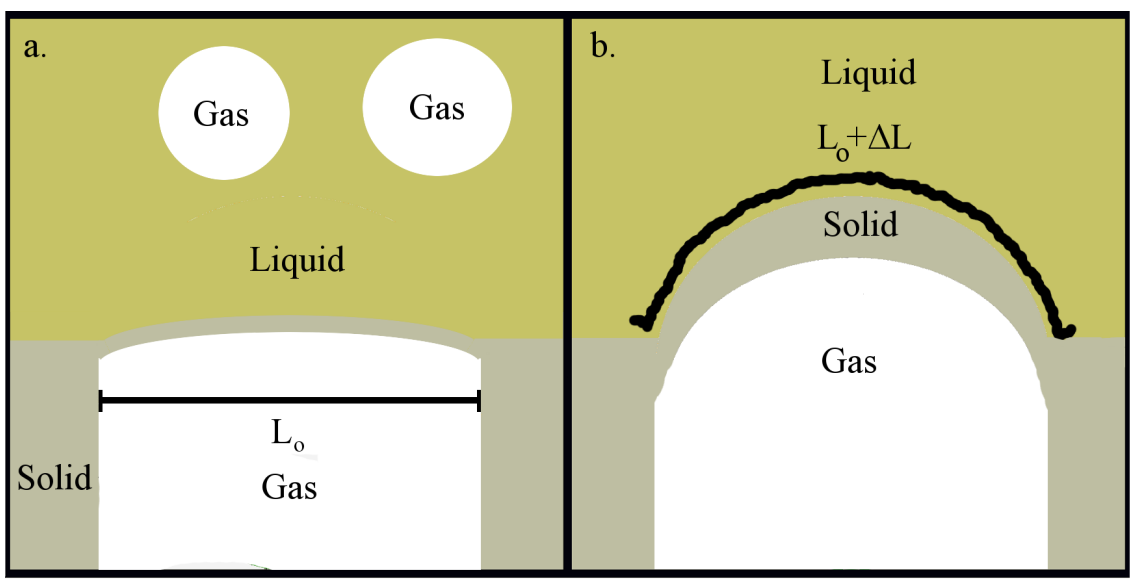

Figure 7.15: Direct gas evolution pore formation mode just after encapsulation (a.) and after creep expansion (b.). $\mathrm{L}_{\mathrm{o}}$ corresponds length of solid that deforms via creep.

According to Frost and Ashby ${ }^{[78]}$, The equation for lattice diffusion creep rate at a given temperature, T, and hoop stress, $\sigma$, is (Equation 7.26),

$$
\dot{\gamma}=\frac{42 \sigma \Omega}{k T d^{2}} D_{v}
$$

where $\Omega$ is the atomic volume of aluminum $\left(1.66 \times 10^{-29} \mathrm{~m}^{3}\right)$, $\mathrm{k}$ is Boltzmann's constant $\left(1.38 \times 10^{-23} \mathrm{~m}^{2} \mathrm{~kg} / \mathrm{s}^{2} \mathrm{~K}\right)$, and $\mathrm{d}$ is grain size (assumed to be $\left.10 \mu \mathrm{m}\right) . \mathrm{D}_{\mathrm{v}}$ is the lattice diffusion coefficient $\left(D_{\mathrm{ov}}=1.7 \times 10^{-4} \mathrm{~m}^{2} / \mathrm{s}, \mathrm{Q}_{\mathrm{v}}=109 \mathrm{~kJ} / \mathrm{mol}\right)$

Assuming an initial pore radius $\left(\mathrm{L}_{\mathrm{o}}\right)$ of $300 \mu \mathrm{m}$ (corresponding to experimental pore sizes) and a particle radius of $12.5 \mu \mathrm{m}$, the pressure due to gas evolution from each particle, $\mathrm{P}_{\mathrm{i}}$ (Equation 2.11) was used to calculate the hoop stress within pores (Equation 7.27). It was assumed that the initial pore tip thickness, w, was $50 \mu \mathrm{m}$ (corresponding to the width of the columnar crown in Figure 3.6). The thickness of the pore tip was 
increased during each time step, with the increase in thickness corresponding to the solidification velocity (from Figure 3.3) multiplied by the thermocouple sampling frequency $(0.56 \mathrm{~s})$.

$$
\sigma_{i}=\frac{P_{i} N_{p} r_{p}}{2 w_{i}}
$$

Hoop stresses found with Equation 7.27 were approximately $10^{4}-10^{5} \mathrm{~Pa}$ in magnitude. At temperatures above the decomposition point of titanium hydride these pressures again indicate diffusion driven creep as the dominant deformation mechanism. ${ }^{[78]}$ These pressures are also far below the equilibrium partial pressure of hydrogen that would halt decomposition according to thermodynamic data (in order to halt decomposition pressures on the order of $10^{6} \mathrm{~Pa}$ are required). ${ }^{[79]}$ Expansion calculations were ended when the solidification front had passed through the entire 12.7 $\mathrm{mm}$ section. The total number of particles attached to pore surfaces assuming uniform dispersion and 100 pores per section was 15000 . Linear estimations for the creep elongation of the pore tip were then used to measure the expansion potential for porosity. These estimations were found through use of Equation 7.28. The linear change in film length was calculated by summing linear pore tip expansions before the solidification front passed through the entire section (Equation 7.29). The results of this calculation are provided in Figure 7.16

$$
\Delta L_{i}=\dot{\gamma}_{i}\left(t_{i}-t_{i-1}\right)\left(L_{i-1}\right)
$$




$$
L_{f}=\sum \Delta L_{i}\left(t_{i}<t_{s}\right)
$$

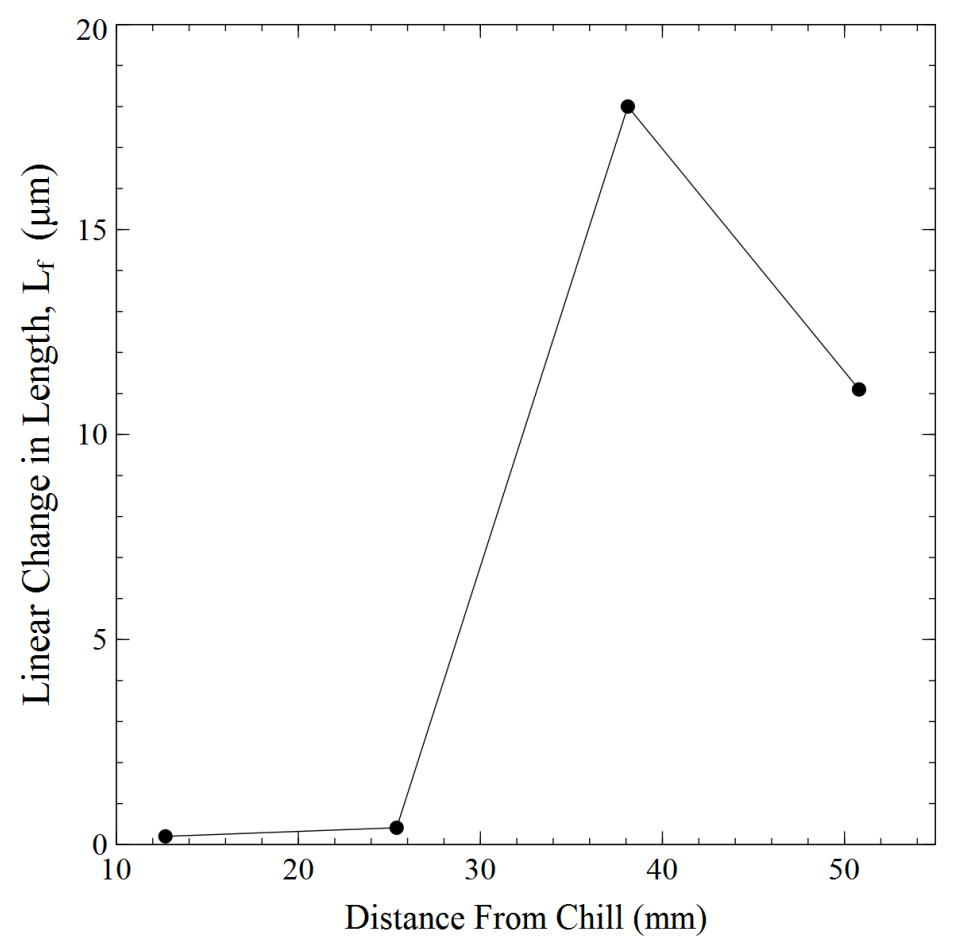

Figure 7.16: Elongation $\left(\mathrm{L}_{\mathrm{f}}\right)$ for a pore with $300 \mu \mathrm{m}$ initial radius and $12.5 \mu \mathrm{m}$ particles connected to the pore surface. Assumes that approximately 15000 particles are attached to the pore surface.

The results of the estimated pore expansion calculations show that for evenly dispersed particles, maximum expansion occurs in sections furthest from the chill. The main contributing factors for this trend are related to cooling rate. At low cooling rates, the solid grows much more slowly leading to higher hoop stresses and more time for pores to expand throughout a section. Also at lower cooling rates, more hydrogen is released to the pore resulting in higher pressure increases and more creep. The magnitude of the expansion is $18 \mu \mathrm{m}$ maximum. This expansion value is roughly $1 / 15$ of 
that for tadpole shapes shown in Figure 5.3. This indicates that pore expansion due to creep is likely very small and the formation of the tadpole shaped pores most likely occurs when the metal is in a slushy state with no resistance to bubble expansion. This also indicates that bubble expansion abruptly ends as soon as a continuous solid layer with a thickness above $50 \mu \mathrm{m}$ is formed. The solidification rates in mold sections under consideration can create this thickness in under $0.1 \mathrm{~s}$. This gives further indication that solid encapsulation is the primary means by which pores terminate.

If pore tips are thin and initial pore radii are small, it is possible that during foam processing, pores may expand ahead of the solidification front and then collapse leading to backfill of pores with liquid. This defect was apparent in many foam specimens as shown in Figure 7.17. As solidification occurs, rupture is less likely due to increased pore tip thicknesses. Pores in this case are likely to retain the tadpole shapes shown in Chapter 5. Given the wide range of decomposition rates, numbers of particles open to pore surfaces, and solidification rates throughout the sample a spectrum between the two extremes (pore growth versus pore rupture) is envisioned. 


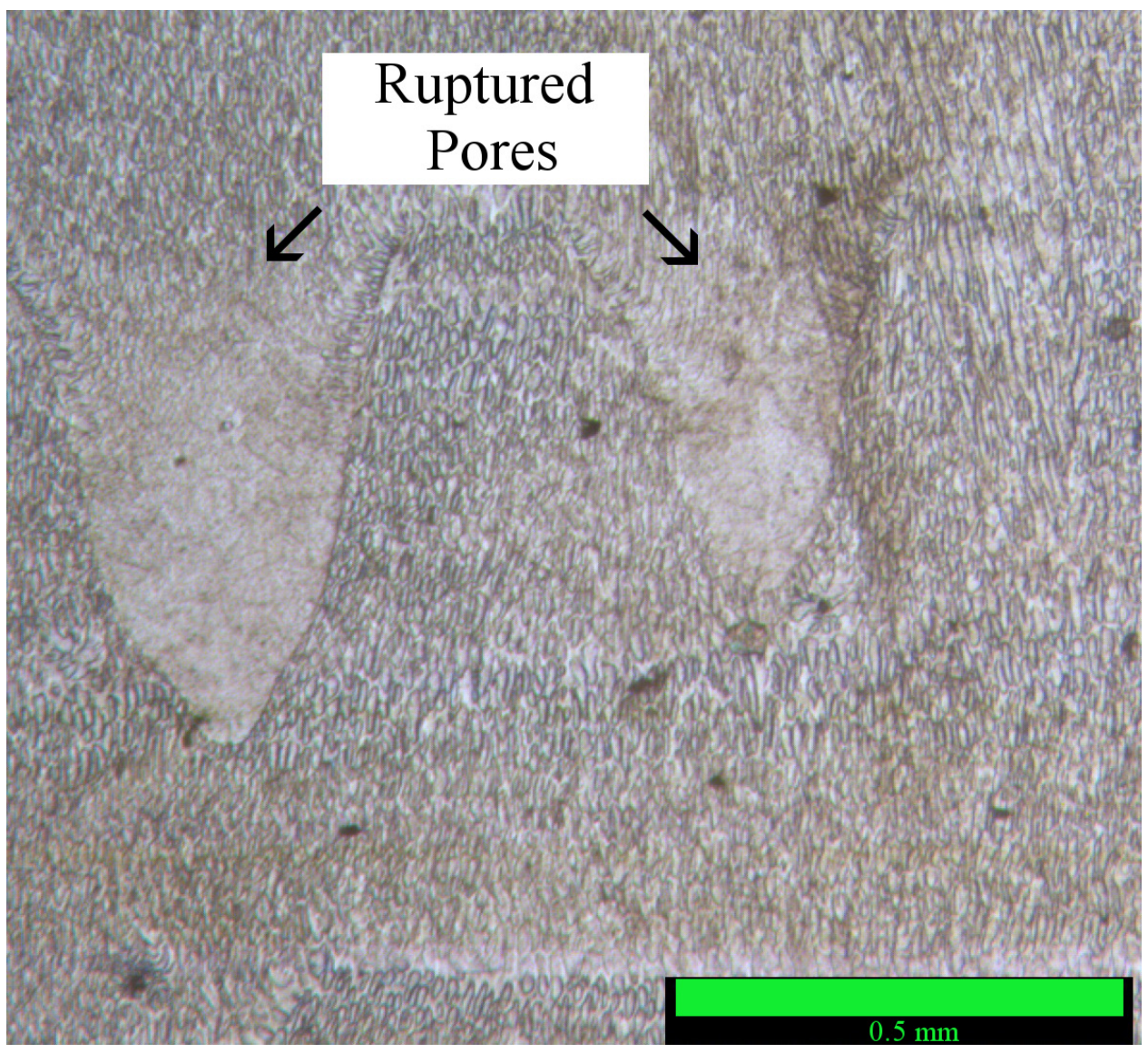

Figure 7.17: Metallographic image of a section approximately $25.4 \mathrm{~mm}$ from the chill plate showing pore that may have ruptured due to overexpansion of pores via direct gas evolution. Sample processed using $\mathrm{TiH}_{2}$.

\subsection{Summary and Conclusions}

Porosity levels have been calculated and compared to experimental results utilizing theoretical treatments of each pore formation mode. No single pore formation mode was found to completely fit experimental trends individually. A mixture of each pore formation mode is most likely. Based on the preceding discussion, direct gas evolution is most likely followed by gas-metal eutectic growth and finally bubble capture. The methods employed above involve several strict assumptions that are unlikely 
to be reflected in the real systems. Gas metal eutectic growth assumed that no gas escaped the system, which from experimental observations is not likely the case. For bubble capture it was assumed that bubble detachment volumes were independent of surface forces. Given the size of bubbles, this assumption may not be valid, but reliable high temperature surface energy data between hydrogen, titanium and liquid aluminum is lacking. Treatment of direct gas evolution involved the assumption that pores may expand freely against the slushy liquid which is most likely not the case.

While the above treatments were limited in their scope, they did highlight several important concepts relevant to thermal decomposition processing of gasarite structures. Gas solubility is low, but since vacuum processing techniques are employed porosity levels generated by gas metal eutectic type growth may be high. Bubbles that are generated from the hydride move through the liquid very rapidly and may only be captured if they are slowed by a large number of oxide particles in the liquid. Direct gas evolution has the potential to expand pores significantly and may account for both pore formation and continued growth.

Future work may include more advanced computational methods be employed to estimate pore development and growth utilizing the three pore formation modes outlined in this work. These techniques could include advanced Lattice Boltzmann fluid dynamics and solidification modeling methods, which reflect the statistical nature of the processes that govern foam development. ${ }^{[19,80-82]}$ 


\subsection{Summary, Process Viability and Future Work}

\subsection{Introduction}

The experimental and theoretical studies presented in Chapters 3-7 have highlighted the key characteristics and challenges of thermal decomposition processing of gasarites. The final chapter will summarize these finding and provide discussion as to their implications for process viability. Because thermal decomposition was developed to replace the gas-metal eutectic method, comparisons between batch versions of these two processes will be made in order to quantitatively assess process viability. Ashby has outlined a method for assessing foamed material viability, ${ }^{[2,24]}$ but this method requires large amounts of consumer and manufacturing data. Since both the gas-metal eutectic process and thermal decomposition process (to produce gasarites) are isolated to laboratory scale, no such data could be obtained. The approach that is used instead, in a fashion similar to Ashby, assigns a weight to each positive and negative processing characteristic in order to assess process viability. Unlike Ashby's method, this approach will not utilize customer data to determine the weighting factors, but will instead weigh the processes on viability scales. The extremes of these scales represent processes or characteristics that epitomize negative and positive traits. For example, the processes with extremes in expendable material costs were chosen as sand casting and investment casting (representing low material cost and high material cost processes respectively). Gas metal eutectic and thermal decomposition were then weighed by how their expendable material costs compared to these processes. In order to determine what processes, or conditions lay at the extremes additional literature review was conducted. 
Each characteristic was assigned a weight and the sum of the scores was taken in order to assess the viability of each process. A high score represents a highly viability process while low scores represent processes that are not viable. Before examining process viability it is first useful to summarize the major findings relevant in this analysis.

\subsection{Summary of Findings}

Chapter 2 served to develop a preliminary theoretical basis on which hypotheses could be developed. Using this construction, it was found that three different pore formation modes were likely in thermal decomposition processing. These modes are gasmetal eutectic growth, bubble capture, and direct gas evolution. Utilizing simplifying assumptions it was found that gas-metal eutectic and direct gas evolution were likely to be the primary contributors to pore formation and growth. Bubble velocity relative to solidification front velocity was too great preventing bubble capture.

Chapter 3 highlighted one of the primary challenges of metal foam processing, the replication of experimental results. ${ }^{[2]}$ Many foaming processing by virtue of their stochastic nature are highly sensitive to initial processing conditions. ${ }^{[19]}$ Many of these conditions such as the initial spatial distribution of pores, cannot be directly measured leading to the potential for many different processing outcomes. Computational modeling efforts for such systems have begun to take advantage of chaos theory and complex systems analysis in order to predict pore morphology ranges. In order to minimize the non-replication of results, foam experimentalists are required to report their findings with an extreme attention to detail. As was demonstrated in Chapter 3, several key processing characteristics in Kim's preliminary studies ${ }^{[20]}$ of thermal decomposition 
processing were not reported leading to major issues with foam processing in the current study. While overall pore morphology results were not replicable the variation of porosity level with increased inert gas pressure agreed with Kim's results.

Chapter 4 entailed modification of Kim's process to produce more uniform foams with high porosity. These efforts relied heavily on the preliminary conceptual model (Chapter 2) in order to develop short hypotheses for the influence of each process change. Mold surface interactions, non-uniform particle dispersion, metal expulsion and several other issues were minimized in order to give a more consistent process. Additionally, techniques that have been used in other metal foam processes were employed in order to demonstrate pore stabilization mechanisms that may be utilized in thermal decomposition processing.

A baseline process was established and expanded characterization trials were completed (Chapter 5). These trials served to establish the pore morphology characteristics, evaluated $\mathrm{ZrH}_{2}$ as another gas source, and provided direct evidence of one of the three possible pore formation modes, direct gas evolution. The ease with which the process was adapted for $\mathrm{ZrH}_{2}$ demonstrates some of the inherent flexibility of thermal decomposition processes. It was found that porosity levels were quite low (maximum of $\sim 10 \%$ for $\mathrm{TiH}_{2}$ and $\sim 6 \%$ for $\mathrm{ZrH}_{2}$ processed foams). High variability was observed in both porosity levels $(4.4 \%$ max- $95 \% \mathrm{CI})$ and pore sizes $(280 \mu \mathrm{m}$ max$95 \% \mathrm{CI})$ despite variability reduction measures.

Evidence of direct gas evolution evoked several questions about the decomposition kinetics of the hydride gas sources studied in Chapter 5 and how they influence pore morphology. A literature review of experimental data revealed a 
considerable gap between the heating rates utilized to characterize hydride decomposition kinetics and those that were observed during foam processing. In order to better characterize decomposition kinetics, a high ramp rate thermo-gravimetric technique was developed and the kinetic triplets for several types of metal hydride were determined (Chapter 6). It was found, in agreement with literature, that decomposition was diffusion limited, but occurred more rapidly than observed previously.

Utilizing data generated in Chapter 6, a theoretical assessment of each pore formation and growth mode was conducted. This was done to understand the contributions of each pore formation mode to overall porosity levels. It was found that despite low gas solubility under processing conditions, gas-metal eutectic driven pore formation could contribute to overall porosity levels. Direct gas evolution was also a likely contributor, although quantification of this effect is difficult due to quantify given unknown powder dispersion values and interactions with partially solidified metal. Bubble capture was determined to only contribute to porosity if significant amounts of alumina stabilizer segregate to bubble surfaces. While this is possible, it is unlikely to be probable in many cases making this mechanism less likely than the others.

Summarizing the key points from the above discussion with regard to the characteristics of thermal decompositions processing:

1. The thermal decomposition method relies on three different pore formation mechanisms each governed by different physical laws.

2. The thermal decomposition process is subject to considerable variability making experimental replication difficult.

3. Variation in porosity levels was somewhat reduced by process modifications compared to the original process laid out by Kim and gasarite structures were formed. 
4. Pore formation mechanisms were determined and zirconium hydride was evaluated as an alternative gas source material.

5. Thermal decomposition processes can easily integrate other gas sources.

6. Porosity levels and pore sizes were quite low for foams produced using either $\mathrm{TiH}_{2}$ or $\mathrm{ZrH}_{2}$.

7. Variation in porosity levels was high.

8. Decomposition of metal hydrides at high heating rates occurs by the same mechanism, but more rapidly than at low heating rates.

9. Gas metal eutectic growth and direct gas evolution are the primary contributors to pore formation and growth.

Many of these findings will now be used to compare thermal decomposition processing to gas metal eutectic processing.

\subsection{Comparisons to Gas Metal Eutectic Processing}

A bulk of the following comparative data came from general reviews published by both Nakajima ${ }^{[32]}$ and Shapovalov. ${ }^{[29-30]}$ Additional literature and internet-based resources were used in order to estimate current material, equipment, and other costs in order to add economic factors to the viability decision. ${ }^{[83-86]}$ The main factors that will be considered are summarized in Table 8.1. Limited data on batch gas-metal eutectic processing of aluminum gasarites was available therefore the porosity and pore size values reported below are from studies conducted utilizing continuous casting techniques. $^{[87]}$ 
Table 8.1: Summary of factors used to calculate gas metal eutectic and thermal decomposition process viability.

\begin{tabular}{|c|c|c|}
\hline & $\begin{array}{c}\text { Gas } \\
\text { Metal } \\
\text { Eutectic }\end{array}$ & $\begin{array}{c}\text { Thermal } \\
\text { Decomposition }\end{array}$ \\
\hline \multicolumn{3}{|l|}{ Production Factors } \\
\hline 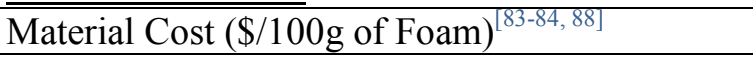 & 0.38 & 0.54 \\
\hline Capital (Vessel Construction) $(\$)^{[84,86]}$ & $\begin{array}{c}20000- \\
80000\end{array}$ & $5000-15000$ \\
\hline Maintenance $*(\mathrm{Hrs} / \mathrm{Wk})$ & 4 & 1 \\
\hline Cycle Time* (Hrs) & 4.5 & 1.5 \\
\hline Safety Risk & High & Low \\
\hline \multicolumn{3}{|l|}{ Foaming Capabilities } \\
\hline \# of Foamed Materials (see Table 1.2,Table 1.3) & 14 & 4 \\
\hline Maximum Porosity Levels (\%) & 40 & 12 \\
\hline Porosity Variability $(\%)^{* *}$ & 7 & 6 \\
\hline Pore Size Variability $(\mu \mathrm{m})^{* *}$ & 176 & 280 \\
\hline Sample Length (mm) & 1000 & 127 \\
\hline
\end{tabular}

As shown, process characteristics were divided into production factors and foaming capabilities. Material costs were estimated by utilizing aluminum prices on the London Metals Exchange $^{[88]}$ and also included mold material costs ${ }^{[89]}$, and gas source costs. ${ }^{\left[{ }^{[3-84]}\right.}$ Capital costs were estimated by quotes received from a pressure vessel supplier ${ }^{[86]}$ and those found for vacuum chambers of similar capacity used in the current study. Maintenance and cycle times were estimated based on experiments conducted in the current study as well as research conducted utilizing gas-metal eutectic for copper gasarite fabrication. Safety risk was assessed by comparing explosive depressurization hazards and combustion hazards between the two processes, with the gas metal eutectic process being much more hazardous than thermal decomposition. All values for foaming 
capabilities for each process came either from the current study or a study on utilizing continuous casting to form gasarites under 5 atm of pressurize hydrogen and solidification rates of $0.9 \mathrm{~mm} / \mathrm{s}^{[87]}$

\subsection{Assessment of Thermal Decomposition Processing}

With the key comparative factors determined it is now possible to assess the viability of thermal decomposition processing versus gas metal eutectic processing in the production of aluminum gasarite structures. The procedure for determining material viability entails evaluating cost, performance and value. ${ }^{[24]}$ Typically, exchange coefficients measuring the cost of process performance are utilized to convert non-dollar value factors into dollarized cost. These exchange coefficients are typically gathered through use broad customer surveys, but for the current study no such data was available, therefore standards of reference were used to rate the two processes on a scale from one to ten (Figure 8.1). A value of 1 represents a detrimental trait for process viability while 10 represents a desirable trait. In order to provide some objectivity and review both processes in broader terms, the scales were set by a brief survey of metal casting

techniques $^{[2,90]}$, and typical foam processing capabilities(including , pore control ranges, and pore variability). Figure 8.1 shows the scales and selected extremes for various processing metrics. Each characteristic was also given a weight with regard to its importance for process viability. Table 8.2 summarizes the values used in assigning scores to the two processes. 


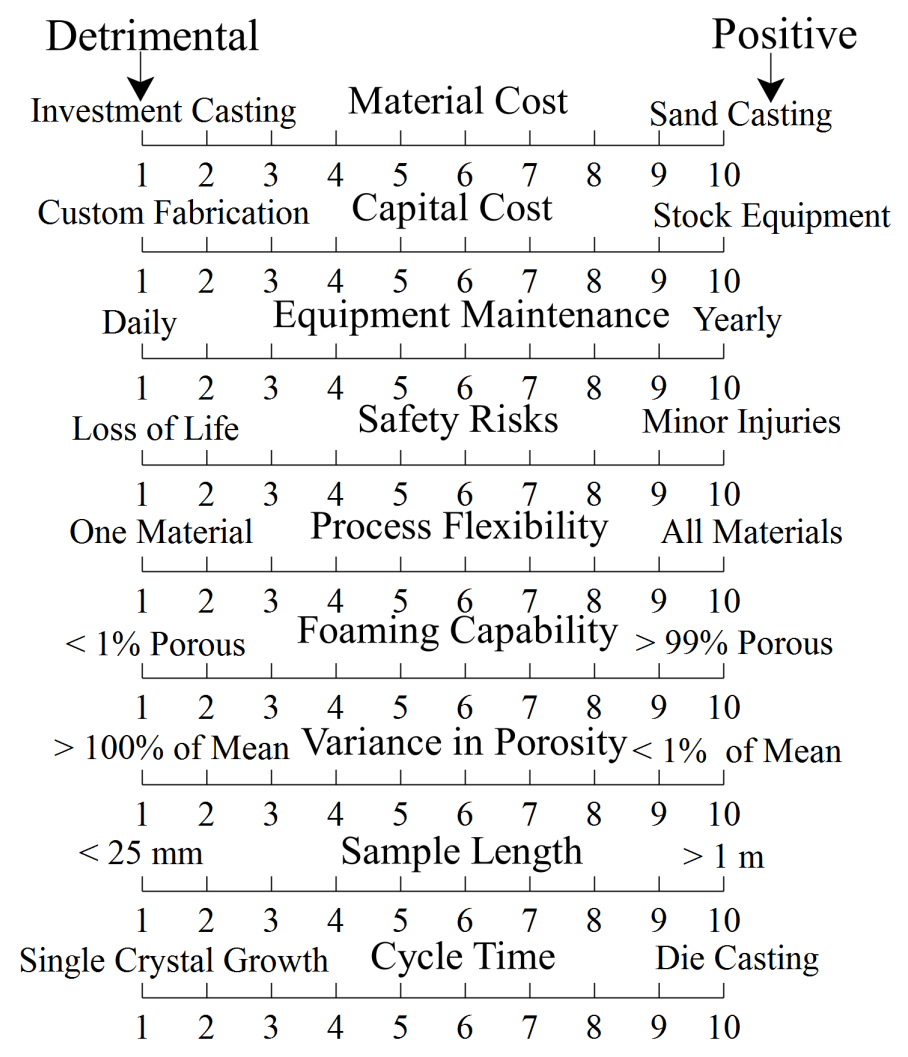

Figure 8.1: Scales used to assess the viability of both thermal decomposition processing and gas metal eutectic processing. Extremes on each scale were determined by either qualitative metrics based on literature or numeric data from experiments.

The result of weighing the factors for each practice is that both are far from ideal (Table 8.2). A low cost, safe, and efficient foaming process would have a score of 100 and these processes received less than half of the perfect score. Gas metal eutectic is slightly superior to thermal decomposition processing, but given the resolution of the weights and indices, the difference is not significant enough to discount one process over the other. The interpretation of the above analysis is that thermal decomposition would tend to suffer many of the same issues as the gas metal eutectic process, mostly due to the current limitations on pore morphology control. In order to improve the case for using 
thermal decomposition additional work is required to better characterize the process and investigate alternative process control modes.

Table 8.2: Assigned values, weights and scores for process viability assessment. Both scores ranked low overall, with gas metal eutectic processing barely proving superior.

\begin{tabular}{|l|c|c|c|c|c|}
\hline \multicolumn{1}{|c|}{ Factor } & $\begin{array}{c}\text { Gas } \\
\text { Metal } \\
\text { Eutectic }\end{array}$ & $\begin{array}{c}\text { Thermal } \\
\text { Decomp. }\end{array}$ & Weight & $\begin{array}{c}\text { Gas Metal } \\
\text { Eutectic Score }\end{array}$ & $\begin{array}{c}\text { Thermal } \\
\text { Decomp. } \\
\text { Score }\end{array}$ \\
\hline Material Cost & 5 & 3 & 1.10 & 6 & 3 \\
\hline Capital Cost & 1 & 8 & 1.10 & 1 & 9 \\
\hline $\begin{array}{l}\text { Equipment } \\
\text { Maint. }\end{array}$ & 2 & 3 & 1.10 & 2 & 3 \\
\hline Safety Risk & 1 & 5 & 1.70 & 2 & 9 \\
\hline $\begin{array}{l}\text { Process } \\
\text { Flexibility }\end{array}$ & 8 & 5 & 1.25 & 10 & 6 \\
\hline $\begin{array}{l}\text { Foaming } \\
\text { Capability }\end{array}$ & 4 & 2 & 1.25 & 5 & 3 \\
\hline $\begin{array}{l}\text { Variance in } \\
\text { Porosity }\end{array}$ & 9 & 5 & 1.25 & 11 & 6 \\
\hline Sample Length & 5 & 3 & 1.25 & 6 & 4 \\
\hline Cycle Time & 3 & 7 & 1.25 & 4 & 9 \\
\hline Total & & & & $\mathbf{4 7}$ & $\mathbf{4 3}$ \\
\hline
\end{tabular}

\subsection{Conclusions and Future Work}

Thermal decomposition processing of gasarites involves a number of interacting variables that the current study has helped to assess both experimentally and through preliminary models. Several contributions to general foaming literature and decomposition kinetics have been made through the completion of the studies outlined above. While the thermal decomposition process suffers from high variability (as is the case with many stochastic foaming processes) it still has some potential to overcome the largest barrier to large scale production of gasarites, usage of high pressure hydrogen gas. 
As future work, it would be of interest to determine whether or not heat treatments may be used in order to expand porosity. It would also be of interest to attempt the process modifications outlined in Chapter 4 on other materials systems that have been evaluated in other studies. For example, in copper foamed with $\mathrm{TiH}_{2}$ it may be of interest if stabilization of porosity is possible to enhance porosity levels and pore morphology. Bubble capture enhancement combined with rapid solidification of copper (due to its high thermal conductivity) may help to promote this pore growth mode. In order to provide direct experimental evidence of pore growth modes it is also suggested that high energy x-ray imaging techniques be utilized. This would help to confirm many of the pore formation mode theories that have been developed in the current work. 


\subsection{Appendix: Thermal Decomposition-Experimental Data}

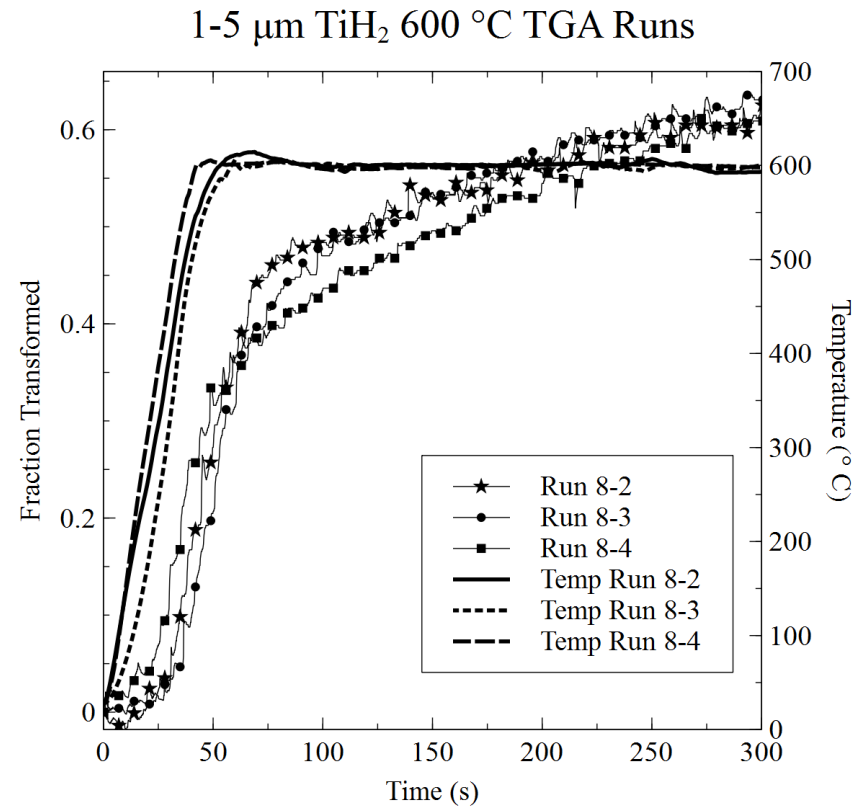

Figure 9.1: All TGA runs of 1-5 $\mu \mathrm{m} \mathrm{TiH}_{1.98}$ held at $600^{\circ} \mathrm{C}(873 \mathrm{~K})$

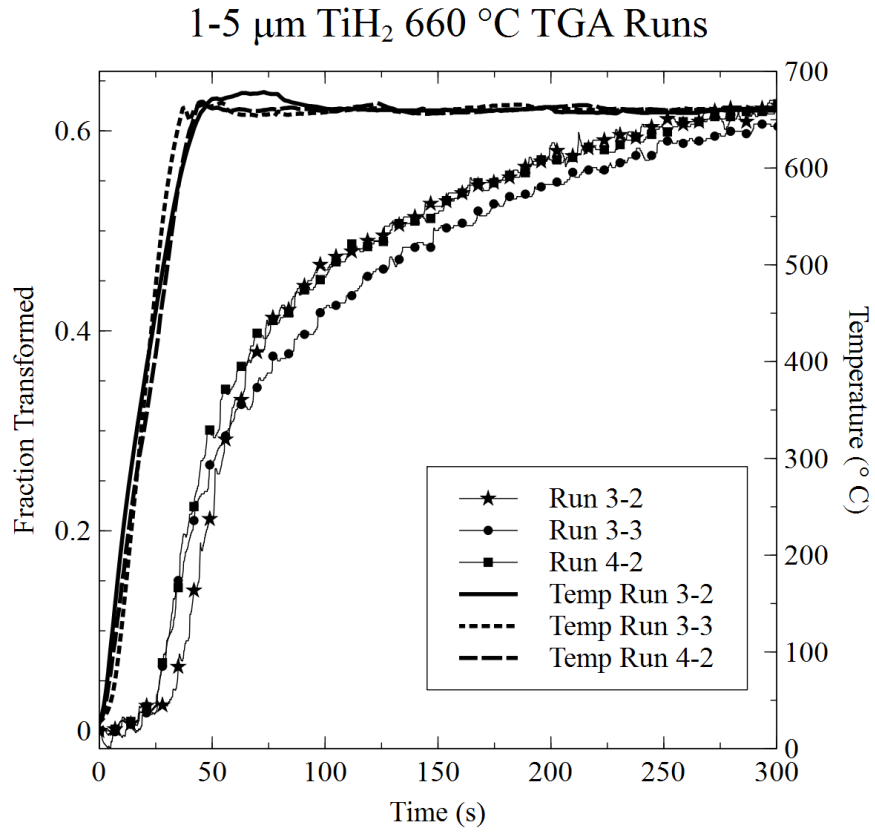

Figure 9.2: All TGA runs of $1-5 \mu \mathrm{m} \mathrm{TiH}_{1.98}$ held at $660^{\circ} \mathrm{C}(933 \mathrm{~K})$ 


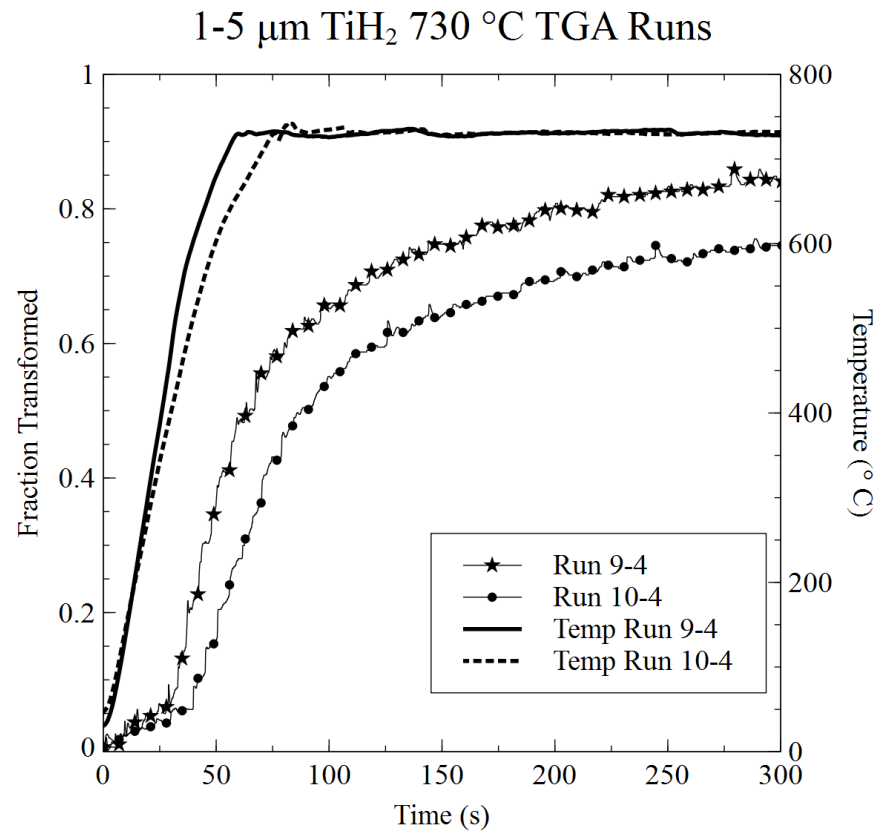

Figure 9.3: All TGA runs of 1-5 $\mu \mathrm{m} \mathrm{TiH}_{1.98}$ held at $730^{\circ} \mathrm{C}(1003 \mathrm{~K})$

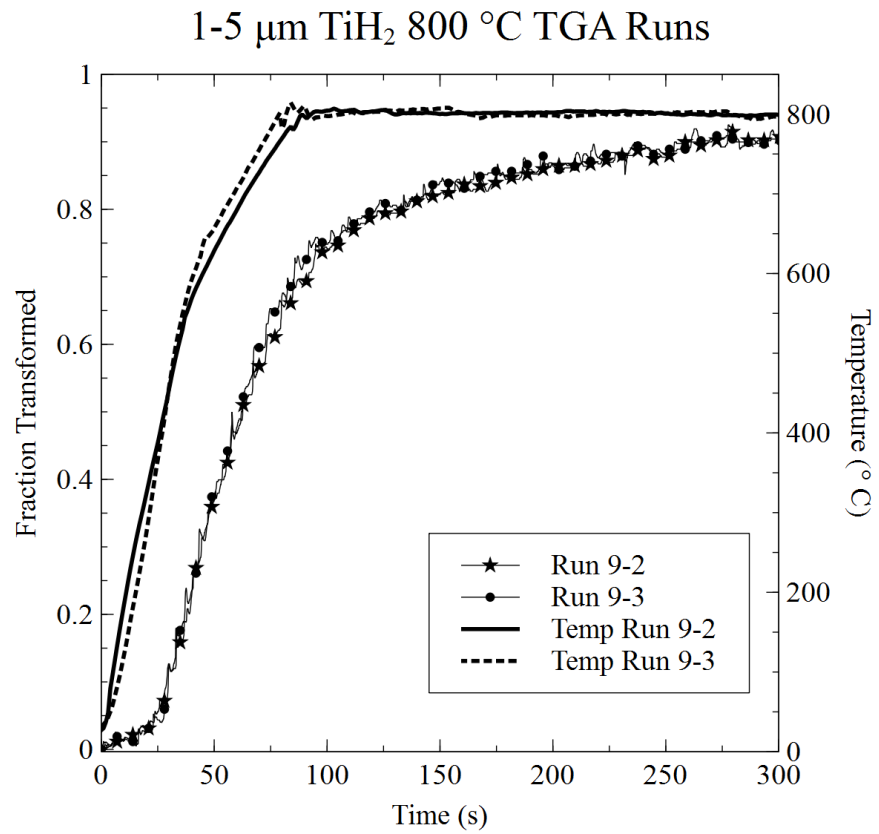

Figure 9.4: All TGA runs of 1-5 $\mu \mathrm{m} \mathrm{TiH} 1.98$ held at $800^{\circ} \mathrm{C}(1073 \mathrm{~K})$ 


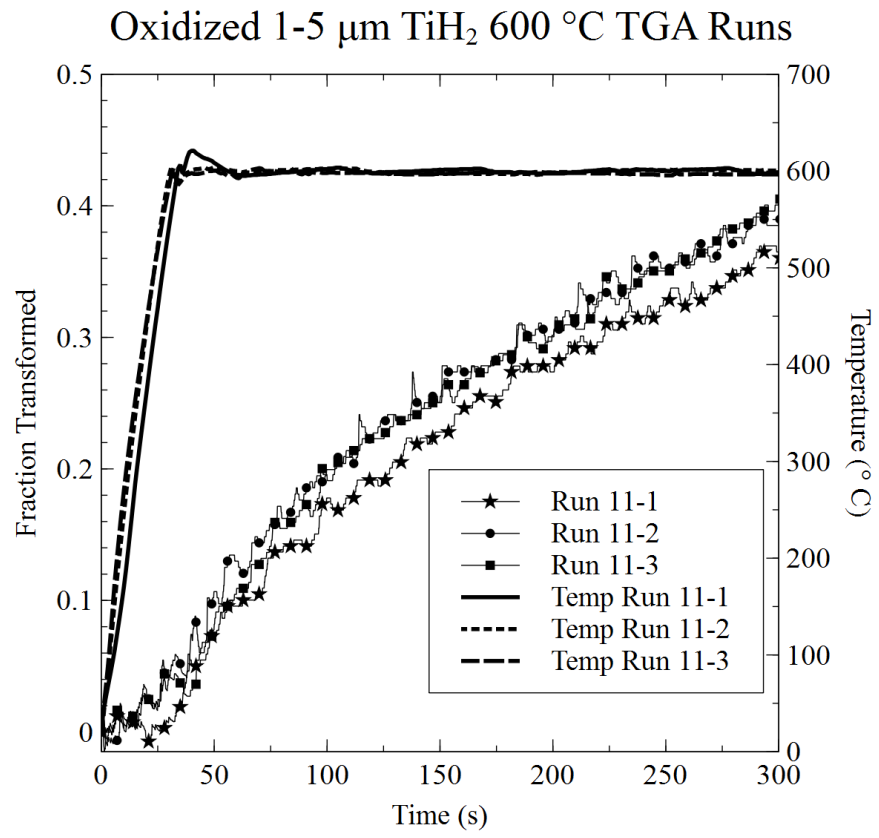

Figure 9.5: All TGA runs of oxidized 1-5 $\mu \mathrm{m} \mathrm{TiH}_{1.98}$ held at $600^{\circ} \mathrm{C}(873 \mathrm{~K})$

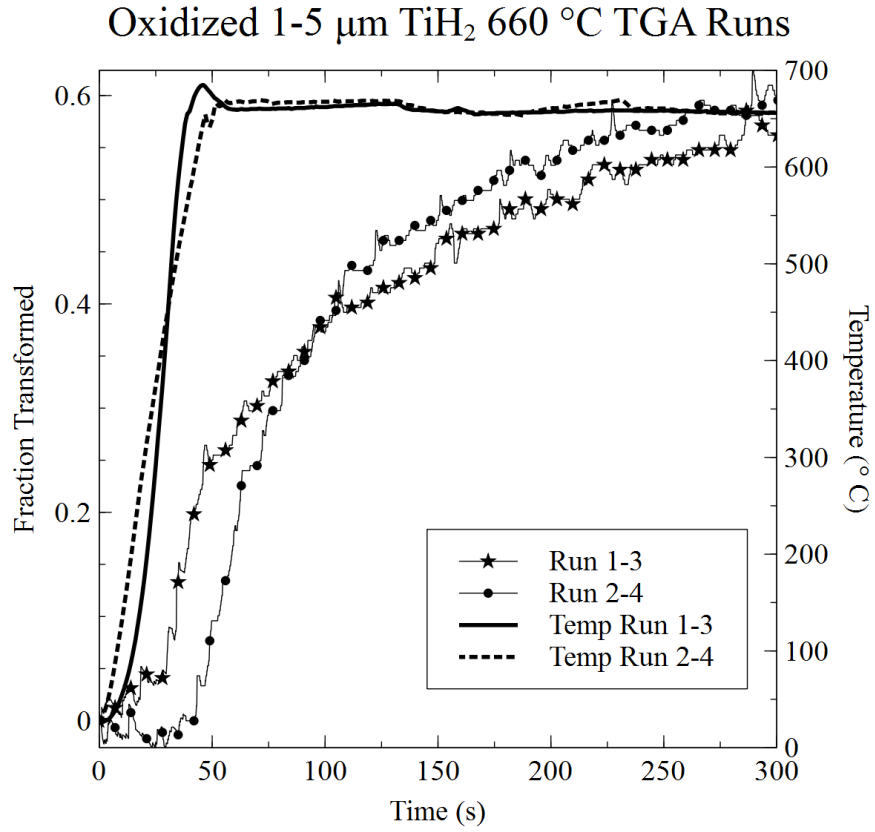

Figure 9.6: All TGA runs of oxidized 1-5 $\mu \mathrm{m} \mathrm{TiH}_{1.98}$ held at $660^{\circ} \mathrm{C}(933 \mathrm{~K})$ 
Oxidized 1-5 $\mu \mathrm{m} \mathrm{TiH}_{2} 730{ }^{\circ} \mathrm{C}$ TGA Runs

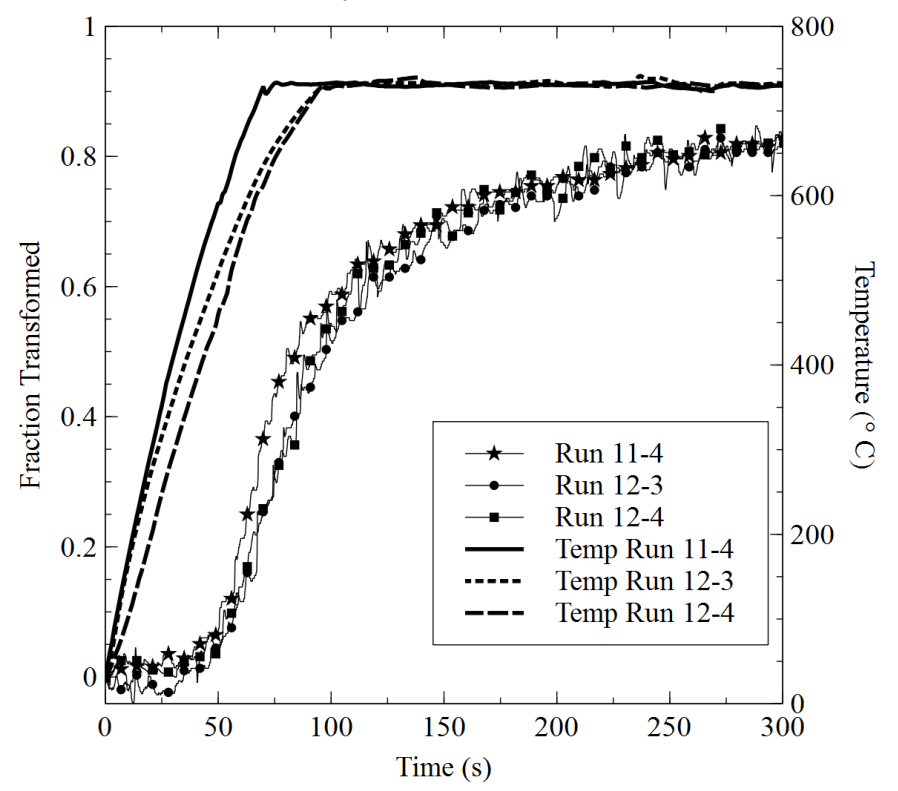

Figure 9.7: All TGA runs of oxidized 1-5 $\mu \mathrm{m} \mathrm{TiH}_{1.98}$ held at $730^{\circ} \mathrm{C}(1003 \mathrm{~K})$

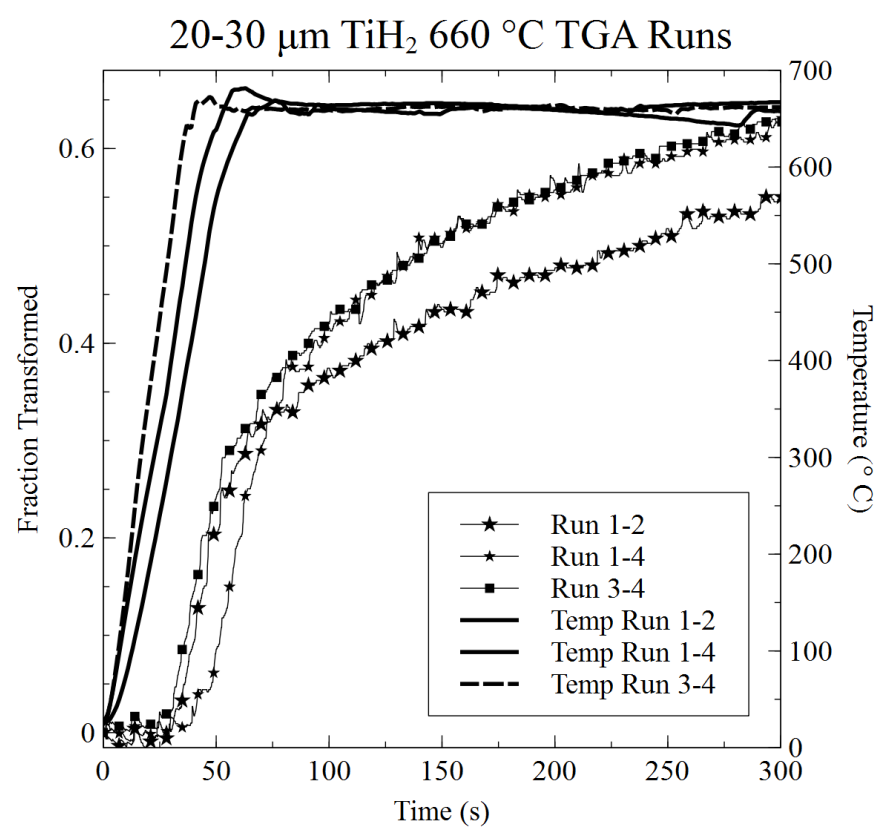

Figure 9.8: All TGA runs of $20-30 \mu \mathrm{m} \mathrm{TiH}_{1.98}$ held at $660^{\circ} \mathrm{C}(933 \mathrm{~K})$ 
Oxidized 20-30 $\mu \mathrm{m} \mathrm{TiH}_{2} 660^{\circ} \mathrm{C}$ TGA Runs

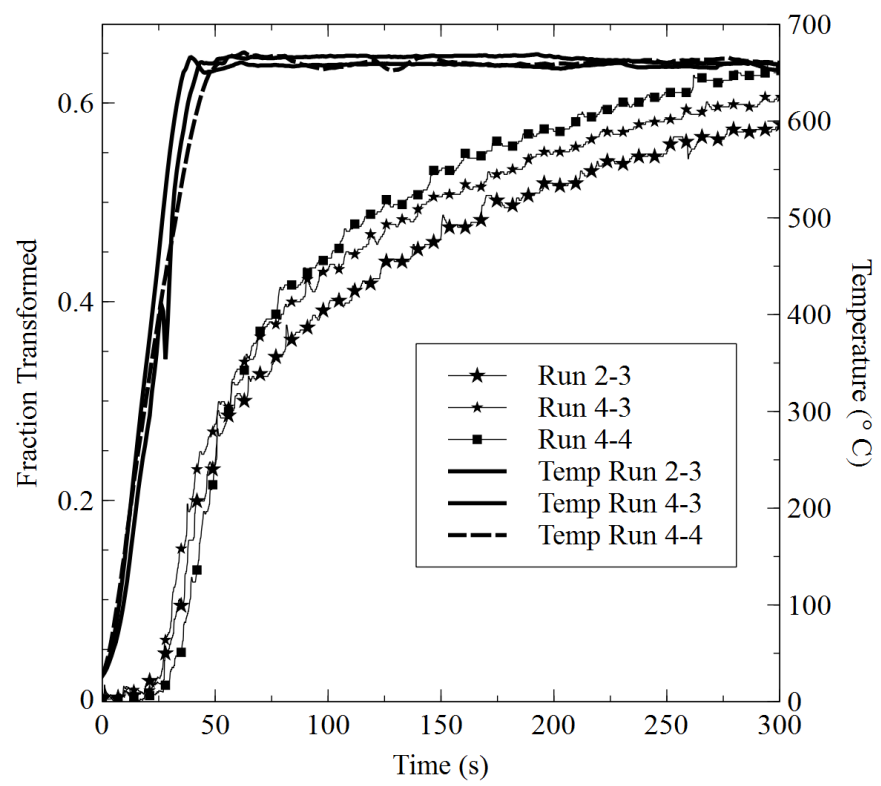

Figure 9.9: All TGA runs of oxidized 20-30 $\mu \mathrm{m} \mathrm{TiH}_{1.98}$ held at $660^{\circ} \mathrm{C}(933 \mathrm{~K})$

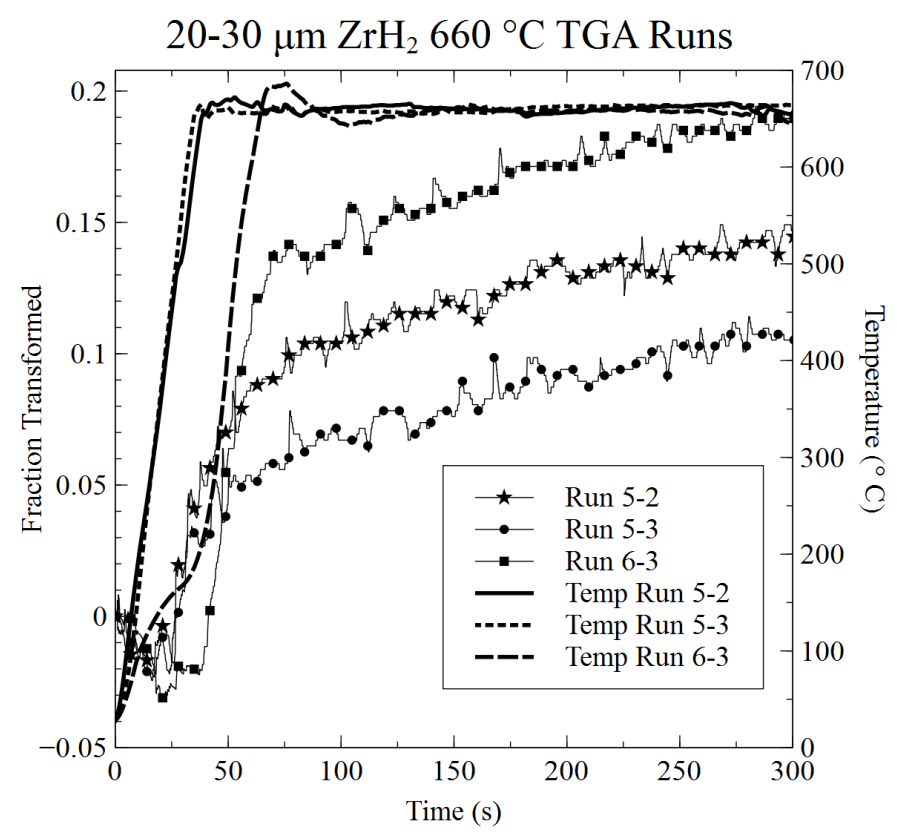

Figure 9.10: All TGA runs of $20-30 \mu \mathrm{m} \mathrm{ZrH}_{2}$ held at $660^{\circ} \mathrm{C}(933 \mathrm{~K})$ 


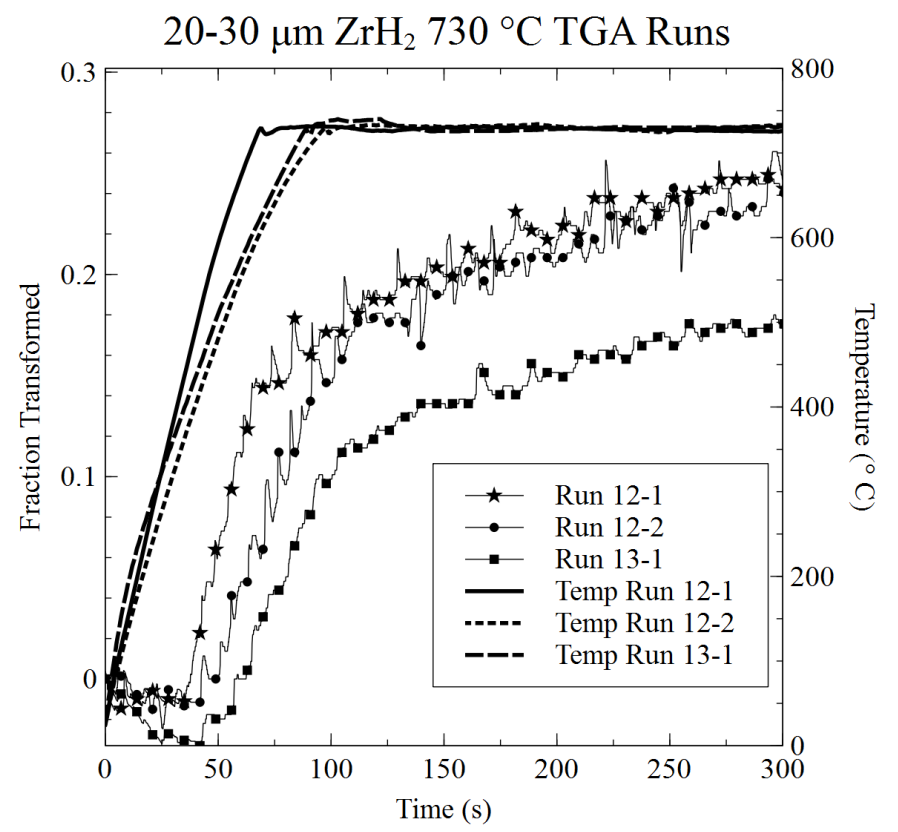

Figure 9.11: All TGA runs of $20-30 \mu \mathrm{m} \mathrm{ZrH}_{2}$ held at $730^{\circ} \mathrm{C}(1003 \mathrm{~K})$

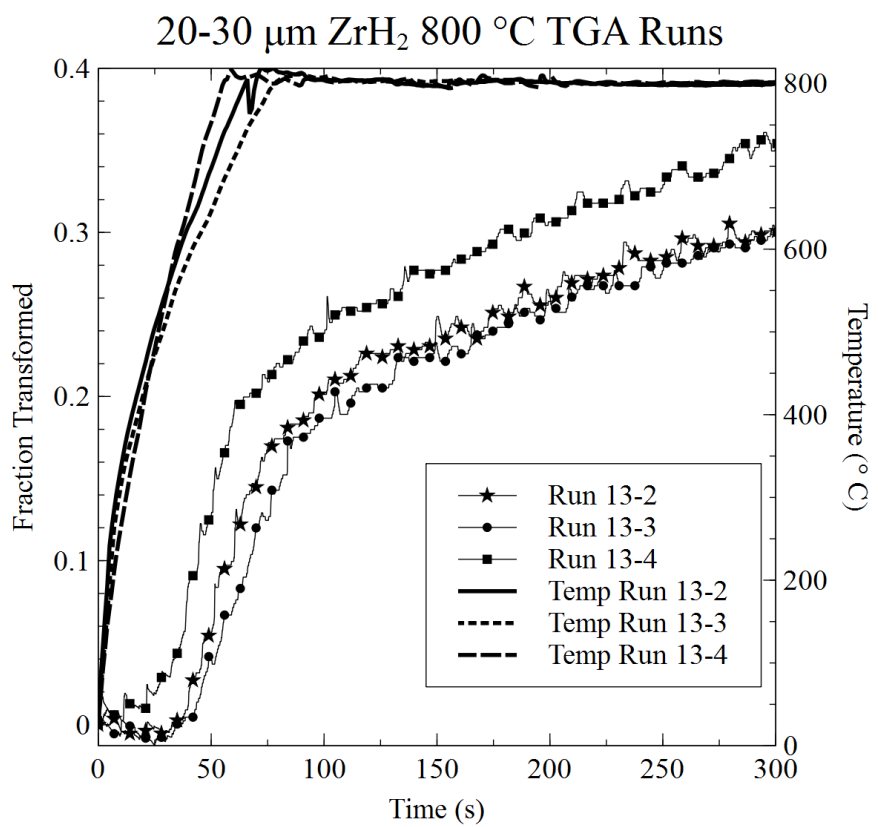

Figure 9.12: All TGA runs of $20-30 \mu \mathrm{m} \mathrm{ZrH} 2$ held at $800^{\circ} \mathrm{C}(1073 \mathrm{~K})$ 
Table 9.1: Non-isothermal model fits for all experimental runs. Minimum and maximum fractions represent experimental regions of model validity.

\begin{tabular}{|c|c|c|c|c|c|c|c|}
\hline Run & Material & $A\left(s^{-1}\right)$ & $\begin{array}{c}\mathbf{E}_{\mathrm{a}} \\
\left(\mathrm{kJ} / \mathrm{mol}^{*} \mathrm{~K}\right)\end{array}$ & $\begin{array}{c}\text { Best Fit } \\
\text { Model }\end{array}$ & $R^{\wedge} 2$ & $\operatorname{Min} \alpha$ & $\operatorname{Max} \alpha$ \\
\hline $1-5 \mu \mathrm{m}-6008-2$ & $\mathrm{TiH}_{1.98}$ & 0.7103 & 24.27 & F2 & 0.98814 & 0 & 0.2906 \\
\hline $1-5 \mu \mathrm{m}-6008-3$ & $\mathrm{TiH}_{1.98}$ & 2.139 & 34.16 & F3 & 0.990331 & 0 & 0.207 \\
\hline $1-5 \mu \mathrm{m}-6008-4$ & $\mathrm{TiH}_{1.98}$ & 0.01570 & 0.5601 & P3 & 0.990762 & 0 & 0.2569 \\
\hline $1-5 \mu \mathrm{m}-6603-2$ & $\mathrm{TiH}_{1.98}$ & 2.409 & 66.09 & D4 & 0.983206 & 0 & 0.1662 \\
\hline $1-5 \mu \mathrm{m}-6603-3$ & $\mathrm{TiH}_{1.98}$ & 3.918 & 41.675 & F3 & 0.98957 & 0 & 0.1512 \\
\hline $1-5 \mu \mathrm{m}-6604-2$ & $\mathrm{TiH}_{1.98}$ & 0.02054 & 1.208 & $\mathrm{P} 4$ & 0.9917 & 0 & 0.2294 \\
\hline $1-5 \mu \mathrm{m}-7309-4$ & $\mathrm{TiH}_{1.98}$ & 0.01658 & 1.076 & P3 & 0.993215 & 0 & 0.4546 \\
\hline $1-5 \mu \mathrm{m}-73010-4$ & $\mathrm{TiH}_{1.98}$ & 0.2180 & 42.92 & D4 & 0.995515 & 0 & 0.4166 \\
\hline $1-5 \mu \mathrm{m}-8009-2$ & $\mathrm{TiH}_{1.98}$ & 0.4157 & 16.24 & F2 & 0.996993 & 0 & 0.6962 \\
\hline $1-5 \mu \mathrm{m}-8009-3$ & $\mathrm{TiH}_{1.98}$ & 0.5510 & 19.70 & $\mathrm{~F} 2$ & 0.996985 & 0 & 0.6479 \\
\hline $1-5 \mu \mathrm{m}-600 \quad 11-1$ & $\mathrm{Ox}-\mathrm{TiH}_{1.98}$ & - & - & - & - & 0 & 0.0123 \\
\hline $1-5 \mu \mathrm{m}-60011-2$ & $\mathrm{Ox}-\mathrm{TiH}_{1.98}$ & - & - & - & - & 0 & 0.0601 \\
\hline $1-5 \mu \mathrm{m}-60011-3$ & $\mathrm{Ox}-\mathrm{TiH}_{1.98}$ & - & - & - & - & 0 & 0.0428 \\
\hline $1-5 \mu \mathrm{m}-6601-3$ & $\mathrm{Ox}-\mathrm{TiH}_{1.98}$ & - & - & - & - & 0 & 0.1463 \\
\hline $1-5 \mu \mathrm{m}-6602-4$ & $\mathrm{Ox}-\mathrm{TiH}_{1.98}$ & - & - & - & - & 0 & 0.0594 \\
\hline $1-5 \mu \mathrm{m}-73011-4$ & $\mathrm{Ox}-\mathrm{TiH}_{1.98}$ & 255.4 & 80.59 & D1 & 0.990185 & 0 & 0.3518 \\
\hline $1-5 \mu \mathrm{m}-730 \quad 12-3$ & $\mathrm{Ox}-\mathrm{TiH}_{1.98}$ & 4.337 & 33.81 & F3 & 0.994798 & 0 & 0.4999 \\
\hline $1-5 \mu \mathrm{m}-73012-4$ & $\mathrm{Ox}-\mathrm{TiH}_{1.98}$ & 0.2961 & 27.62 & $\mathrm{~F} 1$ & 0.990783 & 0 & 0.4993 \\
\hline $20-30 \mu \mathrm{m}-6601-2$ & $\mathrm{TiH}_{1.98}$ & 2.476 & 35.15 & F3 & 0.986261 & 0 & 0.2617 \\
\hline $20-30 \mu \mathrm{m}-6601-4$ & $\mathrm{TiH}_{1.98}$ & 166.9 & 83.54 & D1 & 0.994084 & 0 & 0.2546 \\
\hline $20-30 \mu \mathrm{m}-6603-4$ & $\mathrm{TiH}_{1.98}$ & 1229 & 102.3 & D1 & 0.9892 & 0 & 0.1374 \\
\hline $20-30 \mu \mathrm{m}-6602-3$ & $\mathrm{Ox}-\mathrm{TiH}_{1.98}$ & 1.879 & 35.82 & $\mathrm{~F} 2$ & 0.989709 & 0 & 0.1993 \\
\hline $20-30 \mu \mathrm{m}-6604-3$ & $\mathrm{Ox}-\mathrm{TiH}_{1.98}$ & 4.495 & 41.82 & F3 & 0.982796 & 0 & 0.1617 \\
\hline $20-30 \mu \mathrm{m}-6604-4$ & $\mathrm{Ox}-\mathrm{TiH}_{1.98}$ & 4.612 & 40.60 & F3 & 0.992968 & 0 & 0.2182 \\
\hline $20-30 \mu \mathrm{m}-6605-2$ & $\mathrm{ZrH}_{2}$ & - & - & - & - & 0 & 0.081 \\
\hline $20-30 \mu \mathrm{m}-6605-3$ & $\mathrm{ZrH}_{2}$ & - & - & - & - & 0 & 0.0542 \\
\hline $20-30 \mu \mathrm{m}-6606-3$ & $\mathrm{ZrH}_{2}$ & 0.1213 & 44.68 & D3 & 0.976602 & 0 & 0.1527 \\
\hline $20-30 \mu \mathrm{m}-73012-1$ & $\mathrm{ZrH}_{2}$ & 0.04418 & 43.08 & D3 & 0.990625 & 0 & 0.1628 \\
\hline $20-30 \mu \mathrm{m}-73012-2$ & $\mathrm{ZrH}_{2}$ & 0.01720 & 37.11 & D3 & 0.97981 & 0 & 0.1803 \\
\hline $20-30 \mu \mathrm{m}-73013-1$ & $\mathrm{ZrH}_{2}$ & 0.05418 & 49.66 & D3 & 0.98629 & 0 & 0.1098 \\
\hline $20-30 \mu \mathrm{m}-80013-2$ & $\mathrm{ZrH}_{2}$ & 0.4662 & 29.19 & F3 & 0.981055 & 0 & 0.1393 \\
\hline $20-30 \mu \mathrm{m}-80013-3$ & $\mathrm{ZrH}_{2}$ & 0.2821 & 41.26 & D1 & 0.989978 & 0 & 0.1396 \\
\hline $20-30 \mu \mathrm{m}-80013-4$ & $\mathrm{ZrH}_{2}$ & 0.1443 & 21.45 & F3 & 0.988816 & 0 & 0.1566 \\
\hline
\end{tabular}

-Unable to ascertain fit parameters due to high variance 
Table 9.2: Isothermal kinetic model fits for all experimental runs. Minimum and maximum fractions represent experimental regions of model validity.

\begin{tabular}{|c|c|c|c|c|c|c|c|}
\hline Run & Material & $A\left(s^{-1}\right)$ & $\begin{array}{c}\mathbf{E}_{\mathrm{a}} \\
\left(\mathrm{kJ} / \mathrm{mol}^{*} \mathrm{~K}\right)\end{array}$ & $\begin{array}{c}\text { Best } \\
\text { Fit } \\
\text { Mod } \\
\text { el }\end{array}$ & $\mathbf{R}^{\wedge} \mathbf{2}$ & $\operatorname{Min} \alpha$ & $\underset{\alpha}{\operatorname{Max}}$ \\
\hline $1-5 \mu \mathrm{m}-6008-2$ & $\mathrm{TiH}_{1.98}$ & 0.02725 & 44.03 & D3 & 0.986211 & 0.2959 & 0.6355 \\
\hline $1-5 \mu \mathrm{m}-6008-3$ & $\mathrm{TiH}_{1.98}$ & 0.009696 & 36.45 & D3 & 0.995365 & 0.3069 & 0.6527 \\
\hline $1-5 \mu \mathrm{m}-6008-4$ & $\mathrm{TiH}_{1.98}$ & 0.01274 & 38.26 & D4 & 0.998525 & 0.2569 & 0.6347 \\
\hline $1-5 \mu \mathrm{m}-6603-2$ & $\mathrm{TiH}_{1.98}$ & 0.01390 & 36.63 & D3 & 0.982695 & 0.1827 & 0.657 \\
\hline $1-5 \mu \mathrm{m}-6603-3$ & $\mathrm{TiH}_{1.98}$ & 0.009562 & 33.77 & D3 & 0.992636 & 0.1579 & 0.6479 \\
\hline $1-5 \mu \mathrm{m}-6604-2$ & $\mathrm{TiH}_{1.98}$ & 0.009590 & 36.73 & D3 & 0.987694 & 0.2396 & 0.6551 \\
\hline $1-5 \mu \mathrm{m}-7309-4$ & $\mathrm{TiH}_{1.98}$ & 0.002455 & 26.84 & D3 & 0.988389 & 0.4596 & 0.8713 \\
\hline $1-5 \mu \mathrm{m}-73010-4$ & $\mathrm{TiH}_{1.98}$ & 0.003016 & 31.30 & D3 & 0.989714 & 0.4215 & 0.77 \\
\hline $1-5 \mu \mathrm{m}-8009-2$ & $\mathrm{TiH}_{1.98}$ & 0.001264 & 33.31 & D3 & 0.98234 & 0.6977 & 0.9376 \\
\hline $1-5 \mu \mathrm{m}-8009-3$ & $\mathrm{TiH}_{1.98}$ & 0.001525 & 32.31 & D3 & 0.983808 & 0.6529 & 0.9367 \\
\hline $1-5 \mu \mathrm{m}-600 \quad 11-1$ & $\mathrm{Ox} \mathrm{TiH}_{1.98}$ & 0.2688 & 33.81 & $\mathrm{~F} 3$ & 0.99844 & 0.0182 & 0.4334 \\
\hline $1-5 \mu \mathrm{m}-60011-2$ & $\mathrm{Ox} \mathrm{TiH}_{1.98}$ & 0.2877 & 34.29 & F3 & 0.998015 & 0.0636 & 0.4548 \\
\hline $1-5 \mu \mathrm{m}-60011-3$ & $\mathrm{Ox}-\mathrm{TiH}_{1.98}$ & 0.2479 & 32.64 & F3 & 0.998125 & 0.041 & 0.4643 \\
\hline $1-5 \mu \mathrm{m}-6601-3$ & $\mathrm{Ox}-\mathrm{TiH}_{1.98}$ & 0.02252 & 42.09 & D3 & 0.996023 & 0.1652 & 0.5808 \\
\hline $1-5 \mu \mathrm{m}-6602-4$ & $\mathrm{Ox} \mathrm{TiH}_{1.98}$ & 0.005456 & 26.21 & D3 & 0.983551 & 0.0959 & 0.6098 \\
\hline $1-5 \mu \mathrm{m}-73011-4$ & Ox-TiH ${ }_{1.98}$ & 0.02421 & 44.72 & D3 & 0.965329 & 0.3934 & 0.8611 \\
\hline $1-5 \mu \mathrm{m}-730 \quad 12-3$ & $\mathrm{Ox}-\mathrm{TiH}_{1.98}$ & 0.03354 & 50.64 & D3 & 0.973338 & 0.5021 & 0.8507 \\
\hline $1-5 \mu \mathrm{m}-73012-4$ & $\mathrm{Ox} \mathrm{TiH}_{1.98}$ & 0.02786 & 50.66 & D3 & 0.960188 & 0.4993 & 0.865 \\
\hline $20-30 \mu \mathrm{m}-6601-2$ & $\mathrm{TiH}_{1.98}$ & 0.03838 & 36.42 & D1 & 0.9984459 & 0.2688 & 0.6006 \\
\hline $20-30 \mu \mathrm{m}-6601-4$ & $\mathrm{TiH}_{1.98}$ & 0.01822 & 41.39 & D3 & 0.995801 & 0.2605 & 0.673 \\
\hline $20-30 \mu \mathrm{m}-6603-4$ & $\mathrm{TiH}_{1.98}$ & 0.01707 & 36.71 & D3 & 0.994913 & 0.1449 & 0.6749 \\
\hline $20-30 \mu \mathrm{m}-6602-3$ & $\mathrm{Ox}-\mathrm{TiH}_{1.98}$ & 0.009384 & 36.63 & D3 & 0.997404 & 0.2017 & 0.6225 \\
\hline $20-30 \mu \mathrm{m}-6604-3$ & $\mathrm{Ox}-\mathrm{TiH}_{1.98}$ & 0.01368 & 36.72 & D3 & 0.989061 & 0.1617 & 0.6338 \\
\hline $20-30 \mu \mathrm{m}-6604-4$ & $\mathrm{Ox}-\mathrm{TiH}_{1.98}$ & 0.01089 & 36.58 & D3 & 0.994279 & 0.2378 & 0.6743 \\
\hline $20-30 \mu \mathrm{m}-6605-2$ & $\overline{\mathrm{ZrH}_{2}}$ & 0.003903 & 36.82 & D1 & 0.98581 & 0.0919 & 0.1582 \\
\hline $20-30 \mu \mathrm{m}-6605-3$ & $\mathrm{ZrH}_{2}$ & 0.001905 & 34.57 & D1 & 0.988906 & 0.0618 & 0.1253 \\
\hline $20-30 \mu \mathrm{m}-6606-3$ & $\mathrm{ZrH}_{2}$ & 0.008082 & 45.63 & D1 & 0.982922 & 0.156 & 0.201 \\
\hline $20-30 \mu \mathrm{m}-730 \quad 12-1$ & $\mathrm{ZrH}_{2}$ & 0.02022 & 50.05 & D1 & 0.983882 & 0.1663 & 0.2813 \\
\hline $20-30 \mu \mathrm{m}-73012-2$ & $\mathrm{ZrH}_{2}$ & 0.003802 & 37.89 & D1 & 0.975351 & 0.18412 & 0.22632 \\
\hline $20-30 \mu \mathrm{m}-73013-1$ & $\mathrm{ZrH}_{2}$ & 0.004757 & 38.30 & D1 & 0.99273 & 0.1168 & 0.2086 \\
\hline $20-30 \mu \mathrm{m}-800 \quad 13-2$ & $\mathrm{ZrH}_{2}$ & 0.009580 & 39.19 & D1 & 0.997216 & 0.14 & 0.3416 \\
\hline $20-30 \mu \mathrm{m}-800 \quad 13-3$ & $\mathrm{ZrH}_{2}$ & 0.01932 & 45.72 & D1 & 0.995205 & 0.1429 & 0.3482 \\
\hline $20-30 \mu \mathrm{m}-800 \quad 13-4$ & $\mathrm{ZrH}_{2}$ & 0.01284 & 39.54 & D1 & 0.997913 & 0.1611 & 0.3995 \\
\hline
\end{tabular}




\subsection{Appendix: Copyright and Permissions}

Below is the copyright transfer supporting the use of published materials in Chapters 4-5.

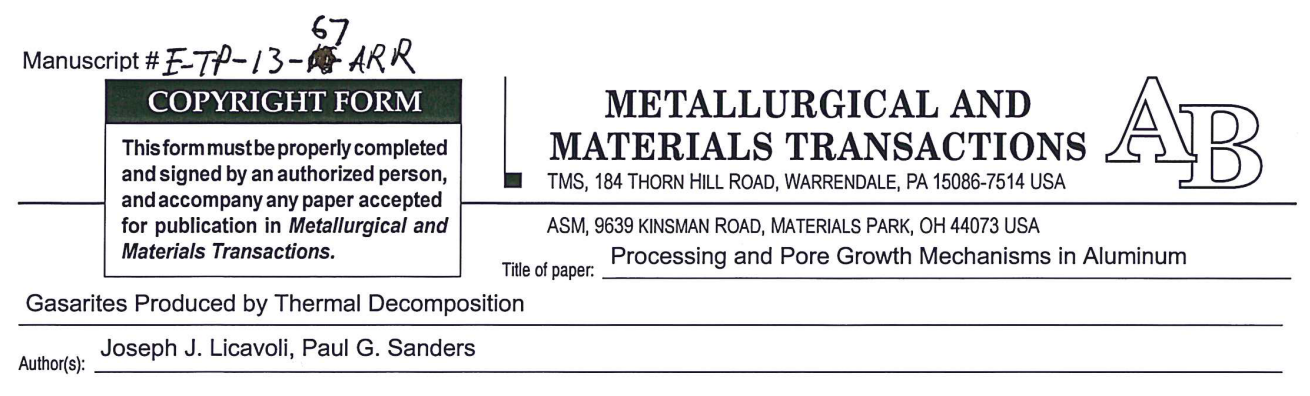

PART A. COPYRIGHT TRANSFER

Copyright, title, interest, and all rights in the manuscript named above are hereby transferred to TMS and ASM International, effective when the manuscript is accepted for publication. This assignment and transfer applies to any other subsequent publication of either organization in addition to the publication designated, provided that proper acknowledgement is made.

THE AUTHOR(S), OR THE EMPLOYER(S) IN THE CASE | I hereby transfer copyright to the paper named above to TMS and ASM International, under the terms OF WORKS MADE FOR HIRE, RETAIN

THE FOLLOWING RIGHTS:

1.) All proprietary rights, other than copyright, such as patent rights.

2.) The right to use all or portions of the above paper in oral presentations or other works.

3.) The right to make limited distribution of the article or portions thereof prior to publication.

4.) Royalty-free permission to reproduce the above paper for personal use or, in the case of a work made for hire, the employer's use, provided that a.) the source and copyright are indicated, b.) the copies are not used in a way that implies endorsement by TMS and ASM International of a product or service, and c.) the copies are not offered for sale.

5.) In the case ofwork performed under U.S. government contract, TMS and ASM International grants the U.S. government royalty-free permission
to reproduce all or portions of the paper, and to authorize others to do so for U.S. government purposes. outlined above and hereby certify that I am a self-employed author or authorized by my employer to transfer copyright, and that the paper has not been offered for publication to any other publisher. Signaturg

Date $9 / 15 / 13$

Name (please print) Joseph Licavoli

IF WORK MADE FOR HIRE:

Name of employer for whom work was performed (please print)

Title of signer

PART B. U.S. GOVERNMENT EMPLOYEE CERTIFICATION

Note: If this work was performed under U.S. government contract but you are not a government employee, you must sign Part A of this form. I certify that all authors of the above paper are employees of the U.S. government and performed this work as part of their employment, and the paper is therefore not subject to U.S. copyright protection.

Authorized Signature

Name (please print)

Name of government organization

\section{INFORMATION FOR AUTHORS}

Work made for hire: If you are an employee and your paper was prepared as a part of your job, the copyright to the paper belongs to your employer. If you as an author sign the copyright transfer form, we assume that you are authorized by your employer to do $\mathrm{SO}$ and that your employer has consented to all the terms and conditions of this form. If not, it should be signed by someone so authorized.

Joint Authorship: For jointly authored papers, only one signature is required if all authors work for the same company; the paper thus is a "work made for hire," the copyright rests with the employer rather than the individuad authors, and anyone authorized by the employer may authorize the copyright transfer. When the authors work for different employers, a separate copyright transfer form must be signed by an authorized agent for each emoloyer. When authors are self-employed, each must sign a separate copyright transfer form. Coauthors who are U.S. government employees are not required to sign this form, but any coauthors outside the U.S. government must sign Part A.

Work performed under U.S. government contract: Authors whose work was performed under U.S. government gever contract but who are not employees of the U.S. govermment are PartA returns reproduction rights to the U.S. governmentwhen required for U.S. governmentpurposes, while retaing

TMS and ASM International copyright protection with respect to reuse of the material by the general public.
Policy on assignment of copyright: As a convenience and courtesy to the technical community, TMS and ASM Policy on assignment of copyright: As a convenience and courtesy to the technical community, TMS and ASM
International routinely grant permission upon request to authors to reproduce graphs, tables, figures, or other portions International routinely grant permission upon request to authors to reproduce graphs, tables, figures, or other portions
of works by other authors for which copyright has been transferred to TMS and ASM International. Both TMS and ASM International reserve the right to use any parts or the entire manuscript in revised editions, derivative works, etc. published by either organization. Ordinarily, TMS and ASM International will not grant to third parties the right to reproduce an entire paper without the written permission of the author(s); permission must be obtained from each author or employer if joint authors/multiple work for hire employers: notwithstanding author consent, TMS and ASM International will not grant reproduction rights to third parties for purposes deemed inimical to either organization's professional or financial interests.
Date

Title

Publisher Indemnity: The author agrees that the article has not been previously submitted for publication or published elsewhere. Further, the author agrees that the article is original and that it contains no matter which is libelous, obscene, or infringes any existing right of privacy, copyright, trademark or any other statutory or common law proprietary or civil right and is not otherwise unlawful. The author agrees to indemnify, defend, and hold ASM International and TMS (The Minerals, Metals \& Materials Society) and its directors, officers, employees, and agents harmless against any claims to the contrary.

FORM SUBMISSION INSTRUCTIONS: Send this form with the manuscript to Metallurgical and Materials Transactions at the address below. If the manuscript is not accepted for publication, this copyright transfer will not take effect.

For further information, contact: Metallurgical and Materials Transactions

Carnegie Mellon University Wean Hall 2323

Pittsburgh, Pennsylvania 15213 USA

E-mail: mettrans@andrew.cmu.edu 
Author rights for the journal Chapter 6 is to be submitted to may be found at:

$\underline{\text { http://www.elsevier.com/journal-authors/author-rights-and-responsibilities }}$

The current authors retain the right to use all published materials in theses and dissertations. 


\subsection{Appendix: Truncated Experimental Pore Size and Porosity Data}

\begin{tabular}{|c|c|c|c|c|}
\hline Run & Section & $\begin{array}{l}\text { Source } \\
\text { Type }\end{array}$ & $\begin{array}{c}\text { Arch } \\
\text { Porosity }\end{array}$ & $\begin{array}{c}\text { Pax-Avg Radius } \\
\text { (um) }\end{array}$ \\
\hline PSSH42 & $A$ & $\mathrm{TIH} 2$ & $1.6 \%$ & 34.2 \\
\hline PSSH42 & $\mathrm{B}$ & $\mathrm{TIH} 2$ & $6.6 \%$ & 336.6 \\
\hline PSSH42 & C & $\mathrm{TIH} 2$ & $5.8 \%$ & 0 \\
\hline PSSH42 & $\mathrm{D}$ & $\mathrm{TIH} 2$ & $4.4 \%$ & 463.4 \\
\hline PSSH42 & $E$ & $\mathrm{TIH} 2$ & $6.5 \%$ & 312.8 \\
\hline PSSH42 & $\mathrm{F}$ & $\mathrm{TIH} 2$ & $7.9 \%$ & 402.6 \\
\hline PSSH43 & $A$ & $\mathrm{TIH} 2$ & $3.7 \%$ & 302.4 \\
\hline PSSH43 & B & $\mathrm{TIH} 2$ & $22.1 \%$ & 392.4 \\
\hline PSSH43 & $\mathrm{C}$ & $\mathrm{TIH} 2$ & $14.1 \%$ & 386.4 \\
\hline PSSH43 & $D$ & $\mathrm{TIH} 2$ & $6.2 \%$ & 416 \\
\hline PSSH43 & $\mathrm{E}$ & $\mathrm{TIH} 2$ & $7.1 \%$ & 848.1 \\
\hline PSSH43 & $\mathrm{F}$ & $\mathrm{TIH} 2$ & $34.7 \%$ & Irregular \\
\hline PSSH43 & G & $\mathrm{TIH} 2$ & $39.7 \%$ & Irregular \\
\hline PSSH44 & $\mathrm{A}$ & $\mathrm{TIH} 2$ & $3.4 \%$ & 300.5 \\
\hline PSSH44 & B & $\mathrm{TIH} 2$ & $20.8 \%$ & 378.9 \\
\hline PSSH44 & $\mathrm{C}$ & $\mathrm{TIH} 2$ & $21.0 \%$ & 450.7 \\
\hline PSSH44 & $\mathrm{D}$ & $\mathrm{TIH} 2$ & $12.1 \%$ & 285 \\
\hline PSSH44 & $\mathrm{E}$ & $\mathrm{TIH} 2$ & $13.7 \%$ & 1294.8 \\
\hline PSSH44 & $\mathrm{F}$ & $\mathrm{TIH} 2$ & $23.5 \%$ & Irregular \\
\hline PSSH45 & A & $\mathrm{TIH} 2$ & $1.8 \%$ & 0 \\
\hline PSSH45 & B & $\mathrm{TIH} 2$ & $11.7 \%$ & 344.2 \\
\hline PSSH45 & $C$ & $\mathrm{TIH} 2$ & $5.2 \%$ & 161.9 \\
\hline PSSH45 & $\mathrm{D}$ & $\mathrm{TIH} 2$ & $2.3 \%$ & 128.2 \\
\hline PSSH45 & $E$ & $\mathrm{TIH} 2$ & $2.7 \%$ & 185.2 \\
\hline PSSH45 & $\mathrm{F}$ & $\mathrm{TIH} 2$ & $7.2 \%$ & 225.3 \\
\hline PSSH45 & G & $\mathrm{TIH} 2$ & $6.7 \%$ & 260.5 \\
\hline PSSH46 & $A$ & $\mathrm{TIH} 2$ & $2.6 \%$ & 82.6 \\
\hline PSSH46 & B & $\mathrm{TIH} 2$ & $2.1 \%$ & 75.4 \\
\hline PSSH46 & $C$ & $\mathrm{TIH} 2$ & $1.8 \%$ & 143 \\
\hline PSSH46 & $\mathrm{D}$ & $\mathrm{TIH} 2$ & $1.8 \%$ & 126.2 \\
\hline PSSH46 & $E$ & $\mathrm{TIH} 2$ & $4.6 \%$ & 274.5 \\
\hline PSSH46 & $\mathrm{F}$ & $\mathrm{TIH} 2$ & $5.8 \%$ & 563.2 \\
\hline PSSH47 & $A$ & $\mathrm{TIH} 2$ & $3.6 \%$ & 95 \\
\hline
\end{tabular}




\begin{tabular}{|c|c|c|c|c|}
\hline Run & Section & $\begin{array}{l}\text { Source } \\
\text { Type }\end{array}$ & $\begin{array}{c}\text { Arch } \\
\text { Porosity }\end{array}$ & $\begin{array}{c}\text { Pax-Avg Radius } \\
\text { (um) }\end{array}$ \\
\hline PSSH47 & $B$ & $\mathrm{TIH} 2$ & $12.9 \%$ & 562.4 \\
\hline PSSH47 & $C$ & $\mathrm{TIH} 2$ & $11.7 \%$ & 573.1 \\
\hline PSSH47 & $\mathrm{D}$ & $\mathrm{TIH} 2$ & $10.9 \%$ & 512.2 \\
\hline PSSH47 & $\mathrm{E}$ & $\mathrm{TIH} 2$ & $4.4 \%$ & 587.3 \\
\hline PSSH48 & A & $\mathrm{TIH} 2$ & $10.5 \%$ & 1120.6 \\
\hline PSSH48 & $B$ & $\mathrm{TIH} 2$ & $4.1 \%$ & 233.8 \\
\hline PSSH48 & $\mathrm{C}$ & $\mathrm{TIH} 2$ & $12.2 \%$ & 293.3 \\
\hline PSSH48 & $\mathrm{D}$ & $\mathrm{TIH} 2$ & $11.5 \%$ & 307.3 \\
\hline PSSH48 & $\mathrm{E}$ & $\mathrm{TIH} 2$ & $13.8 \%$ & 541.8 \\
\hline PSSH49 & $A$ & $\mathrm{TIH} 2$ & $1.8 \%$ & 0 \\
\hline PSSH49 & $B$ & $\mathrm{TIH} 2$ & $1.7 \%$ & 0 \\
\hline PSSH49 & C & $\mathrm{TIH} 2$ & $3.5 \%$ & 216.9 \\
\hline PSSH49 & $\mathrm{D}$ & $\mathrm{TIH} 2$ & $6.9 \%$ & 203.3 \\
\hline PSSH49 & $E$ & $\mathrm{TIH} 2$ & $7.1 \%$ & 184.6 \\
\hline PSSH49 & $\mathrm{F}$ & $\mathrm{TIH} 2$ & $9.7 \%$ & 274.3 \\
\hline PSSH49 & G & $\mathrm{TIH} 2$ & $9.9 \%$ & 701 \\
\hline TiZr1-67 & A & $\mathrm{TIH} 2$ & $1.4 \%$ & 85.0000 \\
\hline TiZr1-67 & $B$ & $\mathrm{TIH} 2$ & $4.3 \%$ & 69.2773 \\
\hline TiZr1-67 & C & $\mathrm{TIH} 2$ & $5.6 \%$ & 44.4125 \\
\hline TiZr1-67 & $\mathrm{D}$ & $\mathrm{TIH} 2$ & $1.8 \%$ & 38.6000 \\
\hline TiZr1-67 & $E$ & $\mathrm{TIH} 2$ & $3.5 \%$ & 56.3143 \\
\hline TiZr1-67 & $\mathrm{F}$ & $\mathrm{TIH} 2$ & $1.6 \%$ & 48.5714 \\
\hline TiZr2-68 & A & $\mathrm{ZrH} 2$ & $8.2 \%$ & 104.7567 \\
\hline TiZr2-68 & $B$ & $\mathrm{ZrH} 2$ & $4.4 \%$ & 68.5061 \\
\hline TiZr2-68 & $\mathrm{C}$ & $\mathrm{ZrH} 2$ & $1.5 \%$ & 0 \\
\hline TiZr2-68 & $\mathrm{D}$ & $\mathrm{ZrH} 2$ & $1.5 \%$ & 0 \\
\hline TiZr2-68 & $\mathrm{E}$ & $\mathrm{ZrH} 2$ & $1.7 \%$ & 0 \\
\hline TiZr2-68 & $\mathrm{F}$ & $\mathrm{ZrH} 2$ & $1.4 \%$ & 0 \\
\hline TiZr3-69 & A & $\mathrm{TIH} 2$ & $4.9 \%$ & 84.3939 \\
\hline TiZr3-69 & $B$ & $\mathrm{TIH} 2$ & $11.6 \%$ & 215.7357 \\
\hline TiZr3-69 & C & $\mathrm{TIH} 2$ & $18.9 \%$ & 349.9297 \\
\hline TiZr3-69 & $\mathrm{D}$ & $\mathrm{TIH} 2$ & $5.9 \%$ & 222.5711 \\
\hline TiZr3-69 & $E$ & $\mathrm{TIH} 2$ & $4.3 \%$ & 370.9250 \\
\hline TiZr3-69 & $\mathrm{F}$ & $\mathrm{TIH} 2$ & $5.5 \%$ & 469.7500 \\
\hline TiZr4-70 & A & $\mathrm{TIH} 2$ & $5.1 \%$ & 1344.7000 \\
\hline TiZr4-70 & B & $\mathrm{TIH} 2$ & $1.7 \%$ & 0 \\
\hline TiZr4-70 & C & $\mathrm{TIH} 2$ & $1.7 \%$ & 0 \\
\hline
\end{tabular}




\begin{tabular}{|c|c|c|c|c|}
\hline Run & Section & $\begin{array}{l}\text { Source } \\
\text { Type }\end{array}$ & $\begin{array}{c}\text { Arch } \\
\text { Porosity }\end{array}$ & $\begin{array}{c}\text { Pax-Avg Radius } \\
\text { (um) }\end{array}$ \\
\hline TiZr4-70 & $\mathrm{D}$ & $\mathrm{TIH} 2$ & $4.4 \%$ & 0 \\
\hline TiZr4-70 & $E$ & $\mathrm{TIH} 2$ & $1.6 \%$ & 0 \\
\hline TiZr4-70 & $\mathrm{F}$ & $\mathrm{TIH} 2$ & $0.0 \%$ & 0 \\
\hline TiZr6-72 & $\mathrm{A}$ & $\mathrm{ZrH} 2$ & $1.4 \%$ & 0 \\
\hline TiZr6-72 & B & $\mathrm{ZrH} 2$ & $1.4 \%$ & 0 \\
\hline TiZr6-72 & $C$ & $\mathrm{ZrH} 2$ & $1.7 \%$ & 0 \\
\hline TiZr6-72 & $\mathrm{D}$ & $\mathrm{ZrH} 2$ & $1.5 \%$ & 0 \\
\hline TiZr6-72 & $\mathrm{E}$ & $\mathrm{ZrH} 2$ & $1.5 \%$ & 0 \\
\hline TiZr6-72 & $\mathrm{F}$ & $\mathrm{ZrH} 2$ & $7.1 \%$ & 0 \\
\hline TiZr7-73 & A & $\mathrm{ZrH} 2$ & $8.1 \%$ & 95.1 \\
\hline TiZr7-73 & $B$ & $\mathrm{ZrH} 2$ & $3.1 \%$ & 0 \\
\hline TiZr7-73 & C & $\mathrm{ZrH} 2$ & $1.6 \%$ & 0 \\
\hline TiZr7-73 & $\mathrm{D}$ & $\mathrm{ZrH} 2$ & $4.3 \%$ & 0 \\
\hline TiZr7-73 & $\mathrm{E}$ & $\mathrm{ZrH} 2$ & $1.4 \%$ & 0 \\
\hline TiZr7-73 & $\mathrm{F}$ & $\mathrm{ZrH} 2$ & $1.4 \%$ & 0 \\
\hline TiZr14-82 & A & $\mathrm{TiH} 2$ & $3.5 \%$ & 197.1 \\
\hline TiZr14-82 & $B$ & $\mathrm{TiH} 2$ & $18.7 \%$ & 281.2 \\
\hline TiZr14-82 & $\mathrm{C}$ & $\mathrm{TiH} 2$ & $11.7 \%$ & 283.8 \\
\hline TiZr14-82 & $\mathrm{D}$ & $\mathrm{TiH} 2$ & $7.9 \%$ & 167.0 \\
\hline TiZr14-82 & $\mathrm{E}$ & $\mathrm{TiH} 2$ & $9.9 \%$ & 326.8 \\
\hline TiZr16-84 & $A$ & $\mathrm{TIH} 2$ & $2.4 \%$ & No visible pores \\
\hline TiZr16-84 & $\mathrm{B}$ & $\mathrm{TIH} 2$ & $10.7 \%$ & 338.3 \\
\hline TiZr16-84 & $\mathrm{C}$ & $\mathrm{TIH} 2$ & $8.7 \%$ & 347.9 \\
\hline TiZr16-84 & $\mathrm{D}$ & $\mathrm{TIH} 2$ & $4.0 \%$ & 446.2 \\
\hline TiZr16-84 & $\mathrm{E}$ & $\mathrm{TIH} 2$ & $2.2 \%$ & 243.4 \\
\hline TiZr16-84 & $\mathrm{F}$ & $\mathrm{TIH} 2$ & $4.1 \%$ & 266.6 \\
\hline TiZr17-85 & A & $\mathrm{ZrH} 2$ & $1.1 \%$ & No visible pores \\
\hline TiZr17-85 & $B$ & $\mathrm{ZrH} 2$ & $1.8 \%$ & No visible pores \\
\hline TiZr17-85 & $\mathrm{C}$ & $\mathrm{ZrH} 2$ & $8.0 \%$ & 34.7 \\
\hline TiZr17-85 & $\mathrm{D}$ & $\mathrm{ZrH} 2$ & $1.9 \%$ & 83.5 \\
\hline TiZr17-85 & $\mathrm{E}$ & $\mathrm{ZrH} 2$ & $5.6 \%$ & 126.7 \\
\hline TiZr17-85 & $\mathrm{F}$ & $\mathrm{ZrH} 2$ & $4.4 \%$ & 133.0 \\
\hline TiZr17-85 & G & $\mathrm{ZrH} 2$ & $7.5 \%$ & 141.7 \\
\hline TiZr21-89 & A & $\mathrm{ZrH} 2$ & $11.4 \%$ & 86.7 \\
\hline TiZr21-89 & $\mathrm{B}$ & $\mathrm{ZrH} 2$ & $3.9 \%$ & 145.1 \\
\hline TiZr21-89 & C & $\mathrm{ZrH} 2$ & $3.5 \%$ & 170.0 \\
\hline TiZr21-89 & $\mathrm{D}$ & $\mathrm{ZrH} 2$ & $8.2 \%$ & Irregular \\
\hline TiZr21-89 & $E$ & $\mathrm{ZrH} 2$ & $6.7 \%$ & 275.6 \\
\hline
\end{tabular}




\begin{tabular}{|l|l|l|r|r|}
\hline \multicolumn{1}{|c|}{ Run } & Section & $\begin{array}{c}\text { Source } \\
\text { Type }\end{array}$ & $\begin{array}{c}\text { Arch } \\
\text { Porosity }\end{array}$ & \multicolumn{2}{|c|}{$\begin{array}{c}\text { Pax-Avg Radius } \\
\text { (um) }\end{array}$} \\
\hline TiZr21-89 & F & ZrH2 & $2.9 \%$ & 364.9 \\
\hline TiZr21-89 & G & ZrH2 & $11.9 \%$ & 475.7 \\
\hline
\end{tabular}




\section{0 $\underline{\text { References }}$}

1. J.J. Licavoli and P.G. Sanders, Metallurgical and Materials Transactions A 2013, pp. 1-7.

2. M.F. Ashby, A.G. Evans, N.A. Fleck, L.J. Gibson, J.W. Hutchinson and

H.N.G Wadley: Metal Foams: A Design Guide. 1 ed. (Butterworth Heinemann, 2000).

3. $\quad$ S.R. Arwade, J.F. Hajjar, B.W. Schafer, M. Moradi, B.H. Smith and S.

Szyniszewski, In NSF Engineering Research and Innovation Conference, (Atlanta, Georgia, 2011).

4. D. Karagiozova, G. S. Langdon and G. N. Nurick, International Journal of Mechanical Sciences 2010, vol. 52, pp. 758-776.

5. K. P. Dharmasena, D. T. Queheillalt, H. N. G. Wadley, P. Dudt, Y. Chen, D. Knight, A. G. Evans and V. S. Deshpande, European Journal of Mechanics - A/Solids 2010, vol. 29, pp. 56-67.

6. $\quad$ N. Jones, International Journal of Pressure Vessels and Piping 2010, vol. 87, pp. 482-492.

7. $\quad$ N. Jones, Int. J. Impact Eng. 2010, vol. 37, pp. 754-765.

8. $\quad$ G. W. Ma and Z. Q. Ye, Int. J. Impact Eng. 2007, vol. 34, pp. 329-347.

9. G. W. Ma and Z. Q. Ye, Int. J. Impact Eng. 2007, vol. 34, pp. 60-70.

10. K. Alvarez, S. K. Hyun, T. Nakano, Y. Umakoshi and H. Nakajima, Materials

Science and Engineering: C 2009, vol. 29, pp. 1182-1190.

11. X. F. Wu and G. Q. Shi, Nanotechnology 2005, vol. 16, pp. 2056-2060.

12. M. N. Qu, G. Y. Zhao, X. P. Cao and J. Y. Zhang, Langmuir 2008, vol. 24, pp. 4185-4189.

13. L. P. Lefebvre, J. Banhart and D. C. Dunand, Advanced Engineering Materials 2008, vol. 10, pp. 775-787.

14. J. Banhart, Advanced Engineering Materials 2006, vol. 8, pp. 781-794.

15. A. Rabiei and M. Garcia-Avila, Materials Science and Engineering: A 2013, vol. 564, pp. 539-547.

16. I. Mutlu and E. Oktay, Materials \& Design 2013, vol. 44, pp. 274-282.

17. N. Babcsán, D. Leitlmeier and J. Banhart, Colloids and Surfaces A:

Physicochemical and Engineering Aspects 2005, vol. 261, pp. 123-130.

18. M. Mukherjee, F. Garcia-Moreno and J. Banhart, Acta Mater. 2010, vol. 58, pp. 6358-6370.

19. M Diop, H Hao, H-W Dong, X-G Zhang, S Yao and Jin J-Z, Int. J. Cast. Metals Res. 2011, vol. 24, pp. 158-162.

20. S. Y. Kim, J. S. Park and H. Nakajima, Metallurgical and Materials Transactions A 2009, vol. 40, pp. 937-942.

21. J. S. Park and H. Nakajima, Journal of Physics: Conference Series 2009, vol. 165, p. 012066.

22. O. Friedl, C. Motz, H. Peterlik, S. Puchegger, N. Reger and R. Pippan, Metallurgical and Materials Transactions B 2007, vol. 39, pp. 135-146.

23. G. Castro and S. R. Nutt, Materials Science and Engineering: A 2012, vol. 553, pp. 89-95. 
24. E. Maine and M. F. Ashby, Advanced Engineering Materials 2000, vol. 2, pp. 205-209.

25. T.H. Wübben and S. Odenbach, Colloids and Surfaces A: Physicochemical and Engineering Aspects 2005, vol. 266, pp. 207-213.

26. S. E. Friberg, Current Opinion in Colloid \& Interface Science 2010, vol. 15, pp. 359-364.

27. G. Kaptay, Colloids and Surfaces A: Physicochemical and Engineering Aspects 2003, vol. 230, pp. 67-80.

28. B. Matijasevic-Lux, J. Banhart, S. Fiechter, O. Görke and N. Wanderka, Acta Mater. 2006, vol. 54, pp. 1887-1900.

29. V.I. Shapovalov and J.C. Withers, In MetFoam 2007, (DEStech Publications Inc., (C)2008.: Montreal, Canada, 2008).

30. V.I. Shapovalov and Boyko L., Advanced Engineering Materials 2004, vol. 6, pp. 407-410.

31. V. Karpov, Mater Sci 2007, vol. 43, pp. 746-749.

32. H. Nakajima, Progress in Materials Science 2007, vol. 52, pp. 1091-1173.

33. L. Yuan and Y. X. Li, Scr. Mater. 2003, vol. 49, pp. 379-386.

34. L. Drenchev, J. Sobczak, W. Sha and S. Malinov, Journal of Materials Science 2005 , vol. 40 , p. 5.

35. T. Ichitsubo, M. Tane, H. Ogi, M. Hirao, T. Ikeda and H. Nakajima, Acta Mater. 2002, vol. 50, pp. 4105-4115.

36. S. K. Hyun and H. Nakajima, Advanced Engineering Materials 2002, vol. 4, pp. 741-744.

37. S. K. Hyun and H. Nakajima, Materials Letters 2003, vol. 57, pp. 3149-3154.

38. J. S. Park, S. K. Hyun, S. Suzuki and H. Nakajima, Acta Mater. 2007, vol. 55, pp. 5646-5654.

39. H. Nakajima and T. Ide, Metallurgical and Materials Transactions A 2008, vol. 39, pp. 390-394.

40. M. Tane and H. Nakajima, Journal of Physics: Conference Series 2009, vol. 165, p. 012065 .

41. T. Ide, M. Tane and H. Nakajima, Materials Science and Engineering: A 2009, vol. 508, pp. 220-225.

42. T. Wada, T. Ide and H. Nakajima, Metallurgical and Materials Transactions A 2009, vol. 40, pp. 3204-3209.

43. Y. H. Song, M. Tane and H. Nakajima, Materials Science and Engineering: A 2012, vol. 534, pp. 504-513.

44. T. Ide and H. Nakajima, Journal of Physics: Conference Series 2009, vol. 165, p. 012064 .

45. H. Nakajima, Advanced Engineering Materials 2008, vol. 10, pp. 816-819.

46. H.R.Z. Sandim, B.V. Morante and P.A. Suzuki, Materials Research 2005, vol. 8, pp. 293-297.

47. M. T. Malachevsky and C. A. D'Ovidio, Scr. Mater. 2009, vol. 61, pp. 1-4.

48. G. Y. Gor and A. E. Kuchma, The Journal of chemical physics 2009, vol. 131, p. 034507. 
49. S. Karagadde, In Supercomputer Education Research Center, (Indian Institute of Science: Bangalore, 2008), p 54.

50. D. Ceotto and F. Miani, High Temp 2013, vol. 51, pp. 568-571.

51. C.B. Fuller, D. N. Seidman and D. C. Dunand, Acta Mater. 2003, vol. 51, pp. 4803-4814.

52. V. Gergely and T. W. Clyne, Acta Mater. 2004, vol. 52, pp. 3047-3058.

53. N. Babcsan, G.S. Vinod Kumar, B.S. Murty and J. Banhart, Trans. Indian Inst. Met 2007, vol. 60, pp. 127-132.

54. K. A. Terrani, M. Balooch, D. Wongsawaeng, S. Jaiyen and D. R. Olander, Journal of Nuclear Materials 2010, vol. 397, pp. 61-68.

55. S. Tanaka, M. Aonuma, N. Hirose and T. Tanaki, Journal of The Electrochemical Society 2002, vol. 149, p. D167.

56. L. Yuan and L. Yanxiang, Scr. Mater. 2003, vol. 49, pp. 379-386.

57. K. D. Carlson, Z. Lin and C. Beckermann, Metallurgical and Materials

Transactions B 2007, vol. 38, pp. 541-555.

58. W. Chen, L. Wang and S. Lu, J. Alloy. Compd. 2009, vol. 469, pp. 142-145.

59. D. Wongsawaeng and S. Jaiyen, Journal of Nuclear Materials 2010, vol. 403, pp. 19-24.

60. H. Liu, P. He, J. C. Feng and J. Cao, International Journal of Hydrogen Energy 2009, vol. 34, pp. 3018-3025.

61. G. Majer, Renz W. and Barnes R.G., J. Phys. Condens. Matter 1994, vol. 6, p. 2935.

62. O. S. Abdul-Hamid, In Department of Materials Science and Engineering, (Massachusetts Institute of Technology: Cambridge, MA, 1993), p 191.

63. S. Vyazovkin, A. K. Burnham, J. M. Criado, L. A. Pérez-Maqueda, C. Popescu and N. Sbirrazzuoli, Thermochimica Acta 2011, vol. 520, pp. 1-19.

64. B. D. Cullity: Elements of X-ray diffraction. (Addison-Wesley Pub. Co., Reading, Mass., 1956).

65. A. K. Sharma, Thin solid films 1992, vol. 208, pp. 48-54.

66. A. Khawam and D.R. Flanagan, J. Phys. Chem. B 2006, vol. 110, pp. 1731517328.

67. G.I. Senum and R.T. Yang, J Thermal Anal. 1977, vol. 11, p. 6.

68. S. Gao and L. Huang, J. Alloy. Compd. 1999, vol. 293-295, pp. 412-416.

69. A. Takasaki, Y. Furuya, K. Ojima and Y. Taneda, J. Alloy. Compd. 1995, vol. 224, pp. 269-273.

70. B. Matijasevic, O. Gorke, H. Shubert and J. Banhart, In MetFoam2005, ed. H. Nakajima and Kanetake N. (The Japan Institute of Metals: Kyoto, Japan, 2005), p 4.

71. P. Magnin and R. Trivedi, Acta metallurgica et materialia 1991, vol. 39, pp. 453467.

72. A. Ludwig and S. Leibbrandt, Materials Science and Engineering: A 2004, vol. 375-377, pp. 540-546.

73. K.A. Jackson and J.D. Hunt, Transactions of the Metallurgical Society of AIME 1966, vol. 236, p. 14.

74. L. Drenchev, J. Sobczak, S. Malinov and W. Sha, Mater. Sci. Technol. 2006, vol. 22, pp. $1135-1147$. 
75. A. Kulkarni and J. Joshi, Ind. Eng. Chem Res. 2005, vol. 44, p. 59.

76. A. Satyanarayan, R. Kumar and N. R. Kuloor, Chemical Engineering Science 1969, vol. 24, pp. 749-761.

77. D. L. Marcus and C. Bonds, Journal of Hazardous Materials 1999, vol. 68, pp. 125-153.

78. H.J. Frost and M.F. Ashby: Deformation-mechanism maps: The plasticity and creep of metals and ceramics. 1 ed. (Pergamon Press, Cambridge, UK, 1982).

79. W.E. Wang, J. Alloy. Compd. 1996, vol. 238, pp. 6-12.

80. N. Martys and H. Chen, Physical Review E 1996, vol. 53, pp. 743-750.

81. D. Raabe, Modelling and Simulation in Materials Science and Engineering 2004, vol. 12, pp. R13-R46.

82. M. Eshraghi and S. D. Felicelli, Int. J. Heat Mass Transf. 2012, vol. 55, pp. 24202428.

83. Unknown, "Hydrogen Fuel Costs" (Hydrogen Energy Systems, LCC, 2012), http://heshydrogen.com/hydrogen-fuel-cost-vs-gasoline/ Accessed 11/29/2013.

84. Unknown, "Alfa Aesar Website" (2013), http://www.alfa.com/en/catalog/36678 Accessed 11/29/2013.

85. Unknown, "Cylindrical Vacuum Vessels" (Kurt Lesker, 2013), http://www.lesker.com/newweb/chambers/Cylindrical_Assembly.cfm Accessed $11 / 29 / 2013$.

86. Unknown, "SPVC Homepage" (2013), http://www.samuelpressurevesselgroup.com/en/Divisions/Pages/Silvan-Industries.aspx Accessed 11/29/2013.

87. T. Ide, Y. Iio and H. Nakajima, Metallurgical and Materials Transactions A 2012, vol. 43, pp. 5140-5152.

88. Unknown, "London Metals Exchange" (2013), http://www.lme.com/en$\mathrm{gb} / \mathrm{metals} /$ non-ferrous/aluminium/ Accessed 12/1/2013.

89. "McMaster Carr Website" (2013), http://www.mcmaster.com/\#shimstock/=pme9fo Accessed 12/1/2013.

90. K. Stöbener, J. Baumeister, G. Rausch and M. Rausch, Metal Powder Report 2005, vol. 60, pp. 12-16. 